\title{
Informal Relationships Between New Zealand SMEs and Sub-National Officials in China
}

\author{
By Gavin Romayne
}

A Thesis Submitted to Victoria University of Wellington in Fulfilment of the Requirements for the Degree of Master of Arts In International Relations

School of History \& Philosophy \& Political Science \& International Relations

Victoria University of Wellington

5 December 2010 


\section{Abstract}

The signing of a free trade agreement was a watershed moment in New Zealand-China relations and provided a number of advantages for New Zealand firms seeking to expand their presence in the Chinese market. However, it is well established that many businesses in China use informal relationships (guanxi) to create business opportunities and facilitate their way through bureaucratic obstacles. Doubts have also been raised in the past about local governments' implementing China's international agreements and about the current efficacy and reliability of China's legal institutions.

This thesis examines the informal relationships New Zealand SMEs based in China maintain with local officials and street-level bureaucrats and how they experienced the implementation of the FTA. Interviews with New Zealand businesspeople in Shanghai and Xiamen reveal that SMEs were encountering problems getting their goods across the border at the lower tariff rates provided in the FTA. They were very positive about the FTA, however, as the profile of New Zealand officials and firms had risen considerably. It is established that New Zealand firms are engaging in collaborative activities with New Zealand government representatives in an attempt to gain further competitive advantage and that the practice of guanxi is adapting in response to Beijing's attempts to formalise officials' interactions with private sector firms. It is suggested that a firm's reputation (mingyu) with officials may be becoming established as an alternative to guanxi.

KEY WORDS: New Zealand, China, Free Trade Agreement, Guanxi, Local Government, Informal Relationships 


\section{Contents}

$\begin{array}{ll}\text { ACKNOWLEDGEMENTS } & 7\end{array}$

1. Introduction 9

$\underline{\text { PART I }}$

2. FORMAL RELATIONS BETWEEN NEW ZEALAND AND 15

CHINA: THE FTA, EXPECTATIONS OF ITS BENEFITS AND ITS $\underline{\text { EFFECTS }}$

$\begin{array}{lll}2.1 & \text { Overview of the FTA } & 16\end{array}$

2.2 Key Outcomes of the FTA for New Zealand 18

2.3 Expectations of Trade Agreements 20

$2.4 \quad$ Public Statements 22

$2.5 \quad$ Examination of Trade Figures $\quad 23$

$\begin{array}{lll}2.6 & \text { Summary of Part I } & 31\end{array}$

$\underline{\text { PART II }}$

3. THE MINGLING OF THE FORMAL AND THE INFORMAL: 33 THE LAW, THE STATE AND GUANXI IN CHINA

3.1 The Administration of Law in China 35

3.2 The Decentralised Structure of the People's Republic of China 40

3.2.1 The Consequences of Decentralisation on Economic Decision- 41 Making in China

3.2.2 The Effects of Decentralisation on Foreign Companies at Street- 50 $\underline{\text { Level }}$

3.3 Guanxi and its Future in a Changing Society 53

3.3.1 Academic Study of Guanxi 58

3.3.2 How Guanxi Affects Businesses in Today's China 61

3.4 The Link Between Guanxi and Corruption 66

$\begin{array}{lll}3.5 & \text { Summary of Part II } & 70\end{array}$ 
$\underline{\text { PART III }}$

4. FORMAL RULES AND INFORMAL RELATIONSHIPS: HOW 74 NEW ZEALAND SMES EXPERIENCED THE NZCFTA

$\begin{array}{lll}4.1 & \text { Methodology } & 74\end{array}$

$\begin{array}{lll}4.2 & \text { Problems at the Border } & 81\end{array}$

4.3 Interactions Between New Zealand SMEs and Street-Level 89 Bureaucrats

$\begin{array}{lll}4.4 & \text { Benefits at the local level } & 100\end{array}$

4.5 The strength of relationships between the governments of New 118 Zealand and China

5. $\quad$ CONCLUSIONS 124

$\begin{array}{ll}\text { BIBLIOGRAPHY } & 131\end{array}$

$\begin{array}{ll}\text { APPENDIX } & 146\end{array}$

Appendix 1: HS Codes and products for all products exported to New Zealand 146 in 2009 valued more than NZ\$10M 


\section{List of Tables and Figures}

Table 1: Phase-Out Periods for Tariffs on Sensitive Products Exported 19 from New Zealand to China

Table 2: Growth in NZ Exports to China Compared with China's 26 GDP Growth and China's Total Imports

Table 3: Composition of Subjects Interviewed

Figure 1: Comparison of NZ Exports to China and Value of the NZ 28 Dollar

Figure 2: Variation in Growth Rates Based on Degree of FTA Tariff 29 Change 


\section{Abbreviations}

APEC - Asia-Pacific Economic Cooperation

ASEAN - Association of South-East Asian Nations

CER - Closer Economic Relations

CIQ - Customs, Inspections and Quarantine

CPC Communist Party of China

EU - European Union

GDP - Gross Domestic Product

FDI - Foreign Direct Investment

FTA - Free Trade Agreement

HS Code - Harmonized System Code

KEA- Kiwi Expats Abroad

MFAT - Ministry of Foreign Affairs (New Zealand)

MFN - Most-Favoured Nation

NAFTA - North American Free Trade Agreement

NZCFTA - New Zealand-China Free Trade Agreement

NZCTA - New Zealand China Trade Association

NZD - New Zealand Dollar

NZTE - New Zealand Trade and Enterprise

OECD - Organisation for Economic Cooperation and Development

PTA - Preferential Trading Arrangement

PRC - People's Republic of China

RMB - RenMinBi (Currency of China, also known as the Yuan)

ROO - Rules of Origin

RTA - Regional Trading Agreement

SEZ - Special Economic Zone

SME - Small and Medium Enterprise

SOE - State Owned Enterprise

TVE - Township and Village Enterprise

UN - United Nations

VAT - Value Added Tax

WTO - World Trade Organization 


\section{Acknowledgements}

This project did not take place sitting in a library or at a computer desk reading the work of other people. In fact, few of the ideas presented here I can claim genuinely as my own. Rather they are combined thoughts of the many people I talked to over the course of the year I spent working on it. To these people I owe a debt of gratitude.

Firstly to my supervisors - Ben for encouraging me to explore my ideas and follow my instincts and spending time with me to work through the ones that vexed me, and Xiaoming for keeping me in line, forcing academic precision on me when it was needed, and for introducing me to his many contacts in New Zealand and China without whom this project wouldn't have progressed as far as it has.

Throughout my field research in Shanghai and Xiamen I met many New Zealanders and Chinese people who gave me their frank assessments of the current state of affairs. I was truly surprised at their openness and the enthusiasm for helping me - a stranger except for a few imploring emails. Despite the busy nature of their lives in China, each and every one of them was welcoming and generous with their time and ideas. Thank you for telling me what you know, and also for being honest in what you didn't know; an often undervalued component of understanding China in my opinion. Without all of you this project would not have been possible.

My thanks also to the many officials I spoke with at MFAT, NZTE, NZ Customs and MAF. The positive relations between New Zealand and China reflect, I think, that despite the differences between the cultures of our two countries, New Zealand is well-served by the officials who drove the FTA through to its completion and continue to develop the ever-strengthening relationship between the two governments. My thanks in particular go to 
Sally Page at MFAT for tolerating my many calls and emails, and to Julie Haack for her advice on pathways and people to be considered. The same also goes to sector representatives from forestry, seafood, horticulture and Maori enterprises who gave me an insight into events in their areas and their work in China.

Thanks also to my officemate and friend Yang. You tolerated my incessant questions about China, and always spoke well in our lively discussions on the nature of China and its future. If you are anything to judge the next generation of China on, the future is bright.

Thanks to my friends and family, my parents and Rachel, Simon and Kezia in particular. You are all dear to my heart. 


\section{Introduction}

A little over a year after the New Zealand-China Free Trade Agreement (NZCFTA) was signed Prime Minister John Key praised the agreement, noting that New Zealand's export earnings had increased 61 percent, or 1.3 billion from the year before. ${ }^{1}$ The established literature on business behaviour in China documents that, while formal procedures are becoming more established, informal relationships still play an important part in how business is conducted (Yang, 1994; Guthrie, 1998; Wang, 2000; Wank, 2002; Luo, 2007; Krug, 2009). Although the Chinese economy has undergone a period of drastic reform and been opened to market forces, central and local government are highly involved in economic decision-making to an extent that is much greater than in developed western economies (Oi, 1992; Nee, 1992; Shirk, 1993; Boisot and Child, 2006; Thun, 2006; Huang, 2008). As New Zealand companies seek to increase their presence in China, in line with the Key Government's objective of doubling New Zealand's trade with China within five years, ${ }^{2}$ it is timely that we gain a greater understanding of the issues facing New Zealand firms in China.

This project seeks to begin such an undertaking within an academic context, examining the informal relationships that New Zealand small and medium enterprises (SMEs) based in China maintain with local officials and streetlevel bureaucrats. The FTA provides the context for this study. The agreement, after all, marks a highpoint in relations between the two governments. Indeed, New Zealand now appears to occupy a privileged position amongst western countries in its dealings with China. But what discernable effects has the FTA had upon New Zealand businesses operating in China? Usually this question would be answered by looking to export figures or foreign direct investment numbers. I argue that upon examination

\footnotetext{
1 John Key "Speech to Federated Farmers National Council" 18 November 2009.

2 "Key aims to double trade with China", New Zealand Herald, 7 July 2010.
} 
these figures do not present a clear picture. Moreover, China's culture, political system and legal system operate differently from New Zealand's traditional trading partners and therefore require additional examination.

Commonly translated as informal relationships or connections, guanxi (关系) is known to be important for success within China (Bjorkman and Kock, 1995; Wank, 1995; Yeung and Tung, 1996; Pearce and Robinson, 2000; Wang, 2000; Hutchings and Murray, 2002; Yang, 2002; Langenburg, 2007; Luo, 2007). Like much in China, however, guanxi's position and efficacy is changing as the country's rapid economic development has fomented change across its society.

Since the reform programme began in China, local government has played an active role in guiding local economic development. Developing good guanxi has been promoted as a means for foreign firms to cope with the street-level bureaucrats, who can wield large amounts of discretionary power and the vague legal environment. Connections with local officials can also gain firms advantages and connections that will help their business while avoiding some obstacles. Seeking to reduce corrupt cadre behaviour, however, Beijing has sought to limit the discretionary powers of low-level officials and establish stronger legal institutions and behaviour.

The NZCFTA established a number of benefits to enable New Zealand products to enter China more freely. Chief among the benefits touted by then Prime Minister Helen Clark and Trade Minister Phil Goff were tariff reductions and improved customs procedures (Clark, 2008; Goff, 2008). This study finds that the benefits of tariff reductions are more ambiguous than traditionally thought. Indeed, following the implementation of the FTA, SMEs were struggling to realise tariff benefits and were frustrated that the process for getting their goods into China had become more complicated. In contrast, however, they were very positive about the effects that the NZCFTA has had on the relationship between New Zealand and China, and were using the 
higher profile and increased status of New Zealand to develop more opportunities for their firms.

The impact that formal agreements, such as preferential trading agreements, can have on informal relationships has not been closely examined within the literature; neither was it given as a motive for New Zealand to consider the FTA with China. Rather, most focus has been applied to tariff levies and the increases in trade that can be expected when they are alleviated. Moreover, comprehensive trading agreements have up until recently usually existed between states with geographic or cultural similarities, providing them with a shared history upon which their relationship is already firmly established.

New Zealand and China's FTA represents a change to this standard. New Zealand's formal, legal tradition stands in contrast to the informal channels of interpersonal relationships that businesses in China have relied upon in the past. Observers of business in China commonly highlight the gap between the formal legal rules upon which business activity in China is supposed to take place, and the reality of how it is actually undertaken. To suppose implementation of the terms of the FTA as agreed is an assumption that requires verification, as informal relationships in China are often as important as formal rules and regulations.

Rather than seeking to evaluate the success of the FTA solely on economic terms, this thesis seeks to also examine the effect the FTA has had below the central government level by looking at interactions at the grassroots level which standard statistical measures cannot provide insight on. This thesis, then, will look at the experiences of businesspeople and how the FTA has affected their activities.

There is a considerable gap in the literature in terms of the experiences of New Zealand businesses in China. Given the importance that China now holds as a trading partner for New Zealand, surprisingly little study has been 
conducted on the relationship or the experience of New Zealand companies operating in China. Only one article has been published on the experience of New Zealand businesses in China and this was published in the mid-nineties, so is now quite out of date. The article, by Alan Au and Peter Enderwick (1994), examined the experiences of 13 small New Zealand companies that were operating joint ventures in China in the late eighties and early nineties. ${ }^{3}$ Most of the companies reported a high level of dissatisfaction and frustration with their Chinese partners, while the follow up survey found a high casualty rate with most of the firms failing or terminating their joint venture.

Outside of academia more studies have been undertaken, but most of these have been either written or commissioned by New Zealand government ministries or agencies such as the New Zealand Ministry of Foreign Affairs (MFAT), New Zealand Trade and Enterprise (NZTE) or the Asia New Zealand Foundation. These are, for the most part, focused on the FTA or the opportunities and challenges available for New Zealand business in China as opposed to actual company performance. Many of these works are discussed in this thesis. 4

This thesis is broken into three parts. Part I first looks at the relationship that exists between China and New Zealand and provides an overview of the

\footnotetext{
${ }^{3}$ Four other articles can also be found on New Zealand businesses involvement within the Chinese market. The first deals mainly with skills and knowledge businesspeople were thought to be most important for doing business in China and the second with marketing strategies. Two other published works also deal with the subject of guanxi. See Brett Martin and Gretchen Larsen "Taming the tiger: key success factors for trade with China" Marketing Intelligence \& Planning 17(4) 1999: 202 - 208; Henry F.L. Chung "International Standardization Strategies: The Experiences of Australian and New Zealand Firms Operating in the Greater China Markets" Journal of International Marketing 11(3) 2003: 48-82; Yunxi Zhu "Managing Business Relationships in New Zealand and China" Management International Review 49(2) 2009: 225-248; Hongzhi Gao "Guanxi Dilemmas and Gatekeepers: A Qualitative Study of Chinese-Western Relationships in Marketing" PhD Thesis, University of Otago, February 2009.

4 "Joint Study Report on the Free Trade Agreement between China and New Zealand" by The Ministry of Commerce, China and The Ministry of Foreign Affairs and Trade, New Zealand; "New Zealand - China Free Trade Agreement (and Associated Instruments) National Interest Analysis"; Ministry of Foreign Affairs and Trade (New Zealand), 2008. Rolf D. Cremer and Bala Ramasamy "Effective Strategies for New Zealand Firms in China" Asia New Zealand Foundation, 2005.
} 
FTA. The motivations for the New Zealand Government, as stated in reports on the FTA, public statements by politicians and papers presented to Cabinet are also examined. These motivations will then be measured against the achievements observable in New Zealand's trade figures with China. By looking back over the previous decade's trade figures I establish that although exports to China did increase in the immediate period following the signing of the FTA, the extent to which tariff reductions contributed towards this increase is unclear.

In Part II I seek to establish contributing factors that can add to our understanding for why the increase in trade activity may have taken place that cannot be explained through economic models. In order to achieve this I turn to the academic literature on China's reform programme and its economic development. Extensive academic study over the last few decades has sought to explain how China's economy has grown so rapidly despite the absence of strong institutions or a clear delineation of responsibilities between businesses and the state. China is not unique in that developing economies often struggle, to varying degrees of success, to implement laws that are seen to be imported (Corne, 1997; Pistor, 2000; Gong, 2004; Clark, Murrell and Whiting, 2008), but its local governments have a record of independent behaviour which promotes local interests rather than those of the central government and have been active in promoting local economic development (Huang, 1990; Oi, 1992; Wank, 1995; Boisot and Child, 1996; Krug, 2000; Segal and Thun, 2001; Kong, 2005, 74-76; Goodman, 2009, 446) as have street-level bureaucrats (Lipsky, 1980; Bruun, 1995; Chow, 2005). Combined with the importance of informal relationships in China's developing economy (Yang, 1994; Guthrie, 1997; Wang, 2000; Wank, 2002; Lagenburg, 2007; Luo, 2007), that something is occurring that falls outside of official figures is not overly surprising.

In the next section, I present the methodology used to conduct interviews with New Zealand businesspeople in Shanghai and Xiamen. The information 
gathered in interviews is then presented in Part III. These interviews reveal benefits that extend upon standard perspectives of the advantages of preferential trading agreements. While China's current legal and political systems present challenges to the implementation of a formal trading agreement, New Zealand businesspeople and government representatives are making extensive use of informal relationships to expand trading opportunities between the two countries.

The concluding chapter summarises the findings of the thesis and offers suggestions for future areas of study. 


\section{PART ONE}

\section{Formal Relations Between New Zealand and China: The FTA, Expectations of its Benefits and its Effects}

Over the last two decades New Zealand's trade with China has grown rapidly, to the extent that it is now New Zealand's second most important trading partner. China's rapid economic growth has enriched millions of Chinese whose spending power has expanded such that demand for many of the products that New Zealand produces has risen considerably. The growth has been most evident in New Zealand's primary goods exports, with dairy products, wood, wool, seafood, and meat, comprising the majority of goods exported to China (New Zealand Trade and Enterprise, 2010: 4-5).

As New Zealand's economy is focused on primary products and services and China's on manufactured goods, there is a high degree of compatibility between the two countries' economies, far greater than that between New Zealand and its traditional trading partners of Australia, the United States and the United Kingdom.

Despite these natural advantages, China presents considerable challenges to New Zealand's exporters. Obviously the size difference - a population of 1.4 billion compared to 4 million - is a major factor for New Zealand's small and medium-sized businesses. But there are also large cultural and language barriers, and differences in the legal and political institutions that each country employs. As individuals and as businesses, New Zealanders have relatively little experience in operating in cultural and political environments different from their own. David Mahon, Managing Director of one of the oldest New Zealand-owned businesses in China, wrote: 
"Many New Zealanders believe in the myth that the country already has a broad global footprint. Of a population of just over four million people, according to New Zealand Treasury statistics, a further 460,000 New Zealanders live in other countries. The majority of these expatriates, over 350,000, live in Australia. The next significant block, some 60,000, live in the United Kingdom, and there are a few pockets in the United States. All are safe, English-speaking alternatives to living in New Zealand... The idea that New Zealanders are largely an adventurous, experimental people who will throw themselves into unfamiliar cultures and adapt is therefore incorrect (2009: 1-2).

In this section I will briefly discuss the steps leading up to the signing of the FTA, its contents, and provide a short analysis of its effects. Given the agreement is still in its formative period, it is still too early to expect any assessment of the agreement to reveal a clear patterns and effects. However, as it is the most important event to have occurred between the New Zealand and China to date, to not discuss the agreement would be remiss. In contrast, we would also expect that the informal benefits of the FTA will be at their highest during in the immediate period following the agreement coming into effect. Furthermore, an understanding of the expectations of what was expected from the formal agreement, will establish what other additional effects have been realised beyond what was initially expected.

Overview of the FTA

During a three-day visit in 2003 to New Zealand by President Hu Jintao, a number of agreements were signed that solidified in writing the rapidly strengthening relationship - a Consular Agreement, an agreement on Technical Barriers to Trade and an arrangement on Mutual Recognition of Academic Degrees in Higher Education (Goff, 2003; Anderton, 2003; Maharey, 2003). Further progress was achieved in April 2004 when New Zealand became the first developed economy to recognise China as a market 
economy and the two countries agreed on a formal Trade and Economic Cooperation Framework that paved the way for formal discussions on the FTA to begin (Clark, 2004; Xinhua News Agency, 2004).

A Cabinet Paper presented in October 2004 details the benefits and the concerns that had been gathered from public submissions and consultations with New Zealand businesses on the prospect of an FTA with China. ${ }^{5}$ They included:

- Strong support for an FTA.

- Removal of tariffs was seen as a significant benefit to many business and consumers.

- Concern about tariff reductions expressed by unions and some sectors of the economy protected by tariffs.

- A strong message from businesses that the FTA should be about more than just tariffs and should include discussions on non-tariff barriers such as standards, labelling and quarantine issues.

- Concerns about restrictions in the service sector in China.

- Concerns over Intellectual Property.

- Issues about the movement of foreign exchange and capital requirements.

- Labour and environmental issues in China.

New Zealand and China entered negotiations in December 20046 following a Joint Study released in June outlining the potential for both sides to benefit from an agreement. The report found that despite the economies' vastly different sizes, there were sufficient reasons to begin negotiations for an FTA due to the complimentary nature of their economies. Assistant Minister of Commerce Yi Xiaozhun led the Chinese side of the initial negotiations; his

\footnotetext{
5 Cabinet Paper dated October 2004, "Free Trade Agreement with China: Release of Feasibility Study and Launch of Negotiations"; obtained under the Official Information Act. 6 "Nation, New Zealand to launch FTA talks" China Daily 22 November 2004; "Free trade talks with New Zealand start" China Daily 7 December 2004.
} 
counterpart was New Zealand Ministry of Foreign Affairs and Trade China Taskforce Director Charles Finny. Rapid progress ensued and two years later the decision was made to accelerate talks.7 By early 2008 negotiations were nearing their end and on 7 April 2008 New Zealand Prime Minister Helen Clark led a delegation to Beijing for the signing of the agreement with Wen Jiabao in the Great Hall of the People.

Key Outcomes of the FTA

The agreement that was agreed to was a comprehensive FTA liberalising trade in goods and services and investment rules. The key outcomes as described on the New Zealand Government's China FTA website covering the agreement are:

- Liberalised trade in goods

- Rules developed to govern trade

- Liberalised trade in services

- An agreement on movement of people

- Processes for facilitating investment

- Conformity assessment of electrical and electronic equipment

- Development of a dispute settlement process

Additional to the FTA, an Environmental Cooperation Agreement and a Memorandum of Understanding on Labour Cooperation were also signed.

The most sought after gains from FTAs are the reductions on tariffs. Of New Zealand's total exports to China before the FTA came into force, 96\% will be eliminated by the end of the phase-in process that ends at the end of 2018. All goods that were subject to less than 5\% tariff beforehand were eliminated, while duties from 6-20\% will be phased out over five years. Tariffs greater than $20 \%$ were reduced to $20 \%$. Certain 'sensitive' products reflecting

7 "China, New Zealand agree to accelerate FTA talks" Xinhua News Agency 14 November 2006. 
exporting strengths of New Zealand, however, were subject to slower reductions. These products and the length of time before tariffs would be eliminated are shown in Table 1.

Table 1: PHASE-OUT PERIODS FOR TARIFFS ON SENSITIVE PRODUCTS EXPORTED FROM NEW ZEALAND TO CHINA

\begin{tabular}{|l|l|}
\hline Product & Phase-out period for tariffs \\
\hline Dairy: butter, cheese and liquid milk & 10 years \\
\hline Dairy: milk powders & 12 years \\
\hline Meat: Sheep, beef and edible offal & 9 years \\
\hline Most seafood products & 5 years \\
\hline Apples & 5 years \\
\hline Kiwifruit & 9 years \\
\hline Wool & $\begin{array}{l}\text { Duty free treatment for } 25,000 \text { tonnes, } \\
\text { raising } 5 \% \text { annually until } 2017, \text { under } \\
\text { a country-specific quota. }\end{array}$ \\
\hline
\end{tabular}

Source: New Zealand Ministry of Foreign Affairs and Trade.

To qualify for preferential tariffs, a Rules of Origin (ROO) system was established for New Zealand goods exporters. This required that authorised bodies, such as chambers of commerce, confirm that exported products were substantially produced in New Zealand by issuing a certificate of origin. Advanced rulings on origin and tariff clarification could also be requested so that a certificate of origin would not be required. However, these could only be issues by Chinese customs (CIQ) which requires that the company making the request has an established presence in China - so companies lacking a representative in China could not receive this benefit. A commitment was also made by China to make all reasonable efforts to release goods from customs within 48 hours.

In the areas of environmental services, construction, agriculture and forestry, engineering, integrated engineering, computer and related services, and 
tourism, New Zealand also received Most-Favoured Nation (MFN) status within China, meaning that any more generous benefits extended to another OECD country would automatically be extended to New Zealand as well. Guarantees of market access and national treatment were also given in certain sectors as well, meaning that New Zealand service firms can operate in China on the same basis as domestic suppliers. ${ }^{8}$

Commitments were also undertaken by both sides to streamline procedures relating to sanitary/photosanitary measures and technical barriers to trade, such as electrical standards, so that it was easier to demonstrate that a product met established compliance standards.

\section{Expectations of Trade Agreements}

Economic expectations were stated quite explicitly stated by China and New Zealand in the Joint Study into the FTA that was undertaken prior to the start of formal negotiations, so establishing the expectations of New Zealand's politicians and policymakers is easily achieved. However, as the Joint Study was concerned only with economic matters, broadening the scope to strategic and political concerns requires some supposition as to the objectives of the Clark Government. ${ }^{9}$

The economic modelling in the Joint Study forecast that the benefits of an FTA would fall substantially in New Zealand's favour. In the first year a 39 percent increase in New Zealand exports to China was predicted. China's exports

\footnotetext{
8 This did not extend to government procurement contracts as China was still negotiating its accession to the relevant section of the WTO. In the interim period China is obliged to extend MFN status to New Zealand firms.

${ }^{9}$ For this study I approached the Ministry of Foreign Affairs and Trade for Cabinet Papers regarding the FTA in the hope of gaining an insight into the issues being discussed by Cabinet and officials. Following discussions regarding the likelihood of relevant information being released and the expense that would be incurred, only one paper was requested from MFAT ("Free Trade Agreement with China: Release of Feasibility Study and Launch of Negotiations"). Some information was withheld from release on the grounds of sections 6 (a), 9 (2) d) and 9 (2) g (ii) of the Official Information Act. The release of further papers was discussed, but I was advised that they would be likely to receive equal, if not more, scrutiny.
} 
would in comparison grow by ten percent - substantial, but somewhat smaller owing to the openness of the New Zealand economy and already low tariffs on most imports. ${ }^{10}$

The expansion of trade obtained through reduced tariffs was not the only gain that was expected. The complementary nature of China and New Zealand's economies means that increased efficiencies and consumption would be likely to take place over time that would contribute to long-term gains from a comprehensive agreement. Significant gains in real GDP (0.25), real consumption (0.55) and total output level (0.25) would be achieved over the following decade by New Zealand. China meanwhile could expect respective gains of 0.07, 0.17 and 0.007 (Joint Study, 2005: 7-8).

These findings are in line with other academic and institutional reports that argue the case for trade liberalisation. While the debate over the short-term costs of trade liberalisation is yet to be resolved, there is firm support for the economic benefits that trade liberalisation brings in the long-term. ${ }^{11}$ The Asian Development Outlook 2002 in its survey of the impact of Preferential Trading Arrangements (PTAs),12 for example, finds "near unanimity that increased trade openness has had a significant long-term positive impact on economic development" (Asia Development Bank, 2002: 159).

\footnotetext{
${ }^{10}$ In the Joint Study for example, static gains over the initial 10 years of the FTA were expected to bring about gains of $0.15 \%$ and $0.35 \%$ in real GDP and real consumption for New Zealand. The Joint Study adds a further $0.1 \%$ and $0.2 \%$ to the expected benefits of the FTA for New Zealand over the initial 10 year period.

${ }^{11}$ For economic modelling analysis see G. Grossman and E. Helpman, "Innovation and Growth in the World Economy" MIT Press, Cambridge, USA, 1991; L. Rivera-Batiz and P. Romer "International Integration and Endogenous Growth" Quarterly Journal of Economics 106 1991: 531-555.

${ }_{12}$ Much of the literature discussing trade liberalisation does not explicitly cover FTAs as they are a more recent feature of global trade. As such some the work referred to in this section was written in reference to Preferential Trading Agreements (PTAs) or Regional Trade Agreements (RTAs) which were more widely discussed during the nineties when they were the preferred method for states looking to liberalise their trade relationships, e.g. NAFTA, the EU and APEC. However, as they are very similar to FTAs, this does not cause any inconsistencies.
} 
Traditionally when economists examined gains from trading agreements, they looked to the expected benefits from the removal of tariffs and non-tariff barriers. These are known as static gains. More recently economists have asked why economies that are more open to international trade continue to make economic gains when static gains have already been fully achieved. The current consensus in the literature is that the answer lies in greater competition and more efficient allocation of resources, known as dynamic gains, but these are thought to be substantial only in the longer term. In terms of benefits gained from the FTA, China was predicted to achieve much from dynamic gains in the long term, whereas New Zealand was to gain substantially more from static gains in the period immediately following implementation. However, for both countries most of the gains predicted in the Joint Study "would be achieved through the removal of tariffs and unnecessary non-tariff measures" (Joint Study Report, 2005: 8).

A final possible benefit is raised in the Joint Study that the authors warn is difficult to mathematically quantify but should not be underestimated. The FTA, they predicate, will increase "investor confidence and interest" because the agreement will signal to the private sector the improving state of New Zealand-China relations. The examples they offer to demonstrate this is through the decrease in risk premiums investors apply to the other economy, or improvements in the prospects of loan applications to fund investments in the other economy (Joint Study Report, 2005: 90-91).

\section{Public Statements}

This section's focus on economic benefits also reflects the arguments for the FTA that were most often cited by the Clark Government for why New Zealanders should welcome the FTA with China. Here, for example, are the words of Hon. Phil Goff, Minister of Trade at the time the agreement was signed: 
“This agreement will create advantages for New Zealand exporters and consequently jobs and growth in New Zealand. Without it New Zealand exporters would be disadvantaged against competitors whose countries did secure free trade with China" (2008).

Likewise, Helen Clark's statement marking the agreement focused almost exclusively on the economic benefits anticipated for New Zealand:

"Over time this FTA will result in the elimination of tariffs on 96 per cent of New Zealand exports to China, and is estimated to lift New Zealand's export revenue from China by between US\$180 to US\$280 million (NZ\$225 to NZ\$350 million) every year.

The signing of this agreement is a very significant achievement for New Zealand. It opens up new opportunities for businesses looking to engage with, or grow their existing links with, China. It will facilitate goods and services trade, and investment. Overall, the FTA reduces barriers to our trade with China" (2008).

The only acknowledgement of non-economic factors in this statement discussed the broader context of the relationship between the two countries:

"[The FTA] promotes co-operation in a broad range of economic areas, and also provides a platform for further engagement at the governmental, cultural, and people-to-people levels." (Clark, 2008).

This statement draws our attention towards the benefits to New Zealand in terms of enhancing the relationship New Zealand has with China, rather than political objectives. As will be discussed later, the value of relationships in China is one of the main differences between the cultures of New Zealand and China. This is especially so in business, where New Zealanders tend to have a business and marketing relationship approach, whereas in China business relationships are built from a base of guanxi and friendship (Zhu, 2009: 243). 


\section{Examination of Trade Figures}

In the previous section the expectations of the outcomes of an FTA were examined. The primary economic benefits expected were anticipated to come from static gains resulting from the decrease in tariff rates; in other words, firms seeking out market opportunities that became more promising owing to the decrease in market-distorting tariffs. Furthermore, removal of non-tariff barriers and the priority given to passing New Zealand goods through customs should make the Chinese market more enticing to New Zealand exporters as red tape is reduced, market efficiencies are realised, uncertainties are reduced, and so forth. Having already established that the primary reason for New Zealand to enter into the FTA with China was for economic reasons, this section examines the trade figures for New Zealand exports to China in order to determine the extent of the FTA's effect.

Initially empirical data on New Zealand's trade was found from information publicly available from New Zealand Statistics. Trade statistics were used to determine the pattern of exports to China based on volume. The decision to use volume rather than value was made primarily because of the fluctuations in the value of the New Zealand dollar vis-à-vis the Chinese renminbi during the studied period, 1999-2009. Although exports are obviously affected by changes in currency, by examining volume rather than value we can determine trends in demand for New Zealand products from China. Also, given the ongoing demand for the New Zealand dollar by currency traders, there is no reason to assume that currency fluctuations will not continue in the coming decade. As such, fluctuation should be considered an unpredictable constant that statisticians, as well as New Zealand exporters, will have to continue to deal with.

To establish the trend that existed before the FTA commenced, the figures below cover the ten-year period leading up to the year anniversary of the 
FTA. ${ }^{13}$ An increase in trade should occur when the FTA came into effect. It is also likely that firms should begin to explore the Chinese market more seriously following the commencement of negotiations for the FTA, when it became substantially more likely that opportunities would arise when the FTA came into effect. This should occur because companies recognise that in order to be prepared to take advantage of the new situation, they would need to perform large amounts of work getting to know the market, finding suitable partners, establishing distribution networks and taking steps to establish themselves as a company that can operate and sell their products in China.

First, then, we need to establish whether or not New Zealand's exports to China present any anomalies. To do this we will first examine China's GDP growth over the ten-year period between 2000 and 2009. The same is also done for China's total imports. By doing this we can establish whether growth in New Zealand's exports correlates with the consistent growth patterns that the Chinese economy was experiencing, or with the growth in China's overall imports of foreign products.

As can been seen in Figure 1, China's real annual growth throughout the noughties was consistently in the region of $10 \%$, dipping to a low of $8 \%$ in 2000 and reaching a high of $11.4 \%$ in 2007 . Imports of goods from all foreign markets increased at a significantly higher rate, twice exceeding $35 \%$ and only decreasing once in 2009 as the world economy slowed as a result of the 2008/2009 banking crisis. Neither of these figures however, demonstrates a correlation with New Zealand's exports to China over the same time period, which fluctuate at different rates considerably over the decade. We do observe steep rises in New Zealand's exports in three years - 2000 (44\%), 2001 (45\%) and 2009 (44\%) - and also significant growth in three other years - 2004

\footnotetext{
${ }^{13}$ During the decade this table covers, four significant events occurred that may impact upon the figures -1) economic recessions in the form of the Asian crises of 1997 and the Dotcom Bust in 2000; 2) China's accession to the WTO in November 2001; 3) the beginning of FTA talks between New Zealand and China in 2005; and 4) the signing and commencement of the FTA in 2008.
} 
(23\%), $2006(20 \%)$ and 2008 (30\%). Small growth occurs in two years - 2002 $(6 \%)$ and $2007(4 \%)$ - while exports contracted in two years - $2003(-4 \%)$ and $2005(-7 \%)$.

Table 2: GROWTH IN NZ EXPORTS TO CHINA COMPARED WITH CHINA'S GDP GROWTH AND CHINA'S TOTAL IMPORTS

\begin{tabular}{|c|c|c|c|c|c|c|}
\hline Year & $\begin{array}{c}\text { GDP } \\
\text { RMB } \\
\text { billion } \\
\text { at } \\
\text { current } \\
\text { prices }\end{array}$ & $\begin{array}{c}\text { Real } \\
\text { annual } \\
\text { growth } \\
\text { rate } \\
(\%)\end{array}$ & $\begin{array}{l}\text { Imports } \\
\text { (US\$ } \\
\text { billions) }\end{array}$ & $\begin{array}{c}\text { Percentage } \\
\text { growth } \\
\text { year on } \\
\text { year }\end{array}$ & $\begin{array}{c}\text { NZ Exports } \\
\text { to China } \\
\text { (NZ\$) }\end{array}$ & $\begin{array}{c}\text { Percentage } \\
\text { growth } \\
\text { year on } \\
\text { year }\end{array}$ \\
\hline 2000 & $8,946.8$ & 8.0 & 225.1 & $36 \%$ & $927,627,967$ & $44 \%$ \\
\hline 2001 & $10,965.5$ & 8.3 & 243.6 & $8 \%$ & $1,345,494,717$ & $45 \%$ \\
\hline 2002 & $12,033.3$ & 9.1 & 295.2 & $21 \%$ & $1,421,667,543$ & $6 \%$ \\
\hline 2003 & $13,582.3$ & 10.0 & 412.8 & $40 \%$ & $1,365,309,692$ & $-4 \%$ \\
\hline 2004 & $15,987.8$ & 10.1 & 561.2 & $36 \%$ & $1,675,827,383$ & $23 \%$ \\
\hline 2005 & $18,386.8$ & 9.9 & 660 & $18 \%$ & $1,555,489,653$ & $-7 \%$ \\
\hline 2006 & $21,087.1$ & 11.1 & 791.6 & $20 \%$ & $1,866,677,213$ & $20 \%$ \\
\hline 2007 & $24,661.9$ & 11.4 & 956.3 & $21 \%$ & $1,934,301,424$ & $4 \%$ \\
\hline 2008 & $31,404.5$ & 9.6 & 1233.1 & $29 \%$ & $2,516,154,892$ & $30 \%$ \\
\hline 2009 & $33,535.3$ & 8.7 & 1000.6 & $-18 \%$ & $3,613,047,492$ & $44 \%$ \\
\hline
\end{tabular}

Sources: China GDP and total imports from chinability.com; 2009 figure for total imports from National Economic and Social Development National Bureau of Statistics of China. Information on New Zealand Exports from New Zealand Statistics' Infoshare.

Table 2 shows that following the FTA New Zealand's exports jumped 44\%, $5 \%$ above the mark predicted by the Joint Study. Notably the $44 \%$ increase in 2009 stands in stark contrast to the $18 \%$ decrease for China's total imports. Interestingly, the similar sized gains of 2000 and 2001 occurred prior to China's accession to the WTO in November 2001 before tariff rates were reduced. However, the year following China's WTO accession saw a 
significant drop in growth. This is despite the fact that the cuts in import tariffs that China made following its accession to the WTO were quite significant - a reduction in the weighted average tariff from 13.3\% in 2001 to $6.8 \%$ at the end of the implementation period in 2010, although most were to be gradually phased in by 2005. It should be noted, however, that these reductions were much smaller in comparison to the reduction of 27 percentage points that took place in the decade prior to accession as China liberalised its economy in preparation for entry to the WTO (Martin, Bhattasali and Li, 2003: 37). ${ }^{14}$ However, significant differences existed in statutory tariffs and the actual level of protection for agricultural products in China (ibid: 43), although for New Zealand's leading exports the main tariff reductions were found in dairy-related products.

If the increase in trade were directly linked to the decrease in tariffs, we would expect to see some correlation between China's total imports following WTO accession and New Zealand's exports following the FTA implementation. No such correlation exists. Indeed, from the information presented in this table, the only constant appears to be that of volatility.

An alternative explanation could be that during this time the New Zealand dollar altered in value, thus affecting affordability of New Zealand products in China. Figure 1 shows fluctuations in the value of the NZD:RMB and New Zealand's total exports by volume over the same ten-year period, 2000-2009. As can be seen, there is no consistent connection between the volume of New Zealand's exports and the value of the currency vis-à-vis the Chinese renminbi.

\footnotetext{
14 These reductions also coincided with substantial changes in the role of the state in China's economy that took place as many SOEs were either privatised or failed as the state reduced its financial support for them. This increased opportunities for new companies, both local and foreign, to replace them.
} 


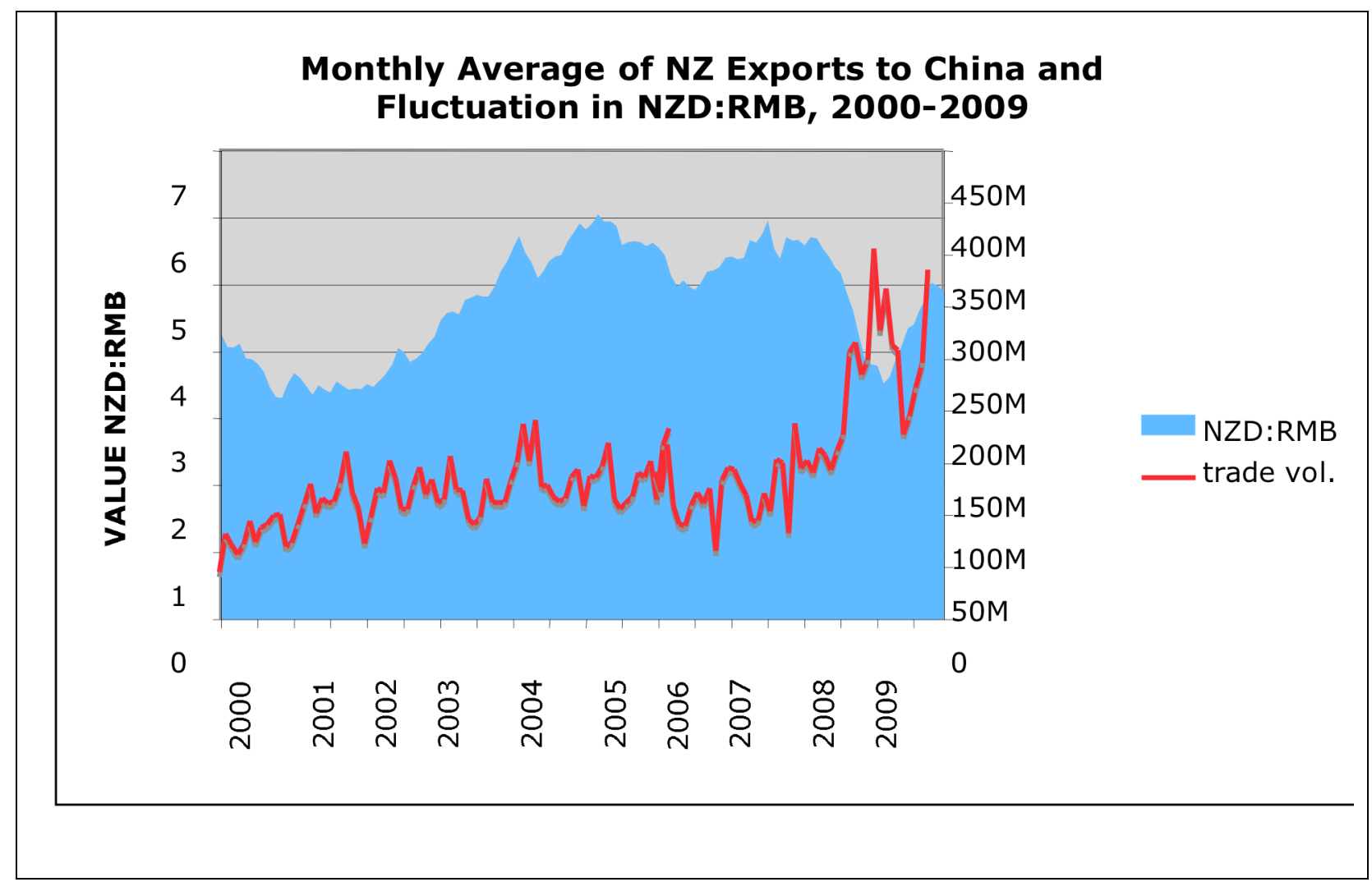

Sources: NZ Exports to China from New Zealand Statistics' Infoshare; Value of NZ dollar to Chinese RMB from Reserve Bank of New Zealand.

It is possible that within the statistics shown in Figure 1 significant movements in single products have been occurring, but are obscured by the amalgamation of all products that New Zealand exports to China. In order to lessen such distortions, one final graph is displayed below. Figure 2 covers New Zealand's most significant exports to China on an annual basis between 1999 and 2009 and displays the variation in year-on-year growth in exports between products based on the degree of change in tariff rate following the implementation of the FTA. ${ }^{15}$

\footnotetext{
${ }^{15}$ New Zealand Statistics, Infoshare. Goods were selected if the total value of the good exported exceeded NZ\$10M for the year ending 2009. One item was excluded as being inappropriate for the study (Confidential Items, HS Code 9809.00, of which just over NZ\$10M worth of goods were exported in 2009. Based upon the rate of tariff change the remaining 43 items were placed into groups of approximately the same numerical value - no change (13), low change (15), medium change (12), and high change (8).
} 
Figure 2: VARIATION IN GROWTH RATES BASED ON DEGREE OF FTA TARIFF CHANGE16

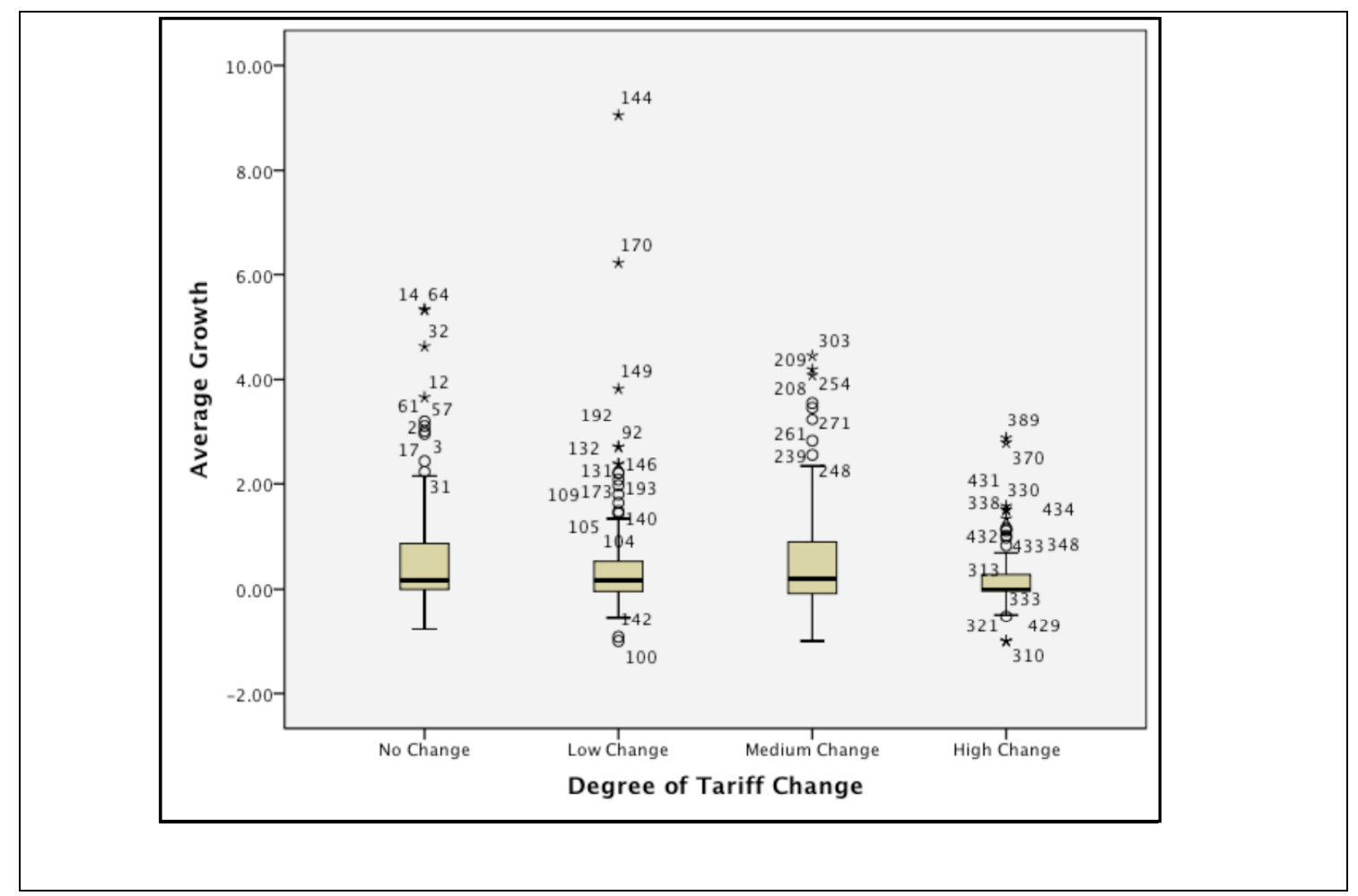

Numbers shown refer to HS Codes for exported goods. See Appendix 1 for the description of each HS Code. Source: New Zealand Statistics' Infoshare.

Again, no pattern is discernable between products having a high, medium, low or no rate of change in their tariff. It can be clearly observed that the box plots for each category overlap and therefore that the means of the four groups are largely the same. This conclusion could be statistically tested. This situation is supported by the literature on links between trade policy, tariffs and trade flows, in which no clear link has been established (Nordås, Miroudot and Kowalski; 2006, 16). ${ }^{17}$

16 The numbers on the graph represent the HS codes for particular products. Four items were removed from the graph, three because of the extreme variation which distorted the visual impression of the overall graph and one, Confidential Items, because of distorting effects (for example, a 19,000 percent increase one year) and because by its nature falls outside of items that are relevant to an FTA.

17 It is for this reason that tariffs are usually left out gravity regressions on the determinants of bilateral trade. 
Indeed, it is only when we examine individual categories of exported goods that we can actually see the impacts small categories of goods can have upon the total numbers for exported goods. While it is true that we can say that New Zealand's exports to China in 2009 rose by 44\% from the year prior, a large amount of this rise can be attributed to just two kinds of products infant milk formula and lumber. This highlights one problem in trying to measure changes in export figures - the difference in market size between New Zealand and China means relatively small changes in the behaviour of the Chinese market can have large effects upon New Zealand's export figures.

Indeed, in neither of these product categories do tariff rates act as a significant influencing factor. Infant milk formula exports by volume increased from $2,816,654$ in 2008 to $3,624,725$ in 2009 , an increase of $180 \%$. Timber exports in two categories 18 increased by volume from 2,007,336,378 in 2008 to 4,698,108,036 in 2009, and from 128,889,842 in 2008 to 236,043,455 in 2009 increases of $134 \%$ and $83 \%$ respectively. The change in infant milk formula exports occurred primarily because of the melamine scandal that led to more parents purchasing imported infant formula products due to fears over the safety of locally made products. Timber exports increased because of subsidies from China's stimulus package for low-cost housing, reconstruction requirements following the Sichuan earthquake and high furniture sales. Furthermore, Chinese timber importers, frustrated at recent years of uncertain supply, searched for new suppliers following a policy change in Russia which added substantial export tariffs to timber being exported in an attempt to increase the value-added portion of its exports. Rather than increasing processed wood exports it caused a drastic reduction in raw timber exports, which New Zealand timber exporters took advantage of (National Business Review; 2008; Acland; 2009; Ribbonwood New Zealand; 2010). However, timber products in this range attracted no tariffs during this period, so there was no advantage gained by them through the FTA. Infant milk powder still attracted high tariffs, and the rate of change from the FTA was low.

\footnotetext{
${ }^{18}$ HS Code 4403.20 Wood; coniferous, in the rough; and HS Code 4407.10 Wood, coniferous; sawn or chipped.
} 
Since the idea of an FTA with China was first raised, statements by New Zealand's public officials have placed much emphasis on the reduction of tariffs for New Zealand goods entering China. This continues presently with prominence being placed upon the competitive advantage lower tariff rates provide New Zealand exporters. The above figures demonstrate, however, that the increase in New Zealand's exports to China should not be attributed entirely to changes in tariff rates, as the effects upon exports are unclear.

Other factors are clearly influential. The size of China's economy when compared to New Zealand's means that small changes within the Chinese economy can lead to big changes in New Zealand's exports, as the figures revealed in respect of wood products and milk powder show. Prices will no doubt have some influence as well, but the factors that contribute to the overall price of product - currency fluctuations, transport costs, weather (for agricultural products) - are beyond the control of exporters. Moreover, New Zealand firms struggle to compete in cost-sensitive markets because few firms are large enough to produce at economies of scale that will be competitive in the Chinese market. As such, most New Zealand exporters attempt to compete in niche markets with products that are at the upper end of the market where consumers are more interested in the quality of a product than its price.

While tariff reductions were the most publicised aspect of the FTA, another of the key outcomes was the easing of rules surrounding investments. If New Zealand is to expand its presence in the Chinese market, more firms will need to make investments and establish a physical presence in the country. This will require a move beyond the buyer/seller relationship that exists with exports, and means firms will need to gain a better understanding of the factors that are different from the New Zealand market and develop relationships. The next section attempts to gain a better understanding of the 
current issues that New Zealand businesses in China may be facing by examining three areas that are have been issues of academic interest amongst scholars examining China's reform programme. 


\section{PART TWO}

\section{THE MINGLING OF THE FORMAL AND THE INFORMAL: THE LAW, THE STATE AND GUANXI IN CHINA}

In developing markets where commercial law is often weak and business practice opaque, human judgement and cultural understanding take on greater importance than in more developed markets...Businesspeople must not underestimate the difficulties of working in developing countries. Underdevelopment might be not only economic, but also social and legal (Mahon, 2009).

The established literature on preferential trading arrangements and liberalised trade makes a compelling case for FTAs. Based on statements made in support of the FTA, the Clark Government followed this orthodoxy believing that by reducing tariff levies on New Zealand exports entering China, a considerable boost to the New Zealand economy would result. And indeed, trade with China has increased since the FTA was signed. The previous section, however, established that tariff reductions have not clearly affected trade; how large or small the tariff reduction was on a product did not significantly affect increases in Chinese purchases. Rather, the boost in trade was seen across many products regardless of the associated tariff level. The two biggest changes were seen in wood, which before the FTA was not subject to any tariff, and milk powder, which only received a small reduction in its tariff when the FTA was implemented. This section of the thesis looks to China itself in order to understand factors that may also be contributing to the increase in exports from New Zealand.

To understand how the FTA is being implemented in China it is first necessary to understand more about how the Chinese economy is governed and the realities that businesses face when operating there. In order to do this, 
the next section looks to the literature for an overview of recent academic study of China's governance and culture and how this affects the behaviour of businesses and government officials.

China, after all, is a country of considerable differences to New Zealand so it is not surprising that people and institutions there behave differently. China's size and population mean it faces many different challenges; to meet these challenges its government is structured such that considerably more power resides with sub-national governments, compared with their counterparts in New Zealand. In turn, these sub-national entities have taken different approaches to how they implement laws and regulations, leading to a great deal of variance between different locations. ${ }^{19}$ A different approach to the law and legal institutions also exists, one that is more informal and allows for considerable interpretation. As such, when interpretation and implementation are more open for negotiation, relationships between individuals become more important. These informal relationships or connections are known as guanxi and have been attributed as one of the most important assets an individual or business in China can develop

So how might this affect New Zealand's FTA with China? The FTA was signed between the governments in Wellington and Beijing. But Beijing's authority in Xiamen, for example, is far weaker than Wellington's authority in Dunedin. There are numerous levels that exist between an official in Xiamen and a highly ranked official in Beijing and each of these will have a different set of priorities affecting how the Xiamen official should be acting - such as implementing the terms of the FTA.

This section of the thesis will review academic debates and issues in three areas: the implementation of laws and regulations; decentralisation of economic governance; and the role of guanxi in China. The literature demonstrates that due to the process of decentralisation, local officials affect

\footnotetext{
${ }^{19}$ The 2008 US-China Business Council's Members' Priority Survey lists amongst its members top ten concerns the uneven enforcement of laws.
} 
outcomes at the local level more than officials in Beijing. A focus on economic development by local government means that priority is given to local concerns affecting economic growth above legal changes prescribed by Beijing. Furthermore, companies often turn to guanxi in order to gain greater assurance that their interests are protected; why this is the case will also be reviewed.

This section, then, seeks to demonstrate through a review of the literature that, compared with formal agreements with China's central government, informal relationships with local government are an undervalued asset that firms should be seeking to develop. I do not seek here to argue that the FTA is not useful for New Zealand exporters, but rather that its efficacy below the central government cannot be assured. This is because the Chinese legal system is not yet independent enough to ensure reliable and speedy outcomes. Moreover, local officials make most of the decisions regarding economic activity in their jurisdictions and give priority to local concerns above those of Beijing. What can be useful in ensuring favourable outcomes, however, are informal relationships.

\section{The Administration of Law in China}

There is a long tradition throughout Chinese history of local independence and of the provinces putting Beijing's decrees quietly to one side. Since the reform era began this traditional practice has had practical application in the priority local governments have placed on economic growth. A flexible approach to policy implementation has allowed sub-national levels of government to decide how laws are implemented, thereby facilitating economic growth (Corne, 1997; Cai and Treisman, 2006; Clark, Murrell and Whiting, 2008). Flexibility is part of the system, is intended, and is supported by the country's leadership. For foreign governments, this raises the question of how much international agreements, such as FTAs, will be respected at the local level. 
China also has a long legal tradition, but one that until last century was based on Confucian values emphasising fairness and justice rather than legality. Even today courts, lawyers and civil cases are considered an option of last resort amongst Chinese, who prefer to settle disputes through negotiation or with the help of a mediator. Since the mid-nineties there has been a determined effort to improve the state of the law books and the court system in China. This has not, however, challenged the established tradition of local officials and street-level bureaucrats having wide latitude in interpreting laws.

Especially during the initial period in the eighties, China's legal system was ill-prepared for the pace and depth of economic development that was taking place. Not only were law books silent on many essentials of a market economy, but the country also lacked lawyers - a career shunned during the Mao era, especially during the Cultural Revolution. While the legal system has developed rapidly over the last 25 years and many young people now study and practice law, there are still issues concerning enforcement and the reliability and neutrality of courts and judges.

As will be discussed in greater detail in the next section, a central pillar of the reform programme was decentralisation. Transferring economic influence and creating incentives for local officials to support the reforms was a key part of the reformers' plans to avoid clashing with conservatives whose power bases were the Communist Party of China (CPC) and Beijing. Greater freedom to interpret regulations was part of this strategy and allowed local officials to make decisions that were most appropriate for local conditions, thereby facilitating economic development.

At the street-level flexibility also exists as decisions are often left to the discretion of officers in charge of monitoring the activities of the households and businesses that reside in their jurisdiction. From members of the police, inspectors from bureaus responsible for ensuring enforcement of the various 
regulations pertaining to health, labour, fire and so on, to neighbourhood committees, these officials of varying degrees of power can decide which activities should be curtailed, which can be overlooked, and, if a sanction is required, how harsh the punishment should be. Relationships with these officials is therefore quite important as a good relationship allows problems to be overlooked, or if that cannot be the case, for the punishment to be as light as possible (Bruun, 1995: 120). The consequences for foreign firms operating in this environment are summed up in one article looking at strategies firms can use to deal with officials at the local level:

\begin{abstract}
"the absence of commercial ground rules results in bureaucrats and powerful individuals interfering with private firms' operations. These individuals have the power to order a firm to stop selling a certain product or exit a given industry altogether, and there are few wellestablished institutions to prevent them from doing otherwise. Enforcement of existing legal and regulatory codes can also be selective and arbitrary. Regulations tend to be interpreted by whoever has authority over a given geographical region or by one of many government departments that has jurisdiction over the firm" (Ahlstrom, Bruton and Lui, 2000: 5-6).
\end{abstract}

Corne (1997) advances the idea of 'legal flexibility' in China - that laws are intentionally written in vague terms in China to allow broad scope for interpretation. ${ }^{20}$ His analysis of Chinese laws shows the following common characteristics:

- Principle-like pronouncements

- Vagueness and ambiguity

- Undefined terms

\footnotetext{
${ }^{20}$ Peter Howard Corne, Foreign investment in China: the administrative legal system, 1997 see chapter 3: Legal Flexibility, pages 94-145. Similar viewpoints are expressed in Irene Y. M. Yeung and Rosalie L. Tung "Achieving business success in Confucian societies: The importance of guanxi (connections)" Organizational Dynamics 25 (2) 1996: 54-65.
} 
- Broadly worded discretions

- Omissions

- General catch-all phrases

This approach is apt given the priority Zhongnanhai has placed on economic development, or, as Corne describes it: "China has opted for a legal system that is in essence as fluid and changeable as the economy and society which it is supposed to regulate" (1997: 94). The rapidly changing nature of the economy means that laws could restrict economically beneficial behaviour or detract from the primary goal of economic development. Allowing local authorities discretion in interpretation places a check upon such events. ${ }^{21}$

Irregular implementation is not just a problem at the local level. The priorities for the CPC remain economic development and a harmonious society. Membership of international organisations that will aid these goals is sought, as it demonstrates the continuing emergence of China as a world power. Accession to the WTO is a good example of these priorities - it helped China's economic development, presented an opportunity for economic liberalisation to be implemented, and showed China's leadership gaining status on the world stage. FTAs, although on a smaller scale, would offer the same benefits. When membership of international organisations threatens economic development or to destabilise society, implementation is less likely to fully occur because there is no level of government that has an overriding interest in seeing that international agreements are implemented.

For foreign businesses, used to operating in environments of greater legal certainty, this will often be unfamiliar ground. The problems below are just some examples of issues facing foreign and local companies alike in China:

${ }^{21}$ Of course local governments in protecting their own jurisdiction have infringed upon the greater national economic interest as well, such as in the early nineties when internal trade barriers were erected by local governments seeking to protect local industry and boost revenue by adding taxes to goods being transported through their districts. 
- The same law can be interpreted differently by officials from different local bodies.

- Local laws may clash with national laws, so that the means of acting correctly can be unclear or even impossible to achieve.

- Directives issued by one authority may contradict those issues by another, leaving officials as confused as businesses and slowing down processes (Wang, 2000: 535).

China's entry into the WTO raised doubts about China's ability to enforce its international agreements. The legal revisions that were necessary for accession involved a large commitment to improving the legal environment, but the liberal language and rhetoric of laws reveal that the objectives of Beijing's leadership circle were economic and social rather than legal (Ya Qin, 2007: 721). The changes that are taking place have seen a shift away from rule by man, but instead of rule of law the new environment is "rule through law" in which the state has been using law to achieve its objectives rather than establishing the legal system as an independent check on state power (Kong, 2001: 1187).

Furthermore, there is considerable doubt as to whether laws that do not fit a country's stage of development are likely to be successfully implemented. Pistor argues that the contents of laws are of "secondary importance to the process of legal development and the compatibility of new laws with preexisting conditions" (2000: vii). Given the rapid development of China's economy, it is appropriate to question whether one should expect any agreements China signs to be fully or accurately implemented by local authorities.

A large number of laws covering foreign investment have been passed during the reform system, but enforcement of those laws has not been comprehensive. Many companies, foreign and local alike, have been frustrated, as those with good connections with local officials appear able to 
flout the law and regulations, taking advantage of the large amount of discretion local officials have been given by higher levels of government as well as weak enforcement by courts. Particularly in the nineties, companies often sought to improve their connections with government by hiring officials or family members of officials. These people would be appointed to high positions in the firm or on the board of directors, or given an ownership stake in the company, but these were often little more than sinecures. Another method was to hire as consultants people who were believed to have good guanxi so that their connections could be used to facilitate introductions (Pearce and Robinson, 2000:34). One must assume that businesspeople make these decisions because the rewards outweigh the costs.

\section{The Decentralised Structure of the People's Republic of China}

Each state makes a trade-off in the structure of its political system, balancing the ability of its leaders to effectively implement policies against establishing checks and balances that ensure power cannot be unilaterally wielded by one person, group, or institution (Cox and McCubbins, 2001: 21). Countries whose political system gives equal weight to these two factors are more likely to be able to deliver competent governance and structure incentives in order to promote economic growth (Kong, 2005: 55). During the Mao years the negative consequences of too much power resting in one person's hands became clear. Since then power has become more widely dispersed throughout the Chinese state. This in turn has facilitated the reform programme by improving the government's responsiveness to changing economic factors and the needs of the population - no mean achievement in a state with the population of China.

The reform programme has had an enormous impact not only upon the economy but also on the practice of governance (Yang, 1994: 541-542). ${ }^{22}$

\footnotetext{
22 Below the national level, China's constitution provides for three levels of government provincial, county and township, but there are a number of exceptions of which both
} 
Decision-making powers have moved between central and local government as Beijing has sought to find a balance between controlling local authorities and allowing them to find pathways to economic development that best suits local conditions. The diversity that can be found across China - levels of development, access to resources, infrastructure and employment opportunities, for example - mean that a 'one size fits all' approach from Beijing would be ill-suited in many parts of the country. By allowing decisions to be made at the local level more appropriate policies can be implemented.

When Beijing signs an international agreement such as an FTA, the implementation of aspects of that agreement falls in many respects to local authorities. Approval for most investment decisions, for example, is made at the local administration level. In a country of China's size, in which the power of economic decision-making is not held strongly by the central government, of what value are the agreements it signs with other states? If local authorities place local interests above those of the agreements Beijing signs, it is likely that the provisions of the agreement may not be implemented as was intended by the signatories.

\section{The Consequences of Decentralisation on Economic Decision-Making in China}

China's reforms begun in the late seventies, spread steadily during the eighties and were accepted for the most part entirely by the mid-nineties. By the time of China's accession to the WTO in 2001, China's transition from command economy to market economy was complete, at least from an ideological perspective if not in a practical sense. Today the economic benefits appear obvious, but reaching this point has been an evolving process

\footnotetext{
Shanghai and Xiamen are examples that provide local officials with greater autonomy than most other cities. Shanghai is a municipality and is treated in a similar fashion as a province in its own right (as are the other municipalities, Beijing, Tianjin and Chongqing). Xiamen meanwhile is a sub-provincial city coming under the authority of Fujian province. Unlike most cities of its size, though, Xiamen has greater independence to set its own economic policies, laws and regulations, reflecting its pioneering role as an SEZ.
} 
throughout the thirty years of economic reform.

China has always been quite decentralised with Beijing often struggling against fiefdoms, warlords and local officials unwilling to automatically follow directives issued by Beijing. ${ }^{23}$ Deng Xiaoping's reforms came at a time when central power was at a low point - Mao's Great Leap Forward and the Cultural Revolution had left the bureaucracies weakened; the public, as well, unhappy with the lack of progress during the last decade, was open to new approaches (Shirk, 1993: 13). Today, political control resides mostly in Beijing, although at the village level some leaders are democratically appointed. Responsibility for economic development, however, is mainly held at the provincial and municipal levels. So while Beijing therefore controls macroeconomic policy, the issues that directly impact most businesses are the responsibility of local officials down.

China's economic growth since the reform programme began has sparked much debate with academic circles regarding China's development and its sustainability. According to North and Weingast, the economic success of developed western economies occurred because of strong legal institutions that guaranteed property rights and gave investors certainty that their investments and profit would be returned to them (North and Weingast; 1989: 803). China's growth has challenged this because these same guarantees do not exist in China. Jean Oi (1992), whose work examined Township and Village Enterprises (TVEs), argued that owners and investors in TVEs did in fact have a fair expectation that their investments would be returned to them, but this was guaranteed through the close relationships formed between entrepreneurs and local officials. Changes that had taken place in the eighties that allowed local authorities access to tax revenues generated within their jurisdictions motivated officials to form these relationships with

\footnotetext{
${ }^{23}$ A common Chinese saying is "Beijing has its policies, we have our regulations", meaning that any law passed by central government can be negated by local officials by creating their own policies.
} 
entrepreneurs and encourage investment and economic development, rather than engage in rent-seeking behaviour.

This debate still continues. Some argue that the policy of allowing economic decision-making to take place at the local level did not drive China's 'economic miracle'. Rather, it took place because of clashes at the central government level between rival factions with opposing ideological predispositions who sought support from local officials, in turn assisting them in order to demonstrate the efficacy of their chosen policies. Cai and Treisman (2006) point in particular to the fact that the two periods of greatest growth were in the late seventies and early eighties, and again in the midnineties, when power was most centralized. The key point missed by Cai and Treisman, however, is that the reforms and institutional learning that they do acknowledge as being key to growth, were a slow and gradual process that took many years to disseminate throughout the economy and influence growth statistics. Furthermore, they fail to give adequate recognition that the large amounts of FDI during these periods was a major factor behind economic growth - something that was almost entirely absent in the ex-Soviet Union states that they offer as a comparison case. A key point remains, however, being that local officials are still working with firms to promote economic growth; Cai and Treisman may question the factors that drove local officials to act in this way, but they are not denying that local officials play a key role in assisting economic development in their jurisdictions.

Over the last two decades scholars have begun to study the relationships that exist between entrepreneurs and officials and how this has affected China's economic development (Nee, 1992; Wank, 1996; Krug, 2000: 15-18; Thun, 2006). These studies describe their findings in a number of ways - network capitalism, state corporatism, hybrid capitalism, patron-client relationships but they all essential describe a similar phenomenon: collaboration between local officials and entrepreneurs in order to generate economic activity. What has emerged is that officials can greatly assist firms, and that many are 
willing to be flexible in their implementation of rules and regulations if they believe a greater good will come about as a result. As Jean Oi described succinctly, "...when officials are forced to choose between protecting local interests and adhering strictly to central policies, the choice is clear" (1999: 178).

The programme of decentralisation is believed to be a key factor in China's rapid economic growth. It provided economic incentives for officials to support economic development projects while at the same time allowing them room to find approaches that suited local circumstances. This system was not restricted to local businesses. Local governments' economic development goals could not be met solely through the ability of local companies. Local governments therefore also extended their assistance to foreign companies who they believed could help develop the local economy (Thun, 2006). This arrangement continues today where foreign firms can bring investments, technology and skills to a local area. As shall be detailed in the section describing the experiences of New Zealand firms in China, some New Zealand firms are working within this system to expand their contacts and business.

While early research on links between business and government focused on guanxi relations between individuals, more recent work has arisen arguing that the state is more involved than ever before. Government officials' focus on economic development has seen the rise of "localistic networks". Whereas guanxi relationships exist between individuals, these networks see the effective policy of entire bureaus being to support local firms. This is done broadly by defining policies and procedures that benefit firms in their jurisdiction, and directly by supporting firms as they seek to build their business networks (Wank, 2002: 114).

The extent of government involvement in the Chinese economy is still a hotly debated topic and partly why some countries withhold designating China as 
a market economy. While in many ways China appears to have embraced the free market, Huang (2008) argues that the last twenty years have in fact seen a decline in market liberalisation. Huang's description of Shanghai is not the model of market liberalisation that World Bank officials describe the city, but rather an example of a "classic industrial-policy state" (212). Shanghai officials, Huang argues, have driven the rapid economic development of Shanghai not only at the cost of local entrepreneurial activity by favouring foreign firms, but also by subsidising the city's infrastructure growth through central revenues, backing for SOEs and large amounts of FDI. In many ways, Huang's argument returns us to the mid-nineties when some denied that Asia's growth was a 'miracle', but rather a simple case of increased inputs creating greater outputs (Krugman, 1994).

Demonstrating similarities with both Huang and Wank, is Eric Thun's work on the development of the auto sector in Shanghai, Beijing and Guangdong. Thun describes three different levels of corporatist behaviour by local government. ${ }^{24}$ The first of these is the local development state in which local officials play an active role in assisting local companies and are "unified and cohesive in their mission to cultivate and develop local firms" (2006: 28). This provided the businesses Thun studied added certainty that they would receive a return on their investment. But local officials went further, assisting chosen businesses and developing relationships between supply firms and their customers so that they resembled a vertically integrated firm. This improved communication between the companies on how products were to be improved or efficiencies found. This is a long-term perspective with the goal of having all the firms involved growing together over the years.

Thun's second pattern of development is the laissez-faire local state in which the local bureaucracy is fragmented and normal market relations exist

\footnotetext{
${ }^{24} \mathrm{Krug}$ and Hendrischke found similar groups, though their labelling differs from Thun's, using the terms "Arm's Length State", "Developmental State" and "Pre-Corporatist State"; as the names imply the attributes of the three groups are much alike. See Barbara Krug and Hans Hendrischke "Framing China: Transformation and Institutional Change through coevolution" Management and Organization Review 4 (1): 81-108.
} 
between firms. In this pattern different government groups are responsible for different firms so that they act at cross-purposes or without coherency, as the local government bodies are not unified in their aims. Furthermore, the businesses involved have only market relations with each other and multiple suppliers are frequently used, often competing on price. ${ }^{25}$

Thun's final pattern is the firm-dominated locality. In this pattern the business groups were national in orientation and their focus lacked involvement by local officials who were incapable of providing financial support, unable to alter policy to support the firm, or incapable of providing guaranteed markets for the firms' products.

The motivations for firms to develop connections with local government will obviously be different depending on their circumstances, but by examining the behaviour and opinions of Chinese firms such as those Thun studied, lessons can be found. The discretion that officials have at their disposal motivates some, as a positive relationship increases the chances for a firm of influencing the behaviour of local government to gain benefits, or at least minimise costs, which David Wank speaks to:

"At the level of local government, [decentralisation] enhances autonomy in administration, control over revenue production, and responsibility for fiscal funding. Governments now have more responsibilities, less centrally allocated resources to achieve them, and greater autonomy to devise solutions. Increasingly they have turned to their regulatory powers in the market economy to derive income in such myriad ways as ad hoc levies of taxes and fines and various kinds of relations with private entrepreneurs" (2002: 101).

The scarcity of reliable information is another common problem in China. Close links with bureaucrats who have access to official sources of

\footnotetext{
25 This is a problem that probably arises when there is a disagreement between competing ministries and authorities over how or which groups are supported and different factions side with particular companies.
} 
information as well as access to proposals being discussed behind the oblique walls of government can also provide valuable notifications and insights for businesses (Krug and Hendrischke, 2008: 94).

Unlike most other East Asian corporatist states, such as South Korea, Taiwan or Japan, China's embrace of corporatist behaviour ${ }^{26}$ was designed to loosen centralized control rather than tighten it (Unger and Chan, 1995: 38-39). Decentralization provided the most flexibility in the dynamic times of the eighties and nineties. By allowing decisions to be made at the local level, officials could respond in the most appropriate manner and act accordingly given their better knowledge of the facts on the ground than those of officials in central government. It also gave the country an opportunity to experiment with different systems for economic success - winning strategies being implemented on a wider scale, and poor strategies being cast aside before damage was done on too wide a scale. Decentralization of administrative power and revenue collection thus encouraged officials to follow strategies that maximized growth and revenue while also giving them tested growth strategies to emulate (Thun, 2006: 16-17).

The corporatist approach employed across China brought together the private sector with local government who were able to assist firms through state agencies as well as signalling their approval for their business activities. Government approval was an important asset for firms during the reform period because of the uncertain state of property rights and the unreliable nature of legal institutions during the reform era. However, the state corporatism approach, for all its benefits, brought with it negative repercussions in the form of corruption and the establishment of clientist networks.

\footnotetext{
${ }^{26}$ By corporatist behaviour I refer generically to the works of a number of scholars who have examined links between China's firms and local governments, such as state corporatism - Oi (1992), network capitalism - Boisot and Child (1996), and market clientism - Wank, 1996.
} 
Decentralisation has meant that engagement with local officials became extremely important for businesses, and many foreign companies in China now acknowledge the important role that working with local government can have on their business. While in the past foreign companies dealt mainly with the ministries of Foreign Affairs and Commerce, today far more of China's government bodies have responsibilities that see them dealing with foreign companies on a regular basis (Wang, 2000: 540; Jarret and Lie, 2009: 36-39). On top of its role as regulator, local government is often a customer as well, allowing some companies to develop closer relationships, but adding a further layer of complexity to the relationship.

The patterns that Oi first saw occurring in the late eighties continue today with local government in China being closely aligned with the businesses in their jurisdiction. Examining the impact of reforms on the changing nature of the state in China, Goodman concludes "The governmental system has become highly decentralised with the exercise of state power resting largely in the hands of the community of interest that has been created between local cadres and entrepreneurs" (2009: 446).

While these operating conditions may be foreign to most New Zealanders, there is little they can do to alter the system in which they find themselves. There is a fixation amongst many government officials with achieving GDP growth in their jurisdiction, not only for the greater good of China, but also in order to further their careers, which is neatly summed by a New Zealand businessman:

One great fault in the emergence of market forces and the rapid expansion of the economy is the Chinese national obsession with growth. True growth is a subtle quality in any economy. In China this seems well understood by the central government but is often neglected by provincial governments chasing short-term GDP targets and industrial development. Economic growth is to many officials the new Chinese ideology, as deeply 
rooted and as blindly followed as any Communist principle of the past" (Mahon, 2010).

Eric Thun's study on the Shanghai's 'local development state' and the auto sector's growth there, demonstrates the role that local officials have played in promoting local economic development and that foreign enterprises have not been excluded from receiving support from local officials (2006). Indeed, much of Yasheng Huang's work has demonstrated that foreign enterprises have in some ways been provided with advantages over local firms to ensure that local growth targets, employment levels and technology transfers were achieved $(2003 ;$ 2008). While Thun describes a positive story of the local government's role in promoting growth, the opposite can also occur when officials stand in the way of development, restrict access to land of materials, or alter regulations that limit a firm's ability to operate.

If even laws written in Beijing are not strictly enforced across China it would seem that local authorities will be prone to selective enforcement and implementation of agreements that Beijing has signed with other nations. For these reasons, then, it becomes clearer why having good relationships with government officials in China is so often emphasised. China's legal system and political structure give officials at lower levels far more power than in most other countries. The vagueness of the operating environment and the constant changes that occur mean businesses are disadvantaged if they are not capable of forming positive relationships with officials (Walton, 2008: 4649; Jarrett and Lie, 2009: 36-39). To some observers, the ability to connect with officialdom is key to successful business operations in China, in the words of Kenneth Lieberthal: "the competitive advantage of most Chinese manufacturing firms comes in large part from their superior ability to understand and 'work' the political dimensions of their own economy" (2006: 58). The question for this project then becomes, are New Zealand firms capable of 'working' the system as well? And if so, does the positive relationship that has developed between the governments of New Zealand 
and China be transferred in some way down to the local level where so many important economic decisions are made?

The process of decentralisation has affected how local officials and businesses interact with each other in order to achieve mutually beneficial objectives. In a country the size of China, firms have to be quite large in order for them reach a level where they attract the attention of local officials. Few New Zealand firms exist that would normally met this criteria. But as shall be shown in Part III of this thesis, evidence gathered in interviews with New Zealand firms in China shows that the FTA has provided a platform for New Zealand firms to meet with local officials that would usually not exist and though them develop informal relationships and broaden their business opportunities.

\section{The Effects of Decentralisation on Foreign Companies at Street-Level}

Street-level bureaucrats are responsible for the issuing of licenses and checking compliance with regulations, and thus have the ability to fine or even shut a company down for not complying with laws and regulations. For larger companies, issues can extend much further as the discretion local officials maintain extends to allocation of resources, local taxation, investment, licensing, and land management, to name just a few of the areas that they can hold significant influence over (Goodman, 2009: 442).

At street-level, dealing with the state may not be such a high stakes game, but outcomes can also be positive or negative. The number of licenses to attain and regulations to meet can weigh heavy upon small businesses. Street-level officials have the discretion to decide which of these are required and which ones they can look the other way on. For a small business, such as most New Zealand businesses are, these interactions are important for the smooth running of their business. 
No matter how tightly worded any policy is, when it comes to actual implementation, guaranteeing that it will be carried out by bureaucrats at the 'street-level' is very difficult. Implementation problems at street-level are a concern of the civil service not just in developing economies, but also in developed economies with structured and well-regulated bureaucracies. Lipsky's study of bureaucracy (1980), and the work of others who have followed, demonstrated that bureaucrats involved in the provision of public services regularly adopt practices inconsistent with policy due to overwork and cumbersome rules and procedures. Increasing amounts of control sought through additional procedures or rules tend to fail to control the behaviour of street-level bureaucrats and only cause greater rifts between upper management levels and staff. Yet it is their actions on a collective scale that reflect the actual policy of a public agency. ${ }^{27}$

While Lipsky's study was based in England, what we know of how China's street-level bureaucracy is equally revealing. Street-level bureaucrats in China can be, in some cases, a virtual law to themselves, with their decisions based very much on their relationship with whomever they are dealing. Ole Bruun, an ethnographer who based himself in a Chengdu neighbourhood for several years, wrote that the street-level bureaucrats there:

"...tend to confine their work to well-defined spheres, and distinction among these is often based on local, even personal, interpretations rather than compliance with legal duties. Interdepartmental cooperation is minimal. Bureaus reproduce a pattern of organization as required by central government, but contradictory to their local purpose. Bureaucratic seclusion within discrete units and the almost absolute power of leading cadres of each bureau offer ample opportunity for malpractice. Examples of such are the deliberate abuse of power, overlapping personal and professional interests, or, as is still frequently the case, insufficient knowledge of states policies and current regulations"'(1995: 111).

\footnotetext{
27 Also see Steven Maynard-Moody, Michael Musheno and Dennis Palumbo “Street-Wise Social Policy: Resolving the Dilemma of Street-Level Influence and Successful Implementation" The Western Political Quarterly 43(4), 1990: 833-848.
} 
Those who ran businesses in the neighbourhood were mostly disparaging of the work of the various bureaucrats who had responsibility for overseeing their activities, complaining often that they charged them too much in taxes and fees and offered little back in the way of services they were meant to. The businesses also complained that the more successful a business was, the more visits they received from local bureaus. In many ways they complained that the bureaus served the interests of those they favoured. Few business owners, however, bothered to complain about the demands that were made of them, either silently acquiescing or attempting to alter the demands more in their favour through "guanxi-type relationships" (120).

One of Lipsky's questions was "what if workers do not share the objectives of their superiors?" In situations where workers lack the affinity of their superiors with the goals of an organisation, where they consider orders from above to be illegitimate, or can find counter methods that block regulations coming into effect, implementation of policy as written is doubtful (1980: 1617). All three of these situations have applicability to China, and not just at street-level. Owing to the decentralised nature of China's political structure even officials at high levels of provincial and municipal government will have objectives such as increasing revenue collection or support of local businesses that could clash with Beijing's international agreements.

Officials in China also realise the declining significance of Beijing in their jobs. The local bureaucracy is likely to be more obligated to local leaders than to higher levels of the state apparatus (Goodman, 2009: 444). The market reforms have created uncertainty for government workers, who often take a government job despite the lower wages because of the increased job security. As their wages have declined relative to the private sector, so too have resources from Beijing. Consequently officials are more likely to look towards their local jurisdictions in hope of finding resources and support (Wank, 1996: 823). Where it occurs, corruption buttresses the declining value of their salary, 
while taxes and fees from private businesses support local government as a revenue source.

While this situation may not be the ideal situation that a business hopes to operate in, given that they have made the decision to operate in China, they must accept that this is the reality in which they find themselves. What they can control is how they choose to behave and adapt to the Chinese system as best they can. In order to do this, it is important that they understand guanxi, for as a popular saying goes "China is a land of guanxi... Nothing can be done without guanxi" (Y. Ju quoted in Tsang, 1998: 67).

\section{Guanxi and its future in a changing society}

As the last two sections have described, the state maintains a strong presence in China's political economy, but within an environment of flexible policy and regulation implementation. In situations where laws and regulations are open to interpretation, good relationships with officials can be vital, not only with street-level bureaucrats who check compliance, but also with local officials of municipal and provincial areas who have influence with civic leaders and policymakers. This section looks at the informal relationships, or guanxi, between businesses and state representatives that bind these factors together and current academic debate about guanxi's future.

Rapid economic development has seen government play an active interventionist role in guiding the economy along a prescribed pathway to economic growth. Although the command economy belongs to a bygone era, five year plans are still developed at the central government level setting goals for the bureaucracy to achieve. These goals filter down through the layers of the Chinese government with officials and bureaucrats being responsible in their own small way for their attainment. Ambitious local officials strive to reach these goals in order to further their careers. 
Studies of business and official behaviour in China have demonstrated that a cooperative approach between businesses and government officials has been instrumental in the rapid development of China's economy (Oi, 1992; Boisot and Child, 1996; Wang, 2000; Wank, 2002; Thun, 2006). These relationships are key to becoming part of the system within which firms can develop a competitive advantage. China's rapidly developing economy has had a tremendous effect upon the business governance and the culture; a firm's guanxi with local officials can assist it to navigate this rapidly changing climate, avoiding pitfalls and developing opportunities.

The relationships with local officials that Oi argued gave de facto property rights to local entrepreneurs, has also been an area academic debate. Around the time that Oi's work appeared, an ethnographer, Mayfair Yang, published Gifts, Favours and Banquets, in which she argued that informal relationships, or guanxi, were central to understanding the behaviour of China's nascent entrepreneurs and economy. Through guanxi connections Yang argued, individuals could trade favours, goods and information which helped them economically (Yang; 1994).

How much guanxi was an essential feature of Chinese culture is often questioned, however. Some argue that guanxi's rise can be traced back to the era of the command economy, but, now that market forces exist in China and stronger legal institutions are appearing, people prefer to utilise them and will increasingly continue to do so as they improve. Guanxi, it is argued, is an inefficient allocation of resources that will not survive market pressures. While guanxi was useful in providing access to goods in a command economy, a market economy provides these more cheaply and through simple buyer-seller relations that are less costly in terms of time than guanxi relations. Similarly, people will increasingly use legal institutions to resolve disputes as they become more reliable (Guthrie, 1998). 
Although the practices that resemble guanxi, or "special relationships" as it is often translated, have existed for a long period throughout China's history the word itself is relatively new, not featuring in either the $1915 \mathrm{Ci}$ Yuan or the $1940 \mathrm{Ci} \mathrm{Hai.28}$ Some scholars go as far as to describe guanxi as the key to understanding the Chinese and their conduct (Langenburg, 2007: 2). Although this could well be an overstatement - connections, friendships and networks are obviously important across all cultures and facilitate business and politics in all societies - it should be not treated lightly, as guanxi is regularly attributed as being a leading factor for business success..$^{29}$ Boisot and Child (1996) perhaps say it best when they state:

"It is therefore not the presence of networking that is distinctive about China's emerging economic order but, rather, the depth and nature of its social embeddedness." 30

Likewise Wang makes similarly strong statements:

"[I]nformal networks in Chinese society stand out for three reasons: (1) the degree to which informal networks contradict and undermine formal institutions is extremely high; (2) the influence of informal networks is unusually strong in every aspect of Chinese life; and (3) the level of institutionalisation of Chinese networks is very low" (2000: 531).

Even for many Chinese, defining guanxi is difficult, as Yang found when she began her ethnographic study by asking her acquaintances what guanxi was, only to find no agreed-upon definition by the practitioners she was studying

\footnotetext{
${ }^{28}$ Langenburg gives a thorough etymological and historical explanation for guanxi. See Eike Langenburg "Guanxi and Business Strategy: Theories and Implications for Multinational Companies in China" Contributions to Management Science Springer, 2007.

29 Yeung and Tung quote Jacobs et al, "A survey on 2,000 Chinese from Shanghai and Qungpu showed that 92.4 per cent of the respondents regarded guanxi as important for their daily lives" another study of 19 businesses in China "showed that guanxi was a necessary condition for a company's financial performance and ultimately long-term business success." Both studies were conducted in the early to mid-nineties. See Yeung and Tung (1996): 166.

${ }_{30}$ Max Boisot and John Child "From Fiefs to Clans and network Capitalism: Explaining China's Emerging Economic Order" Administrative Science Quarterly 41 1996: 623.
} 
(1994: 49); such are the challenges for those studying a social phenomena that only exists informally and outside of any institution. Likewise, there is no readily agreed upon English translation of the word of guanxi. The most common translations found in the literature are "social connections" (Yang, 1994: 1), "relationship or connection" (Yeung and Tung, 1996: 55), “a network of relationships" (Pearce and Robinson, 2000: 31), "informal personal relationships" (Wang, 2000: 534), "personal connections" (Jacobs, Belschak and Krug, 2004: 166), or "social capital" (Luo, 2007: 41), or mixtures and variations of all of the above. An apt description for guanxi is a point of conjecture, I believe, because the concept of guanxi is closely intertwined with two other concepts crucial to Chinese character - social obligation (renqing) and face (mianzi). Both ideas are felt on such a deeper level by the Chinese, that the English language lacks words to succinctly transmit the true meaning that guanxi conveys in Mandarin.

Paraphrasing Bourdieu's definition of social capital, Luo describes guanxi as:

" a form of social capital which creates economic value. Unlike economic capital, in which money or commodities are incorporated into circuits of production in order to produce more money, social capital is an aggregate of actual or potential resources linked to possession of a durable network of more or less institutionalised relationships. Mutual acquaintance and recognition provide credentials which entitle people to various kinds of credit" (2007: 41).

Throughout the eighties and the nineties the 'art and practice' of guanxi became a popular topic of study in China-focused business magazines and academic literature alike. As China became wealthier and the market economy increased the supply of goods and services, use of guanxi to obtain the basics of life declined. But new uses for the old practice appeared. Guanxi became useful to obtain what was now desired - access to better educational opportunities for one's children, transfer to a better danhui (workgroup), and 
introductions and connections that helped one in the business world. Private entrepreneurs and officials alike began using guanxi networks to obtain goods and services at low prices, products that were in short supply, such as steel and electricity, and favourable government contracts and connections that could help them access government-controlled resources and assets, such as land.

Two primary schools of thought exist when attempting to explain how guanxi as it exists today came to be - the sentimentalists, such as Mayfair Yang, who look to China's past and its cultural traditions, and the instrumentalists, such as Oi and Guthrie, who explain guanxi as a consequence of the command economy and weak legal system and question the 'Chineseness' of guanxi.31 The current debate centres around whether guanxi is an evolving feature of Chinese society that will continue to affect how business is conducted as the Chinese economy develops, or whether guanxi was a feature of the command economy that, if China develops a rational-legal system and market mechanisms, will steadily disappear.

For the instrumentalists, guanxi served as a survival system through which people could protect themselves from the vagaries of the state, especially during periods such as the Cultural Revolution. Some claim that historically guanxi was practiced more in the rural areas of China and was absorbed and brought back to the cities by the urban youth who spent time in the countryside during the Communist era (Yang, 1994: 76). There is general consensus, however, that it was during those most turbulent times of the Mao era that the practice of guanxi become a prominent aspect of Chinese society and its use became focused on its instrumental application.

\footnotetext{
31 Many scholars of course seek a middle path. Yeung and Tung firstly explain guanxi through Confucian roots, but argue that its prevalence and instrumental uses expanded greatly under communism; they do not however think the development of China's legal system will in any way diminish the importance of guanxi.
} 
Those of the Yang school of thought believe the declining role of the Chinese state means that guanxi will become more important as individuals seek to alleviate the harsh side effects of the market economy. Those more inclined to Guthrie's perspective claim the use of guanxi began a period of slow decline during the eighties and nineties, which will continue as China's economy improves, market constraints force economic actors to put material profit before the unquantifiable benefits promised through guanxi, and the legal system strengthens.

\section{Academic Study of Guanxi}

Given that they had been kept from studying its society for so long, it wasn't long after China opened its doors that academics arrived and began to examine China. One of the earlier academics, ethnographer Mayfair Yang, published one of the first and most important works on guanxi, Gifts, Favors, $\mathcal{E}$ Banquets, that examined the role of guanxi and guanxixue (the practice of guanxi) in China in the early eighties. Yang's China was connected through webs of gift giving and favours that enabled people to obtain goods and services that were hard to find - special foods, train tickets, good housing and so on. Those who Yang studied thought strategically about how they could develop relationships and obligations that would enable them to obtain through informal channels goods and services that otherwise were beyond their reach.

During the early eighties when Yang was in China, although life was still tough for most Chinese, the country was embarking upon Gaige Kaifang (programme of reform and openness). New laws had been passed encouraging foreign investment and opening China's economy to market forces. In order to get ahead in this environment, guanxi was another instrument that could give a comparative advantage to those who wielded it effectively. Guanxixue was therefore being extended beyond the personal sphere into business. Despite official condemnation of using guanxi, Yang 
found its use amongst managers of state-run companies to obtain raw materials, labour and even tax breaks from local officials. Cadres were perceived to be able to la guanxi (pull guanxi) the most because of their social position, control of resources, and the low amount of oversight of their actions by superiors (1994: 77-87).

How 'Chinese' guanxi is is a question many scholars have debated. Those like Yang who look for backwards into China's culture and history to explain guanxi make solid arguments based upon the 'in-group' or collectivist nature of Chinese culture compared to what is found in the West, which is far more based on individualism. As Jacobs, Belschak and Krug note, guanxi networks are based upon concepts strongly held in Chinese social groups such as loyalty, moral obligation and norms of reciprocity (2004: 170). However, they find that traditional views that guanxi is based mostly upon relationships of blood and family no longer hold true in modern China.

Examining cultural reasons for guanxi is problematic, however, especially in a country such as China that is experiencing such rapid social change. Some of the literature therefore looks towards economic factors for the practice of guanxi. As mentioned above, many academics believe that the reason for the increases in guanxi activity during the Mao and Deng eras was a response to the shortage of goods that the centrally planned economy did not provide for, as well as a risk-hedging strategy to compensate for the lack of strong, reliable legal institutions. Consequentially, as China's economy moves increasingly towards a free market economy and China's legal system becomes more independent and able to carry out its constitutionally prescribed duties, it is believed that individuals' need for guanxi may well diminish (Luo, 2007: 33).

Blood-based guanxi ties may well continue as it is culturally embedded within Chinese culture, but as legal institutions are strengthened, instrumentalists argue, the need for social-based guanxi will diminish. In the business realm guanxi with national government officials will become less important as the 
process of decentralisation continues, thereby increasing the need for guanxi with local officials (Luo, 2007: 32). For foreigner companies this is a twoedged sword; greater legal enforcement will appeal to western firms who will feel more comfortable having a legal environment that more closely mirrors that found at home. However, if guanxi is culturally based, foreign firms in China will become more disadvantaged unless they become familiar with the application of guanxi.

But how much of what Yang saw, was in fact the last vestiges of a practice that would soon become a cultural relic? Guthrie (1998) severely challenged Yang's description of the role guanxi played and would continue to play in Chinese society. Guanxi for Guthrie was on its last legs; what he saw in Yang's work instead were the beginnings of new practices that reflected the strengthening of both legal institutions and the market economy. While Yang's interviews did demonstrate that people used guanxi, from his perspective it was clear that what they preferred were transactions based on market exchanges, rather than sentimental ties weighed heavy with obligation. Although special prices deals would be done for friends and new customers, how, Guthrie asked, was this any different from what happens everywhere else in the world? For Guthrie, then, China was moving irrevocably towards an economy that would soon be similar to other market economies where rule of law governed business, while supply and demand dictated the prices people paid and their ability to access resources.

Guthrie argued that following laws and regulations is becoming de rigueur in the face of better and clearer laws and the government's continued crackdown on corruption. Indeed it does appear that these changes are having an effect, and that both citizens and officials alike are obeying laws more often (Ren, 1997: 2). A clear distinction exists, Guthrie argues, between guanxi, which is a network of acquaintances or relationships, and guanxixue which involves the manipulation of those relationships for benefit. 
Most academics have forged a line sitting somewhere between the positions staked out by Yang and Guthrie. But the gap between the two does present the possibility that China is in the process of creating its own form of capitalism; 'Socialism with Chinese Characteristics' may in fact be a system that is distinctive from the combination of market capitalism and a rationallegal system that has been seen as the key to successful economic development as experienced up till now by the world's developed economies (North, 1994).

Rather than merely establishing and enforcing the 'rules of the market', the Chinese model involves a far more activist role for government. The links that exist between local government, state-owned enterprises, and the private sector in China has therefore drawn considerable attention. Notable amongst these are Oi (1992), Nee (1992), Wank (1996 and 2002), Boisot and Child (1996) and Wang (2000).

Oi (1992) established links between local government and private enterprises were driving economic development during the early reform era, especially in rural areas. Oi described the incentives that existed for officials to promote economic growth, but she also noted examples of the discretion that local officials had and the benefits that they could confer upon enterprises through programmes that ostensibly existed to promote economic growth. Some benefits, such as tax holidays for example, were granted beyond the likely intent of the national regulations that allowed for them, or extended them well beyond what was stipulated by local government (1992: 108). Oi argued that these incentives explained why such rapid economic growth was taking place despite the lack of property rights that Douglass North had argued was necessary for economic actors to make long-term investments. 
Similar in many ways to Oi, but focused on urban businesses, Nee (1992) saw hybrid forms of enterprises emerging as China's economy made the transition from command to market economy, which he labelled 'marketized (redistributive) firm'. These firms had been freed from excessive government oversight and control and were thereby better able to respond to market signals. However, they were also new firms, short on capital, whose owners sought assurance over the rights to their investments. They were able to reduce uncertainty by relying upon their close connections with local government officials who shielded the firms from competition and assured them of regular work. The relationship they formed with local officials also provided them with important information on government policy and gave their greater certainty over their ownership status of their firms. Conversely, firms with such connection could also be penalized as local governments became tempted to become involved in the company because the goals of local officials could be partially met through the behaviour of these firms. A common example cited by Nee is the hiring of staff so local employment goals would be achieved for example. Of course, this made the firms less competitive and therefore less profitable (1992: 10-11).

The benefits, however, did not flow only one way. While enterprises benefited from the guanxi they held with officialdom, Wank (1996) found that, just as Nee had observed, relationships enhanced certainty throughout the marketplace by ensuring delivery of resources, creating reliable expectations and providing reliable information channels in a market where outcomes were less certain, and government decision-making processes oblique. Wank found that entrepreneurs in Xiamen where he carried out his research were "less orientated towards utility maximizing in price calculations than in cultivating the ties with officialdom through which business enhancing benefits flow" (821). The relationships that Wank described added to our understanding of how guanxi acted as a social institution that gave entrepreneurs the confidence to make long-term investments despite the lack of property rights in China. As with Oi, Wank saw incentives for career 
advancement and revenue-increasing opportunities that prompted bureaucrats to engage in cooperative behaviour with entrepreneurs rather than engaging in rent-seeking behaviour. These relationships were symbiotic in nature, which Wank described as patron-client relationships.

Further adding to the picture of the interwoven patterns of behaviour between businesses and government, Boisot and Childs (1996) put forward a compelling case that China's economy is a distinctive form of capitalism, which they label 'network capitalism', in which:

"the system continue[s] to reproduce a model of organization specific to the relations between the governmental authorities and the enterprises within their hegemony. The authorities concerned are industrial ministries, provincial governments, and (more often) local governments. Interorganizational relations between governmental bodies and the enterprises in their purview, relations that in other industrial economies would be conducted at arm's length through markets, are managed through personal interactions" (605).

This occurred, they argue, because China's bureaucracy never developed significant independence from economic actors, unlike the Soviet Union and Eastern-European economies. Chinese officials continued throughout the communist period to rely upon personal connections when coordinating the command economy (604). The key relationship for most firms is not other companies as in a normal market, but rather with local government officials (612). This has been facilitated since 1979 by the "steady decentralization of economic initiative to provincial, municipal, and even more local tiers of government". Like Oi, Boisot and Childs noted the importance of changes to revenue collection, which has reduced the role and capabilities of central government while motivating local governments to develop the local economy (618). 
As China's legal system developed throughout the 1990s, Wank (2002) developed his argument, acknowledging Guthrie's stance that China was undergoing fundamental changes from the 'wild west' times of the previous two decades. Wank agreed that guanxixue was declining in significance as China's market developed, Beijing continued to crackdown on corruption, legal institutions became stronger, and laws and regulations became clearer. However, guanxi continues to matter, he argued, especially at the local levels of government, because of the utility it presents to both entrepreneurs and officials:

"...new types of networks are forged as a response to new constraints faced by local officials and new monetary resources of entrepreneurs in the emerging market economy" (98).

Within these networks "non-standard administrative practices for mutual benefit" are being carried out. Wank describes the importance that entrepreneurs place on maintaining guanxi with local officials, notably in the areas of land use, administrative matters, taxation and licensing and in getting new ventures off the ground (102-105). While guanxixue was viewed as becoming "dangerous and inefficient", it was most useful when dealing with street-level bureaucrats rather than officials higher up the bureaucratic ladder.

Furthermore, more powerful individuals denied using guanxi. Wank argues that Guthrie's belief that this is because of improving implementation of the rule of law may be incorrect - these individuals could be achieving the same outcomes through other means. Indeed, in follow-up research Wank found that those he interviewed were emphasising cooperation between government and business, with local government aggressively leading the way. This was distinct from the traditional practice of guanxi because it emphasised a coordinated government approach involving policies aimed at improving economic activity in the local area, rather than individual officials 
making decisions that benefited individuals and their businesses (107). Although personal networks were still important, Wank believed, that guanxi was experiencing a shift from being based on personal ties to those based on location as the bureaucracy became more professional and there was greater scrutiny over officials' behaviour.

Wank took issue with Guthrie's perspective on three separate fronts. Firstly, Guthrie assumes that improvements in legal behaviour means that guanxi practice is decreasing; secondly, he assumes that the policies of the central government embody the direction of change; and, thirdly, that he employs a reductionist assumption of market economy. By limiting his definition of the market to trade transactions, Wank argues that Guthrie does not allow for important social transactions to be included (99-101), which is particular relevant if ones sees guanxi as being an asset of value which can also be traded.

Wank also notes that guanxi appears to have declining utility as a firm gains a greater foothold in the Chinese market,

"...guanxi practice might be necessary for entry because the relevant licenses and business sites are controlled by local government although its utility is rapidly discounted after entry because the trade relations that are forged after entry hinge on quality and price" (101).

A lack of traditional connections for foreigners means they must engage in 'altercasting' - the establishment of guanxi between two people who have no common connection. The best way to achieve this, they say, is through the introduction of reliable third party - a common use of a guanxi network for the Chinese themselves (Teung and Tung, 1996: 61-62). Whether breaking into a social network of any kind in China is actually possible for Westerners has been questioned by some. Interviews conducted by Bjorkman and Kock for example found that "virtually all respondents - both Chinese and foreign - 
were quite sceptical about the possibility of Westerners to really enter Chinese social networks" (1995: 530).

Since Guthrie's response to Yang, the object of study has moved towards how guanxi functions and its relationship to the business world. Many, including Yang, ${ }^{32}$ argue that the practice of guanxi has gradually changed from its original use of obtaining goods and services on a personal level to gaining advantages in business and in areas which give one better opportunities, such as obtaining positions in companies or with educational institutes. For the instrumentalists, however, guanxi will continue to be sidelined as legitimate legal and market arrangements become better able to provide the same outcomes that people relied upon guanxi to achieve. If this is true then guanxi's position in society will become less legitimate and more associated with corrupt practices.

\section{The Link Between Guanxi and Corruption}

No discussion of guanxi is complete without an examination of the negative face of guanxi, corruption, as the two are often viewed as being so closely connected. ${ }^{33}$ It is important to firstly place a clear division between corrupt practices that are often associated with guanxi and favours that are done out of respect or sentimental ties. Corruption, being in no way a purely Chinese issue, can have its roots in a number of problems such as inadequate pay for civil servants and a lack of transparency. However, personal utilization and maximisation of resources at one's disposal are, after all, easily explained by theories about rational economic behaviour. A culture that is permissive of corrupt activities and offers civil servants opportunities to engage in corrupt behaviour adds another dimension to this problem; after decades of economic hardship and the sudden growth in wealth in post-communist China, the

\footnotetext{
32 See Yang's rebuttal of Guthrie in "The Resilience of Guanxi and its New Deployments: A Critique of Some New Guanxi Scholarship" The China Quarterly 170 2002: 459-476.

33 See for example A. Millington, M. Eberhardt and B. Wilkinson "Gift Giving, Guanxi and Illicit Payments in Buyer-Seller Relations in China: Analysing the Experience of UK Companies" Journal of Business Ethics 57 2005: 255-268.
} 
ground is certainly fertile. It would be unwise to ignore the problem of corruption in China, which is widely acknowledged by even the CPC itself and causes many observers of modern-day China to be critical of the current 'to get rich is glorious' ethos of many Chinese today (Chow, 2005: 13). But the CPC's response to the problem seems often to be based more around ensuring that the public doesn't become indignant at the Party rather than determining how corruption may be affecting the economy; whether anti-corruption campaigns are real and progress beyond the high-profile cases in the media is still to be seen.

Wang distinguishes bribery from guanxi in that bribery is purely instrumental in its aims, while guanxi involves aspects of renqing (obligation) and mianzi (face). Bribery requires no previous ties and has short-term specific aims while guanxi is based on long-term relationships and has undefined reciprocity - even though the reciprocation is understood by both parties to exist. For Wang, the divisions various academics have used to examine guanxi (which he describes as expressive, instrumental and a mixture of both) are all behaviours that can be placed on the same continuum, guanxi being the expressive manifestation while bribery lies at the other end of the continuum as the most instrumentalist expression of the behaviour, and a relationship that lies between the two - say someone who develops close personal bonds with an official, although it was originally undertaken only for the purposes of improving business opportunities - being the mixed expression (Wang, 2000: 536-537).

In her rebuttal of Guthrie's argument against her, Mayfair Yang looked at blat, the Russian 'economy of favours' and how that has developed into corrupt practices that have damaged the Russian economy. She sees corruption as a considerable threat to China because "in the marriage between the developmental state with capitalism, a guanxi culture has given rise to increased corruption in business-government realms" and argues that the study of guanxi should focus on the way that guanxi practices have adapted to 
the development of a market economy (2002: 465). While her original study focused mostly on the lives of ordinary urban Chinese, the corrupt activities occurring in China now are more likely to operate at higher levels of business and government and thus threaten China's economy in a similar fashion to what has occurred in Russia.

The cultural phenomena of guanxi can both enhance law enforcement and be used to avoid compliance. By using guanxi connections companies can reduce fines and punishments for severe violations or avoid sanctions completely for minor infractions. Authorities may decide to avoid prosecutions when a loss of face may result or an individual or firm is known to have very good guanxi with persons of influence (Kong, 2001: 1187-1188).

Activities that may well pass as corruption in the West - officials actively seeking to create favourable operating environments for firms, for example can also be viewed as economically rational behaviour because of the way that tax revenues are gathered in China (Krug, 2000: 17-19). Many firms place officials, or those with close ties with them such as members of their families, in high-ranking positions; this will often be the official's only contribution to the firm. It is an investment of social capital rather than financial capital, but signals to outsiders the firm's connection to influential government parties.

For both firm and official, cooperative strategies outweigh the risks. For officials, on top of the amount of their personal financial reward for being part of the firm, revenues generated by a successful firm located in their area increase the budget of that official and the authority they work for. Not only does their job become easier because of the increased revenue at their disposal, but their career prospects improve, as they are judged to a large degree on the economic performance of their district and tax revenue. Likewise for the firm, access to key officials, their influence and their information gives them a significant comparative advantage in the 
marketplace. These practices are amplified by the decentralisation that has occurred in China during the reform period.

The line between corruption and what are merely good business connections is hard to define, especially when the amount of corruption that takes place is as diverse as that between New Zealand and China.34 For example, when accurate information is difficult to come by, is having someone with close connections to government corrupt or just a wise investment in information acquisition? When officials make the final decisions on whether a firm can make an investment in a district, is hiring the offspring of government officials corrupt, or a strategic decision to hire those people who you know can speak directly with the decision-makers and plead your case?

Interviews conducted by Bjorkman and Kock (1995) found that the common perception was that those who developed good relations with a key decisionmaker had a good chance of securing business deals that that person controlled. One of the reasons they found for good relationships being so important is that trust is integral "to business and information exchange, in particular in relations where illegal elements are part of that interaction." Furthermore, in their description of guanxi they note:

"Guanxi entails a strong social obligation to do favours for another person, e.g. by providing some kind of scarce resource. There is a strong moral obligation to reciprocate favours that have been obtained. The resources used for exchange between the persons may include money, goods, information, status, and services of different kinds... The trust that exists between actors in a social network was seen as particularly important concerning transactions which involved illegal elements such as 'extra commissions' paid to foreign bank accounts or lavish gifts" (1995; 526-527).

\footnotetext{
${ }^{34}$ New Zealand was ranked first in Transparency International's 2009 Corruption Perceptions Index with a score of 9.4; China ranked 79th with a score of 3.6.
} 
Guanxi is often said to be vital to business in China, but foreigners are at a disadvantage as they lack the cultural knowledge of how guanxi functions and how it is developed. As Wang describes, overseas Chinese have a number of advantages over other foreigners when doing business in China - they can usually speak at least one Chinese dialectic and they are familiar with the norms and practices of mianzi and renqing and how relationships and networks are formed within a Chinese society. Another advantage is their familiarity and level of comfort with operating in environments that lack strong rule of law; they are used to dealing with the uncertainties and problems, and have developed a number of tactics for minimizing risk and exposure should situations turn unfavourable (2000: 542-543). Westerners on the other hand are unlikely to have any of these advantages.

\section{Summary of Part II}

This section has attempted to set the context for the realities of the situations that New Zealand businesses operating in China find themselves in. The interaction between uncertain and ambiguous legal conditions and a far greater 'hands on' role of the state in business activity underlines why many China observers and academics advise that firms seek to develop good guanxi with local officials.

China's legal system has developed tremendously over the last few decades as Beijing established a vast number of new laws that have sought to provide legal parameters for a market economy. This was most evident in the years leading to China's accession to the WTO, but it continues as Beijing builds the legal framework to match its economic ambitions. The enthusiasm for law making has, however, not been matched with enforcement of those laws. This has created a grey area for all businesses through which they must attempt to strike a path between compliance, profitability, and practicality; while most business will want certainty around their legal status, businesses must 
ultimately maintain profitability. Complying with all laws and regulations is often difficult because so many bureaus can claim jurisdiction over areas and because regulations often clash with each other.

A flexible approach to legal enforcement has allowed Chinese officials to take a practical approach throughout the reform period. The benefits of such an approach, given the diversity in priorities of across the different cities and regions of China, are quite clear. However, as development has occurred, the benefits of legal flexibility are decreasing and the problem of corruption has become a greater concern for the CPC. While this has seen the legal system improve and anti-corruption programmes flourish, the current situation in China is still some way from the environment New Zealand firms find at home, as can be seen by the difference in international surveys, such as those provided by Transparency International or the Heritage Foundation.

The goal of economic development was the central driving force for decentralising economic decision-making away from Beijing. This allowed local officials with a greater knowledge of local conditions to have a greater say in local development projects and, it is claimed, has greatly contributed to economic growth. This is disputed by some academics, but few deny that collaboration takes place between entrepreneurs and local officials. Collaboration is a mutually beneficial arrangement in which entrepreneurs gain improved access to resources, capital, and information. Eric Thun's work also demonstrates that in some areas officials choose companies to work together in order to develop sectoral capabilities. For officials, career advancement is determined in large part based upon the economic performance of areas under their supervision, thus giving them a stake in driving economic development and helping firms grow.

The vague legal environment and the importance of local government officials underline why the relationships that exist between firms and officials have been an object of much interest for academics; China has established 
economic and political arrangements along the so-called 'East Asian model' 35 in which firms with good government connections have a competitive advantage. While it is likely that local firms will be looked upon with greater favour by local officials, foreign firms are not excluded from participating in collaborative arrangements as long as there is a good case for how the foreign firm's involvement will contribute to local economic development.

Although firms around the world seek to develop relationships with government officials and other businesses, guanxi is seen as a unique feature of China's business environment due to the extent of its embeddedness in the society. How China's economic, social and legal development is affecting the traditional practice of guanxi has been an object of more recent study. Whether the practice is adapting to China's evolving environment, or whether it is fading away as a stronger legal framework develops and the market economy becomes more dominant in China, is still a matter of debate.

The FTA between China and New Zealand represents a formalisation of a relationship between the two states. Few businesses from New Zealand operating in China have the opportunity to interact with officials from the highest levels of central government. Many, however, are brought into contact with local officials and all have contact with street-level bureaucrats. These three levels will be examined in the final section of this study to determine whether or not individual New Zealand firms have gained increased access to or status with sub-national government officials.

New Zealand officials often refer to the 'four firsts' 36 that New Zealand has achieved with China, demonstrating the relationship that exists between the two nations. Informal relationships stand in contrast to the formal agreement

\footnotetext{
35 See for example Jonathan Unger and Anita Chan "China, Corporatism and the East Asian model' The Australian Journal of Chinese Affairs 33: 29-53.

36 In 1997 New Zealand was the first western country to conclude an agreement with China on its accession to the WTO; in 2004 it was the first developed economy to recognise China as a market economy and the first to enter into negotiations for an FTA. The signing of the FTA in 2008 was the fourth first.
} 
between New Zealand and China. While the FTA describes exact changes and formats for interactions between New Zealand and China, guanxi is a constantly shifting and evolving relationship. While it is easy to find references to why guanxi can be wielded so effectively in China, similar statements about the power of legal agreement are less easy to find. How the FTA affected the relationships between businesses and officials will be examined in the Part III of this thesis. 


\section{PART THREE \\ FORMAL RULES AND INFORMAL RELATIONSHIPS: HOW NEW ZEALAND SMES EXPERIENCED THE NZCFTA}

Interviews in Shanghai and Xiamen revealed three areas of interest amongst New Zealand SMEs - at street-level, at the local government level and at the border. At the street-level, businesses must deal with local bureaucrats for whom the FTA is largely irrelevant. When interacting with local officials, the officials' priorities mean that the FTA, while meaningful because it is a signal of the close relationship between New Zealand and China, is less important than the objectives which it is their task to achieve and upon which their future career progression is determined. The third level, at the border, is where the most significant problems have occurred. Importers of New Zealand products have struck significant delays and denials of tariff reductions.

Positive outcomes are also found. The FTA and subsequent diplomatic interactions demonstrate the strength of the relationship between Wellington and Beijing. At the local level there are signs that New Zealand companies are utilising the higher status that the New Zealand Government has achieved in order to expand business opportunities. Broadly speaking, New Zealand businesspeople in China are very positive about the value of the FTA and the future prospects for New Zealand firms.

\section{Methodology}

Part I of this thesis demonstrated that when measured against the trade statistics, the tariff rate changes of the FTA do not appear to be the only determining factors driving exports from New Zealand to China. While 
statistics can tell us the end result of business deals made between China and New Zealand, they cannot provide any information about how business deals were struck in the first place. If anything, given the global economic crises of $2008 / 2009$, it would not have been surprising to find that trade between New Zealand and China dropped. In fact, it increased more than was predicted in the pre-FTA economic models that were used as justification for why New Zealand and China should sign the FTA. ${ }^{37}$

In Part II we examined the academic literature on the flexible implementation of policy and regulations in China, and on the links between local officials and firms and the importance that is placed on maintaining good guanxi with local officials. These sources demonstrate that reading the text of the FTA or analysing trade statistics is unlikely to reveal all of the complexities that exist in the Chinese market today. Interviewing businesspeople engaged in the market will provide insights into actual experiences that cannot be found through other data sources. At the very least, New Zealand businesspeople will be able to tell us more about how the FTA affected their business activities and their relationships with representatives of the Chinese state.

In order to learn more about the experiences of New Zealand businesses in China, interviews were arranged in Shanghai and Xiamen. Shanghai was chosen because of the high number of New Zealanders based there and because as a first-tier city, Shanghai is looked to as a model for other Chinese cities to emulate as they develop. Xiamen was chosen because of the links that exist through the Wellington-Xiamen sister city relationship, which facilitated introductions, particularly important because of the smaller number of New Zealanders based there. Xiamen also represented an opportunity to examine interactions between foreign businesses and local government in a location not as strictly governed as Shanghai is. Xiamen was one of the first Special Economic Zones (SEZs) at the forefront of market

\footnotetext{
37 Analysis done in the National Interests Analysis predicted a 39\% increase in trade in the first year of the FTA; the actual increase was $44 \%$.
} 
reforms in the late seventies and early eighties, it has a large amount of Foreign Direct Investment (FDI), and it has a strong entrepreneurial history and a reputation as a place where policies and regulations can be flexible in order to facilitate business. ${ }^{38}$

Information on New Zealand businesses operating in China is not held in any central database so interviews were arranged through personal contacts and suggestions from my supervisors. Groups such as the New Zealand China Trade Association (NZCTA) and Kiwi Expats Abroad (KEA) proved valuable sources of suggestions for people to speak with. Suggestions from contacts I developed at the Shanghai offices of New Zealand Trade and Enterprise and the New Zealand Consul-General also led to some interviews. As the interviews took place and the interviewees gained a better understanding of the aims of my project, they suggested other New Zealanders they knew who they thought could add their insight on certain aspects of my project.

In all 17 interviews were conducted with a total of 21 subjects. 12 interviews took place in Shanghai and the remainder in Xiamen. Several of the subjects were involved in multiple businesses, making classifying them into separate groups difficult. Several were also keen to be as anonymous as possible so descriptions here are quite broad in order to satisfy these requests. Of those interviewed, 16 were New Zealanders and five Chinese, two of whom had previously lived in New Zealand. Originally I had hoped to interview Chinese officials as well to obtain their perspectives on the behaviour of New Zealanders they dealt with. This proved much more difficult than expected and only three interviews took place, one in Shanghai and two in Xiamen. These were set up through connections by a staff member at the ConsulGeneral's office in Shanghai, a member of the New Zealand China Trade Association and one of my supervisors. The interviews took place mostly in

\footnotetext{
${ }^{38}$ In 2000 Lai Changxing was detained on suspicion of running and smuggling operation out of Xiamen and bribing officials on a large scale, including a former vice-minister of Public Security and a senior PLA general. See "Criminal Empire Spread With Help From Friends in High Places" South China Morning Post 9 November 2000.
} 
English. A full list of participants and descriptions of the nature of their business or position is shown in Table 3.

Table 3: Composition of Subjects Interviewed

\begin{tabular}{|c|c|c|}
\hline Description of Subject & Shanghai & Xiamen \\
\hline New Zealander & 12 & 4 \\
\hline Chinese & 3 & 2 \\
\hline $\begin{array}{l}\text { New Zealanders, length } \\
\text { of time in China, < } 3 \\
\text { years }\end{array}$ & 3 & 1 \\
\hline $3-5$ years & 3 & 1 \\
\hline $5-10$ years & 4 & 2 \\
\hline$>10$ years & 2 & 0 \\
\hline Business Owner & 7 & 2 \\
\hline Government & 4 & 2 \\
\hline Sells Goods in China & 8 & 2 \\
\hline $\begin{array}{l}\text { Imports Goods from } \\
\text { New Zealand }\end{array}$ & 7 & 2 \\
\hline Consultants & 3 & 0 \\
\hline $\begin{array}{l}\text { Hospitality-Related } \\
\text { Sector }\end{array}$ & 2 & 0 \\
\hline Design/Manufacturing & 0 & 1 \\
\hline Food / Beverage - Sales & 2 & 1 \\
\hline $\begin{array}{l}\text { Sale of Manufactured } \\
\text { Products }\end{array}$ & 2 & 1 \\
\hline Retailer & 1 & 0 \\
\hline Food Production & 1 & 0 \\
\hline Logistics & 1 & 0 \\
\hline Factory Operator & 0 & 2 \\
\hline
\end{tabular}

Suggestions from those interviewed in China also led to introductions to people living in New Zealand with experience exporting to China and some 
exporters whom I had previously overlooked. Some of these groups were happy to participate in the study, but formal interviews did not take place. This was done so that the project could focus exclusively on the experiences of New Zealanders living in China since the FTA had commenced and because those living in China would be more familiar with the systems they had to work with and the cultural context that events occurred within. However, conversations both in person and over the phone, as well as emails, did enhance my understanding of some issues, particularly in regard to border and customs issues. Clarification on issues and official information requests were also sought from the Ministry of Foreign Affairs and Trade, the Ministry of Agriculture and Forestry and New Zealand Customs.

A template of the interview questions was approved by the Victoria University Human Ethics Committee before the interviews took place. Before each interview began, the subject was asked to consent to the interview being digitally recorded and was given an Interviewee Information Sheet describing the purpose of the research and the conditions of their participation, and listing how they could contact the researcher or a supervisor in the future. Participants were then given an opportunity to ask any questions they had about the interview and then asked to sign a Consent Form. Once they had signed the form, I informed the participants that a digital recorder had been turned on.

The study of informal relationships is a subject area which does not lend itself to quantitative data analysis because individual experiences vary so greatly. Experiences will also be different depending on sector, location and familiarity with China's bureaucracy and culture. As such, semi-structured interviews were chosen as the best format for gathering data. This format was chosen because few of the participants worked in similar roles or sectors so a set questionnaire would have been unable to cover the range of topics that reflected accurately each different subject's business; for example, many of the subjects were involved in importing New Zealand products and so had a lot 
to say on the topic of Customs, Inspections and Quarantine (CIQ), while others were not involved at all in importing.

Although some questions were asked of all participants and the topic was the same, each interview took its own course. Three areas were covered throughout all of the interviews: the effects subjects had seen arise as a consequence of the FTA, guanxi, and their experiences with local government, $t^{\prime}$ hese last two topics reflecting the ongoing debates about the future of guanxi as the Chinese state attempts to institute more formal regulation, and the extent and effect of local government's involvement in China's economic growth. Some of the topics discussed were ongoing or needed further clarification, so some future correspondence took place via email over the two months following the interviews.

As guanxi is seen as being so important for firms operating in China, the focus of interviews in Shanghai and Xiamen therefore focused on this area. I sought to gain an understanding of how New Zealand businesspeople approach developing informal relationships with government officials, what they were able to do with the resources that were available to them, and, with corruption in mind, what they were comfortable doing. Given the timeframe of when my research was taking place, the end of 2009 - just over a year after the FTA had come into effect - I was also interested in their experience of the implementation of the FTA agreement and how this had affected their businesses. Furthermore, because the FTA marked such a significant event in relations between New Zealand and China, I also asked whether there had been any noticeable improvements in the informal relationships that the subjects had with Chinese officials.

Relationships with officials have been broken down to the three levels street-level officials, local government officials, and central government officials. This is partly done because of the size of the Chinese state and partly 
because the size of a business and the level of interaction that it chooses to have with the state will partly dictate what levels it interacts with.

All firms will in some way or form interact with street-level officials. This term covers representatives of bureaus of the Chinese state which check businesses are conforming to the rules which govern them and their operations. Their concerns are primarily related only to the area for which they are responsible, such as tax, health and safety and employment. Chinese customs was included in this group as, although CIQ comes under the umbrella of a ministerial administrative group, it has direct involvement with businesses in terms of enforcing rules and checking compliance, so more neatly fits into this grouping.

Local government officials refers to officials of higher standing and influence employed at the municipal or provincial level. These officials will often have influence over policy and responsibilities to ensure wider state objectives are being met, such as economic development, investment and revenue collection. Interaction at this level is thus optional, but many firms, due to their size and therefore lack of resources, will not become involved at this level.

At the central government level very few New Zealand firms will be involved and when they do it often requires the presence of New Zealand government representatives. This level is only briefly covered as little information is available publicly, due to commercial sensitivity, and because few firms are willing to discuss their activities at this level.

Readers should note the limitations of the data gathered through interviews. All responses given were self-reported. Though I at no time felt I was being given misleading information, the limits of this study mean verifying data was not possible. The nature of this topic often crosses into areas of 
commercial sensitivity and no requests for financial information were asked of the participants.

There is a risk, when asked about the effects of the FTA, of participants emphasising negative effects over positive ones, or blaming the introduction of the FTA for problems that had always existed or whose occurrence was unrelated to the introduction of the FTA. Likewise, they may have reported positive effects of the FTA, such as the signing of a new client, that they perceived to have taken place because of the FTA, when it is possible that the FTA was irrelevant to the Chinese party.

However, while self-reported data should be treated with caution, businesspeople working in China can offer unique insights that trade data or businesspeople not based in China cannot hope to capture. Firstly, as much as business is often reported as simple market transactions, social exchanges are in many cases equally important. As has been discussed, while this is true in general in all cultures, relationships between business partners can be especially important in China.

While this thesis hopes to capture the immediate effects that these businesspeople saw taking place in the year following the signing of the FTA, the limitations of the data gathered should be borne in mind. The hope is merely that a greater understanding of the factors that have enabled the remarkable growth in New Zealand exports to China of late can be achieved than currently exists.

\section{Problems at the border}

When asked about the direct effects of the FTA, opinions of those interviewed were split between the FTA having no effect, or the effect being negative. Of those who felt the effect was negative, most were involved in the importation of goods into China. Only one importer felt the effect on his business was 
neutral, and this person was involved mainly in importing products that were not subject to any tariffs, or only to very low ones, before the FTA came into effect. Those who were involved in assisting New Zealand businesses in China were more likely to think that the effect on business was neutral in terms of the direct benefits of the FTA. Only one subject felt the FTA had had a positive effect, and this person was a representative of a New Zealand agency.

Typical of the responses when asked what effect the FTA had had on their business was this:

It's become harder. I wasn't here before the FTA was signed, and I suspect it was difficult before then...because New Zealand gets special treatment under the FTA, [customs] officials are neither familiar with it nor particularly happy and this has made it more difficult. They are not able to apply the same rules as they did previously. So whether things are being deliberately blocked or simply misunderstood is an open question. But undoubtedly it has made it much harder.

Importers of New Zealand products were finding that as a consequence of the FTA the goods they were importing were being treated differently than products from other countries. This had resulted in misunderstandings and slow-downs with getting goods through customs. The reactions of the interviewees varied considerably based on their expectations before the FTA was implemented. Some of the importers had expectations that the FTA would bring about a rapid change in costs and procedures. These people were largely frustrated at the results. The other group, and these tended to be New Zealanders who had spent a longer time working in China than the first group, were rather unsurprised and nonchalant; almost as if the FTA was likely to cause problems and delays in the immediate implementation period, and their expectations had been proven accurate. Their expectations of a quick and easy transition to the new FTA regulations have no been doubt 
moderated by their longer experience of dealing with the Chinese bureaucracy. One respondent, who had considerable experience with dealing with the Chinese government over previous agreements, said:

I think it's going to take a long time. It's probably caught up in China's own development in a way...these agreements don't really mean a heck of lot even when you put them in front of a government agency here. It might get you a meeting, it might get people thinking that they should do something, but whether it actually results in something, I haven't any seen evidence of that.

Those who had greater China experience, who were taking a more sanguine approach to the agreement's implementation, were, however, noticeably more hopeful about the steady progress they felt was being made. The impression gained from this group was that expectations of the agreement being implemented immediately as per the agreement, or even shortly after it came into effect, were unrealistic. Typical of this group's response was:

It is just going to take time. The negative effect is that you go nuts trying to get it approved and that is why, if it was not substantial, myself, I would just bring it in, pay the import duty, pay the VAT, and not go through the hassle.... I don't because, to tell you the truth, I am not bringing in so much of the high import customs duty items like food and beverage.

These more experienced 'China hands' were more accustomed to the length of time it can take for a decision made by central government in China to filter its way down so that it is taken as actual policy by local officials and streetlevel bureaucrats. They were more understanding of the situation that Chinese customs officials face, particularly at the Shanghai port, the world's busiest in terms of tonnes of cargo that move through it every year and which employs over 25,000 people. 
However, the core of the problem that was most often raised by the importers was not a lack of understanding with the FTA, but rather the remuneration system, which they perceived to be motivating Customs, Inspection and Quarantine (CIQ, the Chinese customs bureau) to deny New Zealand products the tariff reductions due under the FTA. This was true at both the institutional level and the personal level. As a group, CIQ is judged by the amount of revenue it brings in and is very "revenue focused", so the FTA's tariff reduction programme affects the group's performance. Moreover, from individual customs inspectors to administrators at higher levels, pay is linked to revenue collection. As such, all the staff of CIQ have a personal interest in seeing that tariffs are paid on goods whenever possible. The importers felt that because they were worried about revenue and remuneration loss, CIQ and its officials were not making much of an effort to comply with the FTA.

Others were more pointed in their criticism of the motivations that remuneration established for staff at $\mathrm{CIQ}$, saying that in order to maximize their own income, staff sought ways to deny the tariff reductions. One importer described customs inspectors as now "myopically focusing on the detail" in attempts to deny tariff reductions on the goods his firm were importing. ${ }^{39}$ His opinion was that the default position of customs officials when they were uncertain about whether a product qualified for the tariff preference was to apply the strictest criteria available to them and deny the application. ${ }^{40}$ The other alternative, that they seek more information about the product being imported and how the FTA affects the issue, was leading to further delays for the importer - a situation causing grief to many importers as they are trying to establish a good reputation with their buyers. Many of the importers I spoke to were choosing to pay the normal tariff rates in order to get goods across the border expeditiously.

\footnotetext{
39 Personal interview, Shanghai, December 2009.

${ }^{40}$ Personal correspondence, March 2010.
} 
One unintended consequence of the FTA is that through its very existence, the FTA has given the CIQ officials more opportunities to deny the tariff reductions that the FTA gives New Zealand products. Because goods entering China from New Zealand now require more paperwork than goods not entering under an FTA, ${ }^{41}$ there was more paperwork for CIQ officials to find fault with. All of the importers interviewed expressed frustration with the amount of paperwork that they now had to fill out, and how unfamiliar with the processes customs officials were.

Beforehand an import just needed a few simple documents - a Certificate of Origin issued by a NZ chamber of commerce, a bill of lading, an invoice and a packing list. NOW, there's a whole pack of documents, free trade zone documents that have to have to be issued, meaning this good is subject to the new bilateral agreement between the glorious People's Republic of China and NZ and therefore to apply for the tariff reduction you fill out this and this and this and this...right? And this gives ample opportunity to customs officials, who don't really want to give up the tax revenue.

As part of the comprehensive FTA, non-tariff barriers were closely examined and a number of outcomes agreed to that would facilitate the movement of New Zealand goods into China. These include:

- Cooperation between the customs authorities of New Zealand and China;

- An obligation to cooperate so that customs procedures are predictable, consistent, transparent and facilitate trade;

- Customs authorities are obliged to release products with 48 hours of arrival;

- Advanced rulings on tariff classification and ROOs could be sought.

\footnotetext{
${ }^{41}$ Pre-FTA, around three pieces of paper work were required by the importers of most goods whereas post-FTA this had risen to eight or nine.
} 
When seeking advanced rulings on origin, New Zealand exporters could request a ruling directly from Chinese customs. Advanced rulings on tariff applications, however, could only be made from within China. In practical terms this meant that exporters of New Zealand products were unable to request an advanced ruling. This could only be done in most circumstances by either importers or companies large enough to have a physical presence in China (and who had gone through the necessary registered process to become an established company).

Problems with the changeover were not entirely unexpected, and steps had been taken before the agreement came into effect to mitigate implementation problems. An office was established in Shenzhen ${ }^{42}$ so that importers could pay fees in full when the importer disagreed with the decision of the CIQ official, but wanted to get their goods through without delay. If this occurs, the importer can then apply for a refund of the excess charges through the office.

A problem several importers spoke about was that few Chinese customs officials were prepared to sign the necessary documents that are required by this office. Their belief was that the loss of face that would result from the official's decision being overruled was perceived as too much for the officials. What was occurring instead was the transition of goods across the border was being slowed down as the officials sought clarification of the rules, thereby creating delays. The end result was that few of their goods were processed through customs within the 48-hour period established under the FTA.43

\footnotetext{
${ }^{42}$ It should be noted that the Shenzhen office was established to handle complaints from all importers of foreign products rather than being specifically for importers of New Zealand products; they were, however, being referred to this office in the event of a dispute.

${ }_{43}$ Article 57 (Release of Goods) of the FTA states that "Each Party shall adopt or maintain procedures which allow goods to be released within 48 hours of arrival...". Article 25 (Direct Consignment) of the FTA stipulates that in order to be award preferential trade treatment goods must either be transported directly (Article 251 .a.) or if transiting through a non-Party area they cannot enter the market (Article 25 1.b.i.), and that "the goods do not undergo any
} 
Of particular concern to the importers was the problem of goods that had been transshipped through a third country. Based on the evidence provided by those interviewed, goods shipped directly from New Zealand were being allowed through with few problems. However, those being shipped through a third country, which is a large proportion of goods due to the expense of direct shipping, were being consistently denied tariff reductions. These goods were not being accepted because New Zealand Customs did not produce the kinds of paperwork required by the Chinese authorities.

One New Zealand importer I spoke with had been unable to get any goods through customs with the tariff reductions at any time in the 16 months following the FTA's implementation. The goods he was importing travelled by air from New Zealand, through Bangkok, and then on to Shanghai.44 While regulations had been established by CIQ for transshipment by sea, this had not yet taken place for transshipment by air. Unfortunately for this importer, Shanghai CIQ were insisting upon confirmation from Thai customs that the shipment had not been interfered with, as stipulated under Article 25.2,45 which Thai Customs was unwilling to provide. The importer had attempted to use documents from the New Zealand producer and Thai Air declaring the goods had not been interfered with, but these documents were not being accepted.

In Shanghai, delays in goods passing through customs is particularly problematic for importers because of the cost of storing goods while they are awaiting approval to enter the country. One importer described the consequences of the delays he was encountering in getting goods thusly:

operation there other than unloading and reloading, repacking, or any operation required to keep them in good condition" (Article 25 1.b.ii.).

44 Transshipping of goods from New Zealand to Shanghai is common because of the high cost of direct shipping, so goods are often sent through Thailand, Singapore or Taiwan.

45 Article 25.2. reads: "Compliance with the provisions set out in paragraph 1(b) shall be evidenced by presenting the customs authorities of the importing Party either with customs documents of the non-Parties or with any other documents." 
What you've got to understand is that the one kilometre around the airport and around the seaport is possibly the most expensive shipping kilometre in the whole chain. So at the moment I spend around $20 \%$ of my cost structure, including the cost of the goods, in one kilometre. And that's not the duty, it's the storage costs, and the trucking, and the inwards and outwards, and the paperwork. So what in other international airports takes two hours, in this city, if there wasn't an FTA, it takes two to three days, and that's sort of Holy Grail really, if I can get two to three days, fantastic, but I'm typically clearing the airport in five to six days.

It is likely that CIQ was examining transshipped goods closely because of problems with Rules of Origin (ROO) issues they had experienced with previous FTAs. A policy analyst at New Zealand Customs informed me that they had received a number of queries by CIQ seeking to confirm the authenticity of Certificates of Origin as they suspected fraud in a number of cases. Close inspection of the paperwork is necessary, apparently, as the "noodle soup" of rules covering ROOs across FTAs in Asia had meant that misunderstandings were common between businesses and customs and that some mendacious businesses sought to take advantage of holes in the system. ${ }^{46}$

The key point here seems to be whether or not one takes a long view of the implementation of the FTA. If implementation was expected from the day the agreement came into effect, then the reports of those I interviewed reflect a failure in the implementation. Alternatively, the agreement could be seen as

\footnotetext{
${ }^{46}$ Indeed different ROOs covering trade with different countries will increase administrative and compliance costs for firms with multiple export markets, threatening the precise problems that Bhagwati warned were possible if preferential trading agreements became the dominant form of free trade rather than the WTO format. For a survey of East Asian firms and their perceptions of their complicated, so-called "noodle soup" of FTAs, see Kawai, M., and G. Wignaraja "The Asian "Noodle Bowl": Is It Serious for Business?" ADBI Working Paper 136 Tokyo: Asian Development Bank Institute, 2009: 17-22.
} 
the beginning of a process, one which over several years the details will be steadily implemented and, as part of that process, CIQ will become familiar with the new regulations and processes required of them. From this perspective, given the size of China's customs agency and the relatively insignificant amount New Zealand products contribute to China's total imports, it is not overly surprising that Chinese customs were not allowing all New Zealand products through under the new tariff schedule. This process will take some time. An issue of fairness is raised, though, as New Zealand Customs had prepared itself for the changeover and had not encountered implementation problems. ${ }^{47}$

\section{Interactions Between New Zealand SMEs and Street-Level Bureaucrats}

We came here very early and the officials have come to know me over the years as someone who won't complain, as someone who is quite happy to deal with them on the very low level and nothing ever goes any higher up. And this again is one of the big myths of China, people saying you know you have to have a connection with a higher authority which is actually, it's not just bullshit, it's actually the opposite of the case. If you are doing things correctly, you should never require anything above the bottom level.

When it came to businesses dealing with street-level bureaucrats in China, no evidence was found that the FTA had made their relationships any easier or gained them any distinct advantages. The feedback was mostly that streetlevel bureaucrats were if anything uninterested in the FTA and felt that it was the concern of higher ranked officials than themselves. To some of those interviewed this was no surprise. It was their opinion that attempts to use the FTA as a legal document to force an outcome would most likely backfire. Rather, and these tended to be the more experienced group voicing this

\footnotetext{
${ }^{47}$ A NZ Customs official whose position involved implementing the FTA in New Zealand said that no complaints about the FTA had been received by the agency from any Chinese firm of official body - Personal interview, May 2010.
} 
opinion, differences between a businessperson and a street-level bureaucrat should be resolved through well-established guanxi. An important distinction, however, was that guanxi was defined strictly in terms of a relationship - not as connections with high-ranking officials who could overrule their subordinates. There was also clear evidence that New Zealand businesspeople steer clear of activities which they see as corrupt as they feel it is bad for their business and is likely to cause more problems in the long run than the short-term gains that can be gained through it.

In terms of the immediate effect of the FTA in the day-to-day management of their companies, few of the firms were seeing any noticeable effect from the FTA. There was disagreement over how aware of the agreement street-level bureaucrats were. Some felt it was a big event and one that most Chinese they knew were conscious of; one even said that when he mentioned he was a New Zealander to taxi drivers they would know about the FTA. This stood in contrast to another who doubted whether most local officials were aware it existed, and would probably only find out from briefing material if they were about to meet with a New Zealand official or company.

Given the dominant role that the state plays in China and the greater attention that the Chinese, in comparison to other nationalities, place upon government relationships with other countries, ${ }^{48}$ one might have expected to see that the relationship between China and a Western country would have caused a change in the way that New Zealand firms were being treated by street-level bureaucrats in their routine business. However, there was no evidence for this. The agreement appears to be held as something at too high a level for street-level bureaucrats to be concerned about and they are more concerned with the performance indicators that dictate their career progress.

\footnotetext{
${ }^{48}$ Tianjian Shi, "Cultural Values and Political Trust: A Comparison of the People's Republic of China and Taiwan" Comparative Politics 33 (4) 2001): 401-419; Lianjiang Li "Political Trust in Rural China" Modern China 30 (2) 2004: 228-258.
} 
This is possibly linked in with the strengthening of local regulations and enforcement. More precise rules and guidelines, more consistent enforcement of those rules, and more pressure on street-level bureaucrats to implement them judicially; all these factors add up to part of the shift by local officials towards meeting performance criteria for career promotion. In other words, what a company or businessperson has to offer the local district is more important than where they come from. For a street-level bureaucrat, it is more important to be seen to be performing their job properly than to be concerned with issues related to China's diplomatic relations. ${ }^{49}$

The consistent theme from talking with the New Zealanders was the importance of establishing a warm relationship with the street-level bureaucrats they had to deal with - be they from the tax office, the employment bureau or the health bureau. The emphasis the more Chinaexperienced businesspeople placed on the conversations was that if annoyed, the bureaucrats could cause considerable problems for them. In contrast, small problems and infractions could equally easily be overlooked if a positive and friendly relationship was maintained.

Interactions between street-level bureaucrats and foreign businesses are the sorts of things that can make or break a small to medium business in China. Much of the business literature on China advises that both small and large businesses need to develop good guanxi with local officials - a patron-client relationship, as it is sometimes described (Wank, 1996).50 This not only facilitates the processing of paperwork and introductions to important people, but also acts as a protection when faced with a corrupt official

\footnotetext{
${ }^{49}$ Since 1993, when the civil service examination was reinstated, there is greater emphasis on job performance. In 2006 the CCP's Organization Department issues new guidelines for evaluation and clearly stipulated aside from GDP growth, officials would also be judged on a number of other economic factors as well as social statistics (worker safety, education, welfare), environmental issues and investment in scientific and technological development. See Jarrett and Lie (2209): 37-38.

50 Also see Neil Abramson and Janet Ai "Canadian Companies Doing Business in China: Key Success Factors" Management International Review 39 (1) 1999: 30.
} 
attempting to put pressure on a business for personal gain, as this person can be appealed to for help.

Several of the companies I spoke with acknowledged that having guanxi was important, but found developing this kind of relationship difficult, as well as time-consuming and ethically questionable. To solve this dilemma, some had made the decision to 'contract-out' the establishment of guanxi by hiring firms to deal directly with government agencies in their place. This was done by hiring firms to meet the paperwork requirements of the customs bureau, the tax department, and so on. Such a situation was described by one New Zealand this way:

We just don't have the ability to 'out guanxi' other people. We just don't have the ability. But, having said that, I acknowledge that it is important. So we do not ignore it either because it is the oil that makes the wheels turn in this country. We have the right to go directly to customs and clear customs ourselves, but we don't. We use a customs brokerage company who has good guanxi, who spends the money every year to allow customs officials to go down on a trip to Hainan, or wherever, who takes them out to dinner and ruins their own liver with their baijiu ${ }^{51}$ drinking and all that stuff. They do that. They have that. So in this case I am willing to pay them a little bit of money for their services. As far as I am concerned they are delivering to me customs brokerage services. So we are leveraging their guanxi and I don't get directly involved with customs.

Firms involved in similar practices acknowledged that there was quite possibly some questionable activity taking place between the firm they hired and those whom they sought to develop good guanxi with, but by staying a step removed from the activity they absolved themselves of any actual

51 Baijiu (白酒), literally 'white liquor' is a common Chinese distilled spirit, general made from grains in northern parts of China or rice in the south. It has a high alcohol content and is often served at work functions or celebrations. 
wrong-doing on the basis that they were simply hiring someone else to undertake tasks that were too onerous and costly for their own firm to do inhouse.

When dealing directly with street-level bureaucrats, many of those interviewed made the point that respecting the authority of street-level bureaucrats was very important. What can complicate an issue is the use of higher-level connections who are in the position to influence the decisions of a lower-level bureaucrat when a serious problem occurs.

Going over the head of the street-level bureaucrats was an action that needed careful consideration because of the long-term ramifications it could have. While many of the businesspeople I spoke with said that after years of working in China they had developed good connections who were wellplaced to help them, they were very reluctant to make use of these connections and would only do so in the most serious of situations. A preferred method for dealing with the situation was to try and resolve the situation with the person concerned. If the situation warranted escalating to a higher level, the bureaucrat should be told that this would be done and that a higher-level person in the company would also be handling the situation from now on. One interviewee explained the problem this way:

They have this expression that if you have a powerful friend he will take care of your big problems, but the result is that you're going to have many, many more small problems. Shao yidian dawenti, dor yidian xiaode wenti. Because that just pisses off the people at the bottom so they're just going to go come after you for every little thing knowing full well that you can't come running to the big boss over petty matters.

What remains important in such a scenario is saving face for the official and respecting the authority implicit in their position. In this scenario, quoting laws and regulations, such as those that are provided for in the FTA, could 
well backfire on foreigners as this would be interpreted as an attempt to undermine a bureaucrat's authority by questioning their knowledge of Chinese laws. Such an act also questions their authority by demonstrating that a higher authority exists and that the business considers this more important.

The story below demonstrates the value in maintaining a good relationship with street-level bureaucrats. In this case the outcome was selective enforcement of the law by a policeman that enabled the business owner to begin operating before the necessary paperwork had been filed with the authorities. It describes a situation in which the New Zealand owner of a bar and restaurant negotiates with a local police official for licensing requirements to be overlooked in order that he could open his operation as quickly as possible despite having not fulfilled all the necessary official paperwork.

When you're opening a bar you go through all the series of approvals and then when everything is done, in other words you go get a licence, you've gone through your health bureau, your labour bureau, etc, you've got everything chopped, the last step is you go down to the police station and you ask for their chop and on the policeman's chop you can then commence doing business.

But normally you've got your business ready to go before going through all the bureaucracy. So for example this third pub I had, we were ready to go, it was decorated, I had the staff, the food, we were ready to do business. So we did. We just opened and started doing business.

The local policeman, whom we had a good relationship with, came in and, he came in at lunchtime and it was all happening and we sat down. All around us food was being delivered, drinks were being poured, checks 
were being paid for...we probably had 150 people in the place eating lunch. It was pretty obvious that business was going on.

But the conversation that I had with the officer was, he asked me when we would be opening for business and my response was "We will open for business when you give us permission to open for business, Officer Zhang." And Officer Zhang said "Fine, you do appreciate that you're not allowed to do business until we tell you you can," and I said "Oh yes, we understand that, Officer Zhang. I always want to abide by the laws of China and we will not open for business until you tell us we open for business."

This was the nature of the conversation, and we're drinking tea and smoking cigarettes, we shake hands we go away and everything's cool. And a few weeks later we get our final chop.

The point of all that is that I was respecting his authority. So even though I was bullshitting, he knew I was bullshitting and I knew that he knew and that makes bullshitting $O K$ as long as everyone knows. The one hundred and fifty people in the bar were kind of irrelevant. To his face I was respecting his authority, and that's how you do things.

If you had sat down with Officer Zhang and when he said when are you opening for business and you say "oh, we've sort of opened already Officer Zhang. I'm so sorry it was a little early," he will screw you. And so there's a certain subtlety required in dealing with the officials and respecting authority is a big, big thing. Really, a big thing. And I think that's one of the difficulties that big companies have, if they try and do it black and white they run the risk of not showing the proper respect for the officials. 
The person telling this story had spent more than 15 years living in Shanghai and as his story demonstrates has come to feel very comfortable operating in the local culture. When asked about how street-level bureaucrats had changed over the years, he commented that incidents like the one above happen less and less often these days. Sometimes when dealing with a younger street-level bureaucrat he felt foolish as, trying to establish a good relationship, he asked about the bureaucrat's background and family, only to receive replies that related directly to their job.

Several other of the longer-term expats agreed that there may well be a change taking place with China's civil service as older workers retire, replaced by younger workers who never experienced the political campaigns or shortages of the Mao era that supposedly drove guanxi's importance within Chinese society. Rather, most of these people commented on how these younger entrants were increasingly well educated, smart and knowledgeable about the outside world.

The businesspeople were uniform in the opinion that there are many regulations that by law they were required to comply with, but they found that these laws often contradict one another. Often this is because there are many authorities competing for influence over an area. With several different authorities come different standards so full compliance with all regulations is difficult, if not unachievable. When asked to expand upon this point, one businessperson gave the example of the fact that he had 43 separate licenses for his business. Such a complicated operating environment, especially one in which as foreigners the business owners have limited language skills, leaves a business exposed to the risk of being found guilty of some violation or having to incur extra costs in order to become compliant. Having a good relationship with street-level bureaucrats therefore adds a degree of security. Alternatively, as described previously, reliance upon knowledge of the law or good legal representation was not seen to be a positive way to resolve disputes. 
There was a wide degree of divergence between the New Zealanders I spoke with about links between corruption and guanxi. One long time resident in China thought that the existence of corruption and the need for connections with officials was, and always had been, vastly overblown. Another, again with considerable experience, expressed vivid distain for guanxi practices in general because guanxi was, he felt, a cover for corrupt activities.

Despite the range of feelings on the link between corruption and guanxi, all the New Zealanders I spoke with ruled out use of corruption to influence government workers at all levels. Resorting to bribery or similar tactics was felt to be a short-term solution to what would become a long-term issue, or, as one said, "Guanxi that is based on [bribery] is the worst type of guanxi you can have." 52 The impression of both the New Zealanders and the Chinese who I spoke with was that the current crackdown on corruption, although certainly driven primarily from Beijing, was a genuine attempt to reduce such behaviour. Government workers at lower levels were reportedly becoming more wary of taking bribes. Some of the businesspeople felt that being foreigners insulated them from the problem because they are seen as a risky and unknown quantity; the perception being that foreigners are far more likely than locals to report corruption either to the authorities or to their country's representatives. They also felt that the size of their companies meant that for most officials the possible benefits of corrupt activity did not outweigh the risks that exist in the current environment.

It was also considered that the government's crackdown on corruption was genuine and the situation, especially in Shanghai, was changing for the better. ${ }^{53}$ This trend was expected to steadily spread to other areas in the future

\footnotetext{
52 Personal Interview, Shanghai, December 2009.

${ }_{53}$ Many of those I spoke to, while based in Shanghai, were increasing their business activities to other cities. They agreed that Shanghai was in many ways different from the rest of the country, especially in comparison to the less developed areas in the west of China. However, their belief was that local officials across China look to Shanghai in order to gauge the direction of policy and its implementation.
} 
as well. Furthermore, the government's policy of rotating bureaucrats meant that corruption would only bring short-term gains before a new, quite possible incorruptible official replaced them, in which case the firm would then have to alter their behaviour so that they complied with government standards and regulations anyway. As foreigners, most of the New Zealanders also felt that they constituted too much of a risk for the officials to attempt corrupt activities.

How the interviewees viewed transparency - whether or not regulations were easily accessible, for example - showed a clear difference based on length of time spent in China. Those who had been in China longer felt that the situation, while not ideal, had vastly improved from earlier years. In particular, they said that most information they needed had now been made accessible via the Internet so it was now far easier to find out regulations. An important caveat, however, was that one needed to know which bureau was in charge of monitoring an issue.

In comparison, those who spent less time in China felt very frustrated by the lack of easily accessible information, often feeling that rules and regulations were sprung on them. The difference in these perceptions probably has more to do with experience in finding information in the past and knowing where to find it on each occasion; the longer-term residents would also have a wider circle of contacts who can point them in the right direction. Greater familiarity with the Chinese language seemed to help two of those interviewed in particular, whereas most of the new arrivals spoke no Chinese.

At the street-level then it appears the practice of guanxi remain strong in ways that reflect the sentimentalist approach purported by the likes of Mayfair Yang. The businesspeople emphasised that the existence of a warm relationship between themselves and street-level bureaucrats was important in allowing them to operate their businesses more freely. When a positive relationship existed, small problems could be overlooked, and larger 
problems could be worked out rather than having fines imposed or their business activities curtailed. Hence, sentimentalist relationships are utilised, but for instrumentalist gains.

In contrast, at the street-level the idea that Guthrie advocates of increasingly legitimate behaviour based upon respect for the rule of law was not supported by the opinions of those I interviewed. The focus on the importance of having a positive relationship with a street-level bureaucrat so that concerns over regulations could be overlooked, red tape avoided and expeditious processing of paperwork take place and the like, all indicate that guanxi at the street-level still remains important even within developed cities such as Shanghai and Xiamen. Such relationships are developed in order to avoid legal sanction or restriction of behaviour. Furthermore, when asked explicitly whether they would turn to a lawyer if they had a problem, all those interviewed suggested that such an avenue should only be ventured down if all other options had failed. Legal action indicated that the relationship had broken down so far that negotiated solutions, the preferred pathway, were futile. Any legal action taken would, they advised, mean that future relations would be impossible or, at the very least, extremely difficult.

This affirms an aspect of Wank's assertion that while Guthrie was right to say that while managers' use of guanxixue is decreasing, this does not necessarily indicate they are moving towards increased compliance with the rule of law. The businesspeople I spoke with were not curtailing the development of guanxi because they saw it as illegitimate or incapable of producing benefits, but because the perceived risks of doing so to have increased and because of the associated costs in time and money (as well as, in some cases, because of the eating and drinking involved, their health). This is supported further by their belief that they are insulated from corruption not because it no longer occurs, but because foreigners are perceived by street-level bureaucrats as being too risky to solicit bribes from. Furthermore, the fact that some of the businesspeople hired local businesses because they had good guanxi with 
street-level bureaucrats indicates they also perceive that benefits arise from guanxi, but they wish to avoid that activity firstly because of the risk and secondly because of the costs involved in establishing good guanxi.

As is always the case with research on corruption, it is difficult to judge how accurate the information the researcher is being given. The reasons that were given by the businesspeople for wishing to avoid corruption were remarkably consistent across the group, however, and therefore lend credibility to their statements. The owners of the smaller firms I spoke to were also hoping to sell their businesses at some point on the future, so wanted their books to reflect actual assets that could be reported and recorded. Naturally, corrupt activities or 'assets' could not be recorded on their companies' balance sheets. Corruption, then, was seen as an unwise approach because the short-term rewards were outweighed by the potential long-term costs; in other words, it just made better business sense in the long-term.

The respondents' replies regarding corruption indicated a complex relationship with the law. Given the strong moral component and concern for the long-term fiscal cost that corruption could place upon their businesses, it appears as though these businesspeople sought not to deny the legal authority of street-level bureaucrats; if anything they wished for a high standard of legal behaviour from them. This likely indicates their appreciation of the corruption-free environment they know from New Zealand and their desire to see that replicated in China, but also their appreciation of the Chinese environment which allows them to utilise a good relationship to avoid regulations that restrict their actions or impose onerous costs upon their businesses.

Benefits at the local level

The next level we examine is the local level where New Zealand and Chinese firms interact, and Chinese local government officials become involved, as do 
representatives of New Zealand - from MFAT, NZTE and the occasional visit by mayors via sister city relationships. ${ }^{54}$ At this level there was evidence of a positive effect of the FTA with most respondents thinking that local government officials were aware of the agreement and that they saw it in a positive light. However, reflecting the literature that documents local officials' focus on economic growth, the importance of performance indicators for local officials dominated at this level, so the focus on economic growth at the level trumps other considerations, such as those of the FTA.

As was discussed previously, the importance of maintaining good relationships with local government officials is often emphasised in the literature because of the extent that officials are involved in business dealings. This increases with the size of the company and the investment that they are making relative to the local economy. The small size of New Zealand companies, especially in the context of the Chinese economy, often means they are overlooked by local officials in China. Where New Zealand firms do have scale and are making investments that compliment local economic objectives, support from local officials is present.

While developing a good relationship with officials will progress the development of a project, the economic fundamentals of any situation should not to be underemphasised. Local government officials reviewing investment activity are still focused on attracting investment, GDP growth and employment for their area, as these are the main criteria by which their job performance is judged. However, it is important to distinguish between the different motivations of the different officials who attend investment discussions. The objectives of Labour Bureau officials will be different from

\footnotetext{
${ }^{54}$ A report in 2008 listed 27 existing sister city relationships between New Zealand and China. The relationships varied in their strengths of their relationships, although many cities reported being overwhelmed by the size difference. New Zealand's major cities maintain the following relationships: Auckland - Guangzhou, Wellington - Beijing and Xiamen, Christchurch - Wuhan and Gansu Province, Hamilton - Wuxi, Dunedin - Shanghai, Waitakere City - Ningbo. Roger Matthews et al "Sister City Relationships and Opportunities, between Chinese and New Zealand Cities: A paper for the Metro Sector of Local Government New Zealand" February, 2006.
} 
those of the Environmental Bureau, and different again from those of the mayor's office, the tax office and so on.

Local officials are set GDP and FDI targets by which their performance is graded (Huang, 2008: 176). These are set at the central level based upon the current Eleventh Five Year Plan, which expires at the end of 2010. The economic focus of the plan promotes balanced growth, efficient use of resources, maintenance of high levels of employment and improvement of environmental conditions in China. 55 There are signs that although Beijing is attempting to shift focus from the rapid-growth model of previous plans, ${ }^{56}$ local officials still focus on high GDP growth, which in the past has been used as the major indicator of successful governance (Jarrett and Lie, 2009: 37).

While this shift of emphasis may well be true along the developed coastal areas, officials in the less-developed areas of the interior are still focused on economic issues. The increasingly competitive nature of doing business in the tier one cities ${ }^{57}$ was a reason given for giving other areas a closer look, partly because relationships with local officials and businesspeople were easier to form because there are fewer foreign companies competing in these areas and so officials were still eager to attract FDI. The opportunities available in these areas was highlighted by one consultant I spoke with:

Sometimes you're better off going somewhere that might be a bit slower, but you might get through the relationship thing you might get some priority, and that relationship might allow you to get that application at the head of a pile rather than buried at the bottom of it. Honestly, some of

\footnotetext{
${ }^{55}$ The Eleventh Five-Year Plan saw the introduction of the concepts of "Scientific Approach to Development" and "Constructing a Harmonious Socialist Society" as well as greater emphasis on social and environmental issues.

56 The 2007 White Paper on Energy for example includes a section on coordinating energy goals while keeping in mind the environment. Key objectives included in the paper are controlling greenhouse gas emissions, fighting pollution, lowering vehicle emissions, and strict environmental management of energy projects.

${ }^{57}$ Tier one cities are the are major cities of China - Beijing, Shanghai and Guangzhou; tier two cities consist of the likes of Chongqing, Wuhan, Ningbo and Dalian.
} 
the fastest experiences I've had have been in the provinces, where they will drive this for you if you can show them how this is going to work.

Those I spoke to who were involved in investment activities all commented that within both Shanghai and Xiamen, polluting factories were now almost certainly to be denied approval from local authorities. In Shanghai, regional headquarters were now the preferred mode of investment, while in Xiamen high-tech, 'clean' industries and tourism were the focus, while maintaining their traditional strength on logistics and shipping.

Added to this, while in the past local officials were keen for almost any form of foreign investment in their jurisdiction, the developed coastal regions were becoming now increasingly picky about the types of businesses they were willing to allow to become established. In Shanghai, for example, factories, particularly pollution-emitting factories, were no longer being approved, as the local government's objective was to become a hub for regional offices.

We'll often take companies of different sorts to various jurisdictions, not just Shanghai and they'll just say 'nah, we don't want that.' Well what do you mean? Is that illegal? 'No, well under WTO, or FTA or China law we're allowed to have a business of this scope in this district...yes? 'No...we don't want that thanks, we don't want free trading companies in here, we only want these companies.' And that's their right, what are you going to do? Sue them? That's their right. So they're saying we want these types of companies and we want this and here's our standards, our registered capital standards are higher, our environmental standards are higher or what ever they might be.

Comments such as this highlight positions that local officials find themselves in which are difficult to resolve. As Beijing signed the FTA with New Zealand, local officials are obliged to implement the agreement. However, they are also under an obligation to meet the economic growth objectives set 
for their department, local district, or province, depending on where their responsibilities lie. Where these two interests intersect - say, for example, a New Zealand firm wishes to make an investment in a clean energy-producing plant, there is no clash and the project is likely to be welcomed and supported by local officials. Where there is a clash, and a local industry will likely suffer as a result of the competition that the New Zealand firm entering the market produces, the investment becomes far more problematic for local officials. My field research found that this was indeed the case. Where New Zealand companies were investing in projects that were complementary to the objectives of the local government, they were finding local government to be supportive and helpful. Alternatively, where the project fell outside of the development plan local government had for their district, regardless of the rules that exist under the FTA the local government was not interested in the project. 58

In reality, this should come as no surprise. The FTA gives New Zealand investors the right to 'national treatment' (except in regards to some existing measures) and 'most favoured nation status' so that no firms from another country will gain an investment advantage over a New Zealand firm as China signs future agreements. ${ }^{59}$ As the final say in all significant investments belongs to local government (or central government if the investment is large enough), even though they may not appreciate it, New Zealand companies are receiving equal treatment in comparison to their Chinese counterparts; a polluting factory is equally likely to be denied permission in Xiamen whether

\footnotetext{
${ }^{58}$ Quantifying New Zealand's investments in China are difficult because the statistics that are kept are subject to confidentiality agreements between companies that supply information and New Zealand Statistics. As such, some years the numbers are not publicly released and only the code confidential is given by New Zealand Statistics. The following trade states are available however and show increasing amounts of investment - New Zealand total investment (in NZ\$) in China: 2004 - \$104M, 2005 - \$414M, 2006 - \$333M, 2007 - Confidential, 2008 - Confidential, 2009 - \$455M (Source: New Zealand Statistics).

59 These rules do not include advantages such as the receipt of subsidies or government procurement. Government procurement contracts appear to be one of the rising areas of conflict between China and its trading partners. As reported in The New York Times, new rules in this area gave broad latitude to officials to deny foreign firms the opportunity to bid on public works projects. See "Foreign Companies Chafe at China's Restrictions" New York Times 16 May 2010.
} 
it is foreign-owned or locally-owned. The practice of screening investments however, does raise concerns as to whether local authorities will in time come to live up to the FTA and allow New Zealand enterprises a greater latitude in their investment decisions. Under the WTO, foreign companies already have investment rights, but this has not altered the actions of local authorities which allows, in the words of Kong, ample room for "manipulation and constitutes a major barrier for foreign investment participation" (Kong, 2001: 1198).

The larger a company, the greater its need to be in contact with officials at a reasonably high level. One representative of a large New Zealand firm made sure that he spoke regularly with the executive assistant of a highly ranked official in a province in which they had made a significant investment. He found this contact useful for relaying important changes that were taking place, but would also keep the assistant informed of the activities the firm was undertaking, and felt that being open with the official would demonstrate the firm's good intentions and strengthen the relationship. He didn't believe, though, that this relationship would help them gain financial support from the official; as a foreign firm he said that they did not expect this. But the communication demonstrated respect for the official and he felt this would help the firm in the long term, especially as that official gained higher office. The company was also considering establishing scholarships for local students interested in their field of operation and, possibly, some help for government officials to learn more about their operations in New Zealand.

Another businessperson whose company works with New Zealand local governments to maximise their sister city relationships said although working with the tier one cities was difficult for New Zealand, the scale of difference being so great that there was never going to be a lot of benefit for the Chinese side to become heavily involved, when it came to dealing with second and third-tier cities, the support he received was much more substantial. One city he was working with was offering free use of public spaces, free use of LCD 
screens in the city, and staff to assist with event management. The issue from his perspective was that tier one cities like Shanghai have so many of these relationships, and are so commercially important, now that they have many offers coming in. Approaches by New Zealand groups therefore get lost in the crowd. However, smaller cities outside of the main centres, say of three or four million people, have ten or fewer sister city relationships and are trying to internationalise along the direction that the major cities have already done. In these cities, therefore, local officials valued the opportunities that $\mathrm{New}$ Zealanders offered much more than their peers in the larger cities.

While local state officials are important in China, and the laws and regulations that have been passed during the reform era are enforced more regularly, neither offer the final word on how most businesses should behave on the ground. Good relationships can only take a business so far, and in the long-term market fundamentals of price and quality take precedence when local officials are deciding how much support to give foreign firms. This idea that while having guanxi is good and useful, it cannot compete over the long run with a better product and a better price is a point of view supported by Guthrie's research that market forces were increasingly forcing managers to behave in ways that maximised returns over guanxi relationships (1998: 279). As one New Zealand businessman said in the course of my interviews:

But it doesn't matter how good your guanxi is if your performance in business is sub-standard, the Chinese people will not respect you not matter what you do. So I think it is just better to concentrate on being a good performer in business. And earning the respect and that little bit of guanxi, than trying to just concentrate all on developing these relationships. Again I don't want to under stress, or say that they are not important. I just think they might be a little overrated.

Giving further credence to the views of Guthrie, though, were some businesspeople who felt that complying with regulations was now sufficient 
for operating a business in China and that the time when one had to resort to homien guanxi (backdoor connections) to resolve issues was passing. Some in fact believed that obeying regulations (as far as was practically possible, of course), being a responsible and law-abiding business today had benefits in itself and was developing a new kind of guanxi in itself with local officials:

...the old gaunxi might be diminishing in value and a new type of gaunxi, based on doing your job, doing good business and trying to be a good corporate citizen.

The idea that reputation is becoming more important has been raised in other works. Wank suggests that new networks are forming as the Chinese economy develops:

\begin{abstract}
"These new networks are named in the business community as reputation (mingyu) embodying perceptions of status and norms of respect, and place (difang), invoking perceptions of locality and values of expediency. Inasmuch as they invoke particularistic identities to link private firms and local governments in non-standard administrative practices for mutual benefit, these networks do not conform to a market transition. Instead, they suggest a process of pluralising power in which new types of networks are forged as a response to new constraints faced by local officials and new monetary resources of entrepreneurs in the emerging market economy." (2002:97-98).
\end{abstract}

This idea was more commonly held by those who had been in China longer. This likely reflects the success in enforcing laws China's legal system had made during their time in China and, that they had learned which regulations must be complied with and which could be put aside, thereby encountering fewer problems with local officials. In contrast to this, one of the more recently arrived New Zealanders I interviewed spoke about the importance of building relationships: 
There's another thing about China or in fact about commerce here, and that is the important factors are quality, price and relationships. I would suggest that in New Zealand and Australia it's in that order: quality, price and relationship. Whereas in China I would say it's relationship, price, quality.

This speaker's words echo that of Yeung and Tung almost verbatim - "guanxi is important (perhaps more important) than price and quality" (1996:54). The difference in perceptions between businesspeople experienced in China and those newer to the environment has been highlighted in several academic studies before. These studies indicate the size, type of business and length of time to be important factors that contribute to a business' perception of the importance of guanxi.

Yueng and Tung point out that smaller and newer businesses are also more likely to advocate that guanxi is highly important (1996: 60). This study supports that proposition. Most of the new companies interviewed for this study felt guanxi was something they needed to develop. Those who had been in China longer spoke of how they did have guanxi, but they were hesitant in using it, or they didn't think it was that important.

The participants in this study suggest that a middle ground exists for established firms, as is suggested by the earlier speaker's proposition that quality business performance earns a firm a reputation that is becoming as important as traditional views of guanxi. Guanxi should certainly not be ignored, however, for as has been put succinctly, "While knowledge of cultural differences...will not always guarantee, its absence (ignorance of Chinese culture, including the role of guanxi) usually leads to failure" (Yeung and Tung, 1996: 60). Guanxi remains an important aspect of doing business in China, in part because of the still developing nature of the legal system, but 
also because guanxi networks are seen as a reliable way of deciding whom a business should become involved with.

As Wank argues in response to Guthrie's critique of Mayfair Yang, businesspeople in China may well be moving away from guanxixue, but that doesn't necessarily mean that practices are moving towards standardised practices found in the West. If businesspeople are following government regulations more closely, is this because market forces are compelling such a change, or because they have decided that guanxixue is now too risky or too costly?

All of the subjects seemed opposed to corrupt practices primarily on moral grounds, while opinions were split on whether guanxi was a cover for corruption. They also perceived that officials believed that because they were foreigners, attempting to engage in illegitimate activities was too risky for officials. However, as a group, the subjects expressed a dislike for corrupt practices and believed it unnecessary to engage in corrupt practices. Some then went on to suggest that this behaviour was earning them a level of respect from officials who had also turned away from corrupt practices and who appreciated dealing with a firm who was not attempting to misled them.

The moral objections to corruption that the New Zealanders exhibited may well have been transmitted, either overtly or implicitly, to the officials so that it was clear to them that illicit behaviour was not welcome. Alternatively, given the small size of most of the businesses with whom I spoke, officials may have decided that the possible benefits of corruption were too low. Both of these possibilities however, demonstrate that risks have increased such that petty bribery is no longer a major concern, at least for foreign firms in Shanghai and Xiamen.

Many of those I spoke with expressed the sentiment that this was not the case in all of China and I was told that if I conducted similar research in smaller 
cities, particularly in the interior or China, my findings were quite likely to be different. Furthermore, it was asserted that sectors that necessitated cooperation with central government were where companies had to develop guanxi, for example:

If you are in a controlled, sensitive industry like telecommunications for example, you WILL HAVE TO go and nurture your guanxi because those decisions are all made at central government so they cannot be signed off locally. But if you're in a normal business, say for example the lumber and log business, you don't need to overdo it.

A number of similarities were found with a paper on Australian expats and their perceptions of business practices and guanxi. Hutchings and Murray found that there was a large difference in perceptions between Australians who had been living in China for more than three years compared to those more recently arrived. Interestingly, the person in their study who had spent the longest time in China, 25 years, had similar feelings about guanxixue as a New Zealander who had spent 15 years in Shanghai:

"Guanxi will not decline with globalisation. It never really existed. Guanxi is crap - it always was. Everywhere in the world has networks/relationships. China is no different - never was, never will be" (2002: 86).

Anytime you hear, particularly a Chinese person who says "I have connections" it's bullshit, it's more trouble than it's worth. They're the people you avoid, because it's just not necessary...most foreigners still think that it's handy to have powerful connections and most foreigners still think there's a great deal of corruption that goes on and the simple fact is that it is not. 
In comparison to those subjects who had spent a considerable length of time working in China, across my interviews with companies and businesspeople who were relatively new to China, their estimates in the importance of developing guanxi was much higher. An example of how this refected in their behaviour was their appreciation of having New Zealand officials at events or travelling with them to government-sponsored events was evident. Having officials, such as MFAT officials, representatives of NZTE, or mayors on sister-city related trips, accompany them was, they felt, important to develop and maintain relationships with their customers. New Zealand officials being present at a signing or function between their firm and a client significantly raised the importance of the event for the Chinese side, lifting the status of the New Zealanders, often quite significantly above what even the New Zealanders themselves felt was appropriate for their size. An example given of this was a contract signing between a New Zealand firm and a far larger Chinese firm. The inclusion of the New Zealand Consul-General on the list of invitees saw the president of the firm attend rather than just the vicepresident. Following the signing the Managing Director of the firm felt that he was being treated with respect by that firm far more than the size of his company would usually have warranted.

Shortly before my research was conducted, a trade delegation had travelled with the Consul-General to Ningbo, a city of over two million people that lies outside of Shanghai, in order to facilitate introductions between New Zealand firms and possible customers. There was broad agreement amongst all those who had been on the trip, or who were aware of it, that it had been tremendously successful. This was they felt, directly linked to the increased profile New Zealand now had because of the FTA.

It appears that particularly in these smaller cities, where there are fewer official delegations and less competition amongst foreign firms relative to Shanghai, both officials and businesspeople felt considerable opportunity lay. One New Zealander described the situation as: 
For lack of a better term there's lots of warm fuzzies about. There are. But New Zealanders don't understand China and that's our problem because... and that's more of an attitude again, because we don't spend the time, or probably have the desire to understand China. Now if we did we would quickly understand the fact that New Zealand got that FTA means a lot to the Chinese, it means a lot to the Chinese people.

The New Zealand businesspeople were of the belief that the New Zealand Counsel-General and NZTE officers in particular had gained prominence because of the FTA. The higher visibility they now had had in turn led to better access to Chinese officials than would usually be the norm for economies of New Zealand's size, or than they had been able to achieve in the past. Particularly for those businesspeople who had well developed connections with these offices, the benefits of having officials along at events had been greatly enhanced by the FTA. Several businesspeople noted that because of the role that local government plays in economic decisions in China, the involvement and opinions of government officials are considered to be a far more important factor by the Chinese than by their New Zealand counterparts.

Indeed the value for New Zealand businesses of NZTE and MFAT acting as facilitators of introductions that it was one of the easiest and most beneficial ways they could improve their relations with local officials and their Chinese customers. For the Chinese, the face to be gained from attending a function with high-level representatives of a country with good relationships with China was important, as their attendance raised the profile of the event. Of course, from the Chinese perspective, that the New Zealand businesspeople were able to invite along high-ranking officials also improved the New Zealanders' status. It was felt that because of these meetings and the connections made at them between local government officials and 
businesspeople in China, opportunities would be created for the participating New Zealand firms.

Lacking an established set of relationships to facilitate introductions, companies that are new to China need to build guanxi in order to break into the market. The involvement of MFAT and NZTE staff, as well as sister city visits, demonstrates an example of the building of guanxi between New Zealand firms, companies and local governments in China, or 'altercasting' as Yeung and Tung labelled it. This tactic, as reported by many of those interviewed for this project appears to be proceeding well.

The example of the New Zealand firm that invited the Consul-General to a contract signing, thereby raising the profile of the event so that the president of the company attended, is an example of a New Zealand firm adapting practices to local culture for their own benefit. People holding high positions within government command a lot of respect in China and their involvement in any project adds respectability and status to it. Lacking many of the traditional relationships that facilitate introductions and business in China, working with New Zealand officials appears to be a way that firms can establish that respect.

The connections that are being developed between New Zealand firms and staff from MFAT, NZTE and local government representatives bear striking resemblance to the localistic networks that Wank described developing in Xiamen in the nineties. It seems highly probable that having seen the close connections between local governments and firms, New Zealand businesses and government have replicated a similar system, an example, if you will of 'if you can't beat them, join them.'

Entrants to the Chinese market are known to struggle, as they lack the networks that many Chinese businesses utilise. The presence of high-ranking New Zealand officials brings status to events hosted by New Zealanders. This 
in turn increases the likelihood of Chinese officials and businesses being present, giving businesses more opportunities to build their own networks and develop opportunities.

Confirming previous studies - Tsang or Wank for example - this project has identified that guanxi appears to have diminishing returns over time; firms that were less than five years old placed greater importance on the development of guanxi than well-established firms. If the role of state is as important as Huang argues it is, events hosted or attended by New Zealand representatives give New Zealand firms the opportunity to develop guanxi with people who could offer significant help to firms new to their market. If they are able to demonstrate how their business plans can assist the economic development plans of government officials this could give them greater comparative advantage.

While the guanxi that could be developed through visits from New Zealand officials was a consistent theme with both officials and businesspeople that I interviewed, many felt that it was an opportunity that New Zealanders not in China underestimated and were not making enough of. Relationships with local government were seen as very valuable to the firms in China. Those with permanent representatives in China thought that other firms who were dealing with China, but lacked staff permanently based in China, were overlooking the opportunities that these connections created. As one said,

I think the [NZ companies] that are here permanently and have teams on the ground are getting good at [dealing with local government officials] because they've realized it's a key to success. I think the ones that haven't got full time resources on the ground are just going backwards rapidly really; I mean they need to be here to understand to figure out what's important and what's not important. 
Several of those interviewed also commented that sister city relationships are not valued as highly by New Zealanders as they are by the Chinese and that New Zealanders should recognise the opportunities that can come from them.

I don't think we understand the value in the sister city relationships and the leveraging those sister city relationships. You know...the mayor of Dunedin has got the right to meet the mayor of Shanghai whenever he comes here. You've got Christchurch and Wuhan, Waitakere and Ningbo. You've got a number of these relationships... a bit like the FTA...the Chinese take them a lot more seriously than we do. It's government relationships and they look to government for direction, so if the government says deal with Christchurch, they'll deal with Christchurch. They are opening a privileged thoroughfare there that we should be racing to get into and engaging and I know a lot of groups that are, but again we're not taking them or using them anywhere near as seriously as the Chinese will.

A 2008 report from Local Government New Zealand detailed the state of many of these relationships and found that the New Zealand cities were struggling to deal with the size differences that existed with their Chinese peers (Matthews, Murphy, Harris and Beaman, 2006: 8-9). It seems that the size comparison creates a perception problem when dealing with interactions at this level for New Zealand firms.

Those interviewed in Shanghai were particularly keen on the role that MFAT, NZTE and mayors visiting China could play in facilitating introductions. While New Zealanders tend to overlook sister city relationships because of the low-profile role that mayors and councils play in New Zealand politics, the same is not true in China where mayors play a very important role because of the decentralisation of the Chinese state. An appointment as mayor of a major city is an indicator of a politician who has been selected as a 
possible candidate for future high-level positions within the CPC.60 One businessperson noted that whereas Prime Minster Key was unable to meet the Mayor of Shanghai, Han Zheng, through the sister city relationship the Mayor of Dunedin, Peter Chin, had met him in October of 2009 and April 2005. This was likely to be repeated again as Chin had invited Han to meet his delegation at the New Zealand pavilion at Shanghai Expo.61

In comparison the businesspeople in Xiamen, which lacks representation by New Zealand government officials, felt that more assistance would be very beneficial to them. They felt the relationship they had developed with Xiamen city officials was very positive, but, once again, that local officials in Xiamen placed more value upon it than their counterparts in Wellington did. Wellington is Xiamen's second-oldest sister city relationship and a strong relationship between the local government and the New Zealand community there was evident, but did seem to rely on a few key individuals who were very active in maintaining the links, while another representative of the New Zealand China Trade Association was active in promoting Xiamen in Wellington. One of the New Zealand businesspeople in Xiamen had been attempting for several years to get a New Zealand carving erected in a Xiamen city park that celebrated its relationships with other cities around the world. However, the Wellington City Council had been reluctant to offer financial support to the project.62

As previously discussed, though, while positive relations developed with local government were seen as helpful, at the end of the day decisions made by local government are only part of the equation. The unknown quantity in these issues is the degree to which the Chinese company that a New Zealand

\footnotetext{
${ }^{60}$ Jiang Zemin was Mayor of Shanghai and Vice-Premier (and likely successor to Wen Jiabao) Wang Qishan was Mayor of Beijing. Three of the nine members of the current Politburo Standing Committee of the CCP have held mayoral positions in the past Jia Qinglin - Beijing, Li Changchun - Shenyang, and Zhou Yongkang - Panjin.

61 "Otago to have presence at World Expo" Otago Daily Times 13 May 2010. The two mayors also meet each other in April, 2005.

62 Personal Correspondence, May 2010.
} 
firm is dealing with interacts with local government officials, and whose opinion takes precedent and to what degree. One consultant's opinion was that while the FTA greatly enhanced the prestige of New Zealand and New Zealanders in the eyes of officials, he felt that the prestige an official would gain by having a US firm set up in their jurisdiction would still outweigh that of a New Zealand company. Again, this was a problem related to the small size of most New Zealand firms, as the scale of most American firms and the potential benefits to the local district would likely far outweigh those that most New Zealand enterprises would offer.

Another reason given for making sure a good relationship with local officials existed was because so many changes are occurring in the regulatory environment in China. These changes affected negotiated agreements with local government or with business partners. This inevitably leads to either conditions having to be renegotiated or a compromise having to be established. In this situation a strong and healthy relationship between the parties was most likely to be able to accommodate everyone's goals within the new reality.

Engaging with local officials and maintaining good relationships is positive for companies in three ways. It opens up the opportunity for favourable interpretations of legislation. This does not mean engaging in activities that could be construed as illegal, but acknowledges that in China laws and regulations are written to allow flexible implementation by local authorities, as has traditionally been the case, especially since the reform era began, so that maximum economic gains can be made. Moreover, by taking into account local objectives and working with government it is less likely that laws will be interpreted so as to adversely affect a company. Good guanxi with local officials also broadens a firm's network, meaning that a firm can be introduced to more opportunities that exist in the area. 
The positive reaction of those interviewed could be attributed in part to the fact that as a group, New Zealanders in China are on the receiving end of the benefits of the FTA but suffering few of the costs. The costs of an FTA, such as increased domestic competition and cheaper imported goods that can threaten native business, do not affect this group. Kawai and Wignaraja for example, found that firms perceived that the greatest gains from preferential trading agreements came from increased market access and preferential tariffs (2009: 16), something that those interviewed are well positioned to gain from because their businesses are based in China. Furthermore, they also suggest that firms overweight the perceived benefits but undervalue the real costs, while larger firms have more complaints than smaller firms (2009: 16-18).

The strength of relationships between the governments of New Zealand and China

The most positive effect of the FTA was articulated by those I interviewed when discussion moved to the effects of the FTA on the relationship between the governments of New Zealand and China. All those interviewed were extremely positive about the position that the New Zealand Government had established for itself, except one, who felt that now the FTA discussions had been concluded there would be less opportunity for engagement between the governments of the two countries:

When we were negotiating the FTA it gave us a reason for Chinese officials to meet with us because we were in the process of doing this thing. Now that the thing has been completed, it's kind of past history effectively. We always knew there would be a one or maybe two year time frame when New Zealand would have a very positive feeling in the mind of Chinese officials in that this was an opportunity to really push things. Now that the agreement has been done and dusted, I guess our special thing that we provide is maybe not there anymore. 
This point of view was seemingly being refuted though by the efforts of New Zealand representatives who were using the FTA as a reason to increase contacts with officials in areas outside of the tier one cities that had not yet been the focus of much attention. Trade delegations visited three cities in the last six months of 2009, following on the heels of Prime Minister John Key's visit to China in April of the same year, which also included a number of representatives from New Zealand's business community. New Zealand officials were also keen to continue to maintain the high profile the country had received following the FTA, with a large presence in the Shanghai Expo in 2010 and also large campaigns promoting New Zealand as a tourism destination in Shanghai and Beijing.

The two-year time frame for New Zealand to benefit from the FTA was based largely on the belief that Australia or a similar-sized developed economy would quickly follow New Zealand in procuring a trade deal with China. However, by the time my field research was taking place, in the wake of the Rio Tinto scandal, this was no longer the case. Those who claimed to have reasonably good connections to officials seemed very sceptical that larger developed economies would be inking an FTA anytime soon with China:

The Chinese put a meat ban on America about six years or more and from the people I speak to there's not a sign on anyone's horizon that it's going to change in anytime that anyone can think of. I don't know what's going on behind the scenes, but that's a major political issue and it's not going to go away. And when there's no real justification for it in China that means there's another reason for it which is a lot stronger. Like the Aussies, the Aussies are not going to get an FTA for as long as I'm going to be here, and I don't know how long that's going to be so...first they said they were going to be first and then they were going to be right after us, look at the politics that's going on with the fall out of Rio Tinto." 
Indeed, it increasingly appears that relations between Beijing and Wellington, rather than having peaked with the FTA, are continuing to develop. There has been a notable focus on China since the Key Government took over the Treasury benches in Wellington. A strengthening relationship between the two states at the official level has been demonstrated a number of times since the FTA was signed. New Zealand's Prime Minster, John Key, made China one of his first official visits, meeting both $\mathrm{Hu}$ Jintao and Wen Jiabao. He has travelled twice more to China, including a visit to the Shanghai Expo in 2010. Five other high-level ministerial delegations were scheduled to visit the Expo as well (Groser, 2010).

One of the clearest signs of the strengthening relationship occurred in May 2010 when New Zealand's Trade Minister and Minister responsible for Climate Change Negotiations, Tim Groser, was invited by Premier Wen to talks with India, Indonesia, South Africa and Brazil on climate change. New Zealand was the only developed nation present at the talks between the large developing nations, whose size made New Zealand's inclusion all the more apparent. This indicates the unique nature of New Zealand's relationship with China, especially when compared to other Western states.63 New Zealand also reportedly received support from Vice-Premier $\mathrm{Xi}$ Jinping during his June 2010 visit to New Zealand for its bid to gain a seat on the United Nations Security Council in 2015.64 Another sign is the prominent position that was given to New Zealand in the headline event for 2010 in China, the Shanghai World Expo.

As the first developed economy to sign an FTA with China, New Zealand appears to have firmly established itself as a 'friend of China', one that stands in a unique position, especially in comparison to other western nations. This view was reflected particularly by one Chinese official I interviewed:

\footnotetext{
63 "NZ minister defends China's climate change image" Radio New Zealand News 9 May 2010.

${ }^{64}$ Fran O'Sullivan “China Ready to back NZ's UN bid” New Zealand Herald 19 June 2010.
} 
Why do you think that New Zealand was chosen by China as the first country to sign an FTA with? The most important reason is that New Zealand is regarded as the most-friendly country for China. The second reason is that New Zealand and China have no economic or trade conflicts, we have no conflicts. What we have are joint interests. No conflicts of interest, no arguments over trade, and here in China, not just in Shanghai, New Zealanders are regarded as the most peace-loving and friendly people in the world.

In other words, the New Zealand government has done very well out of the FTA process and is now viewed very favourably by the Chinese government and its people. There seemed little doubt amongst those interviewed that the signing of the FTA had raised considerably New Zealand's profile amongst the Chinese. One long-term Chinese businessperson felt that knowledge of the FTA was common amongst a wide range of people, and that the FTA signalled to the Chinese people that their government had extended a hand of friendship to New Zealand and, therefore, they in turn should treat New Zealanders more favourably because of this. That the FTA is well known seems unlikely, however, as, when asked a similar question about knowledge of the FTA amongst customs officials, the expectation was that it was unlikely that they were very familiar with the agreement or even its very existence, let alone the details.

It appears likely indeed that the FTA has greater symbolic value to the Chinese Government than it does to New Zealand. That New Zealand was the first developed economy that China choose to sign an FTA with demonstrates a strong relationship for the Chinese, ${ }^{65}$ whereas for most New

\footnotetext{
65 Indeed the Chinese have long held New Zealand in a favourable light, which can partly be traced back to the work of Rewi Alley. Alley was one of the few foreigners allowed to remain in China following the CPC's victory against the KMT in 1949 based upon his service during the civil war and his work in education and assistance in setting up the Gung Ho (工合) cooperatives.
} 
Zealanders, including government officials in New Zealand, China's importance still seems to be discussed almost entirely in economic terms.66

Western perspectives of what a signed document means can vary considerably from the Chinese perspective. For the Chinese, an agreement is often seen as a symbolic act that signals the evolution of a relationship, but is not viewed as binding and can be renegotiated at any time (Cunningham, 2005; MacKenzie, 2005). One interviewee directly raised the possibility that New Zealand and China probably had different interpretations of what it was that the agreement meant. China's other FTAs, he argued, were a measure of the relationship that existed between the countries, citing ASEAN as an example. ${ }^{67}$

Conversely, New Zealand's main trading agreement is CER with Australia, a country with which it has strong, multifaceted ties and where the largest number of New Zealanders can be found living outside of New Zealand. The economic benefits that flow from the trading relationship between Australia and New Zealand are the focus of CER, while the strength of the relationship is measured in other areas like the countries' shared histories, geographic location and similar cultures.

So far only two events have placed any strain on the relationship between China and New Zealand. The first of these was the melamine scandal, centred on the San Lu Group (三鹿集团), which New Zealand's largest company, Fonterra, had a forty percent share of. ${ }^{68} \mathrm{New}$ Zealand and Fonterra remained relatively unaffected by the scandal however, as most of the blame was directed towards the Chinese executives of San $\mathrm{Lu}$. This possibly reflected the fact that it was from New Zealand that Beijing first learned of the issue.

\footnotetext{
${ }^{66}$ As discussed earlier in the section detailing expectations from FTAs, announcements by the likes of Prime Minister Helen Clark and Trade Minister Phil Goff described the benefits to New Zealand almost exclusively in economic terms.

${ }_{67}$ Personal Interview, Shanghai, December 2009.

${ }^{68}$ For more on the melamine scandal and its effect on Fonterra, see Fran O'Sullivan "So long, Sanlu" New Zealand Herald, 2 May 2009.
} 
Following the scandal, New Zealand Prime Minister John Key visited Beijing on a tour. During an official dinner he took Fonterra's Chairman, Henry van der Hayden, to the head table to discuss their problems with Premier Wen. The outcome of this discussion was that New Zealand undertook to assist China with advice on food safety issues, an offer warmly received by the Chinese. ${ }^{69}$ The second event was far more minor, but involved a protesting New Zealand MP scuffling with a Chinese security team as China's VicePresident Xi Jinping visited the Beehive. Interestingly, this incident was not reported in the Chinese media, except in the English China Daily, reflecting perhaps China's desire to play the incident down.

${ }^{69}$ In comparison the problems related to mining giant Rio Tinto reflected far more poorly on Australia. It was rumoured that the arrests were a response to the refusals of Rio Tinto to allow Chinalco to increase its stake in Rio Tinto. For the Rio Tinto bribery case, see "Rio Tinto's Stern Hu jailed for 10 years" The Australian 29 March 2010. 


\section{Conclusions}

Since Douglas Guthrie wrote his response to Mayfair Yang's Gifts, Favours and Banquets, much debate over the development of guanxi and its role in China's developing economy has taken place. Much in China has also changed. The growth in China's economy has brought it into the global economic system and membership in the WTO necessitated substantial changes to laws pertaining to its economy and foreign investment. As China's development continues it is likely that it will integrate further and sign trading agreements with other developed economies as it has with New Zealand.

In Part I we examined the New Zealand-China FTA and its effects on New Zealand's exports to China. When it was signed, many praised New Zealand negotiators for having secured a deal that offered New Zealand a number of wins. Even in the middle of one of the most troublesome times in the global economy for decades, New Zealand's exports to China during the first year of the agreement exceeded the predicted 39\% increase, increasing $44 \%$. The current literature on FTAs has focused on the static gains that arise from the removal of tariffs and non-tariff barriers. More recently, the economic literature has sought to explain how dynamic gains contribute to the longterm benefits of preferential trading arrangements. This study has identified that the growth in exports cannot be solely attributed to static gains, while it is too soon for dynamic gains to have been realised.

Part II of this thesis demonstrated how political, legal and cultural conditions in China are markedly different from New Zealand. Laws and regulations are often not as black and white as they are in New Zealand and local officials often act at cross-purposes to their superiors in Beijing. Street-level bureaucrats also wield significant discretionary powers that can both help and hinder firms. Due to the move away from a command economy, decentralisation of economic decision-making has meant that local 
government officials have responsibility for most decisions that affect SMEs. Their positions also mean that they are capable of making connections between businesses that foster economic activity. These differences make the informal relationships individuals and businesses develop more important because warm relationships with local officials and street-level bureaucrats can assist firms to broaden their opportunities and ease bureaucratic burdens.

This thesis has sought to determine whether the strength of the relationship that exists between China and New Zealand has had benefits for New Zealand SMEs operating in China. The FTA has certainly helped Wellington strengthen its relationship with Beijing; on all fronts; things have never been better between the two countries. But as Part II demonstrated, there are situations where there is a wide gulf between the promises Beijing aspires to deliver and the objectives of sub-national governments and officials.

Part III of this thesis revealed the findings of interviews with businesspeople and officials currently operating in China. The research shows that when dealing with street-level bureaucrats, there is no sign that the FTA has had much impact on relations. However, as firms engage with officials at higher levels the influence of the FTA becomes more pronounced. It is at these higher levels that collaboration between New Zealand government representatives and businesses appears to be paying off the most, and perhaps it is at this level, a level that economic models offer little insight on, that some of the unpredicted gains by New Zealand exporters are perhaps being achieved.

The subjects of this study reported problems getting their products through customs; rather than improving customs procedures, it appears that the FTA's early implementation period proved troublesome for importers of New Zealand products. The subjects suggested that this was due to CIQ as a department being revenue-orientated and the remunerated of its staff being based upon revenue collection; these motivations have stood in the way of 
New Zealand goods receiving the treatment accorded under the FTA. Problems with documentation have also caused delays in goods getting across the border as customs officials sought opportunities to impose tariffs.

The FTA has had no discernable effect when dealing with street-level bureaucrats. Moreover, attempts to use the FTA when there was disagreement over laws or regulations could well backfire on the company. When dealing with street-level bureaucrats the subjects instead emphasised the need to respect the authority of the person they were dealing with and cultivate a warm and friendly relationship. While this approach has much in common with the development of guanxi, the subjects accentuate the relationship aspect of guanxi, rather than instrumentalist aspects more associated with guanxixue.

Although street-level bureaucrats are seldom in a position to help a business, their capacity to create problems is quite large. One of the interesting findings from this study was how the subjects believed that by doing their best to comply with local regulations and having a helpful approach with street-level bureaucrats, they were develop a new bond or status based upon their reputation. Reputation (mingyu) implies being a company that is not obstructive, complies as much as possible with a bureau's rules and seeks to be, shall we say, a 'good corporate citizen'.

By seeking to develop a good reputation firms made the street-level bureaucrat's work much simpler. In the past dealings with street-level bureaucrats were often problematic and marked with the imposition of small fines or charges. Problems may have been resolved with small bribes or perhaps dinners. This change in approach may signal that the crackdown on corrupt activities over the last decade may be having an effect. At the very least, it has made street-level officials wary of the risks corruption poses to their position and they may be calculating that attempting to do so with small foreign companies is not worth the risk. Such behaviour demonstrates that 
Guthrie's prediction that individuals would use guanxi less as China's economic and legal institutions strengthened may be correct. However, in line with Wank's (2002) criticism, it does not demonstrate that firms are moving towards using these institutions, only that they are moving away from guanxi because street-level bureaucrats perceive the risk to be too great while firms may believe that the costs in time and resources of guanxi do not offer certainty of returns. Businesspeople seeking to enhance their reputation represents a change in informal behaviour, rather than a strengthening of formal institutions.

At the local government level guanxi still appears to be significant and it is at this level where subjects provided the most positive feedback in regards to the effect of the FTA. Having the opportunity to meet with and develop guanxi with local officials was highly valued because firms believed it assisted them to meet potential clients and develop their presence in the market. The NZCFTA has assisted New Zealand government representatives to assist firms by lifting their status within China, thereby allowing them to meet with more Chinese officials. Even though these visits do not offer the same financial returns as great as larger firms from larger countries, they do entice Chinese officials to meet with New Zealand's representatives who visit China or are based in China because of their high status. New Zealand firms too appear to be benefiting as well through their involvement with trade delegations.

The interview subjects also responded favourably when asked about trade missions. Unfortunately there is scant information compiled on the outcomes of the various trade missions that take place via sister city relationships, while NZTE has only just recently begun to examine the commercial benefits that have resulted from its various efforts to boost trade with China. Most of the information that has been collected cannot be released because of its commercially sensitive nature. What information is publicly available indicates this may in fact be the case. An annual fair held in Shanghai for New 
Zealand food and beverage companies, for example, saw the number of companies more than double, despite far stricter standards for the companies wishing to be involved..$^{0}$

Interviews with New Zealanders in China revealed that despite the issues over tariffs and access, the FTA was very popular. Almost all of the Kiwis spoke of the benefits that the FTA had brought to in terms of relationships with the Chinese. Further study of this is required to determine whether relationships are really capable of bringing such large benefits to firms from a country that has recently signed an FTA. While New Zealand's progress on signing FTAs with other states seems set to continue, it is possible that China is a unique case, given the involvement of the state in guiding economic development and the embededness of guanxi. As such, comparisons to other developed economies signing FTAs with China may provide more insights.

At the local level, officials are focused on reaching local objectives of economic growth, employment and development. At this level officials can see advantages of working with a foreign company that can assist them to meet their goals. A problem for many New Zealand firms has been breaking into the Chinese market, so it is notable both that it was the firms that were newer to China who felt that guanxi was more important, and that these same firms expressed the most enthusiasm for how the FTA was helping them extend their contacts with local government officials.

The small size and composition of the group studied limits the ability to draw conclusions about what is happening with far larger companies who sell significant quantities of goods that constitute a far larger percentage of New Zealand goods than those who were interviewed for this study. Most of these companies are reluctant to share much about their China operations so it is very difficult to obtain either figures about their commercial activities or their opinions and experiences. It is quite possible that these larger companies are

${ }^{70}$ Personal correspondence, June 2010. 
not having the same difficulties as the smaller companies interviewed for this study. If and when they encounter difficulties, it is likely that they have the resources and connections to have problems solved quickly. If this is the case, they would be receiving the benefits of lower tariffs and better access. It is also likely that they are receiving the benefits that this study has highlighted.

These issues should be considered and further examined as New Zealand signs future trade deals with other countries. The recently signed FTA with Malaysia, the Closer Economic Partnership with Hong Kong, and the likelihood of an agreement soon being reached with India offer such opportunities. Although these states have their own distinct cultural and political traditions, they offer the chance to once again examine the behaviour of New Zealand firms, the economic effects of an FTA and the changes to the relationships between government officials and businesspeople based overseas.

Beyond the trade benefits, the FTA represents an investment by the New Zealand government in social capital with the Chinese government, one that appears to be paying dividends. The Key Government has already achieved a number of small diplomatic successes and despite initial fears that New Zealand would fall out of the spotlight after the FTA was completed, has managed to maintain a high level of interaction with Chinese officials. Turning these events into long-term gains is possible given the positive light that New Zealand is now seen in China.

To capitalise on the FTA with China, to transition from the guanxi that was established through the FTA, New Zealand firms and government officials need to move to the next stage - guanxixue, or to la guanxi. To do this, the government and enterprises should utilise a different approach than the one they use in their traditional markets. Such a model needs to acknowledge the role that the Chinese state plays in the economy and use the strength of existing informal relationships to create a comparative advantage for New 
Zealand firms, as it appears that benefits that can be achieved thereby may well be not fully appreciated or understood by traditional models that have sought to judge the value of preferential trading agreements up to now. This study has revealed that this appears to already be occurring in the locations studied. 


\section{Bibliography}

Abramson, Neil and Janet Ai (1999) 'Canadian Companies Doing Business in China: Key Success Factors', Management International Review 39 (1): 7-35.

Acland, Henry (2009) Growing Appetites http://www.asianz.org.nz/ourwork/action-asia-business/action-asia-insights/growing-appetiteschina (Date accessed: 18 March 2010).

Ahlstrom, David, Garry D. Bruton and Steven S. Y. Lui (2000) 'Navigating China's Changing Economy: Strategies for Private Firms' Business Horizons January-February: 5-15.

Anderton, Jim(2003) China - New Zealand education relationship further cemented http://www.beehive.govt.nz/release/china+nz+ministers+sign+arrang ement+technical+barriers+trade (Date accessed: May 25 2010).

Au, Alan Kai Ming and Peter Enderwick (1994) 'Small Firms in International Joint Ventures in China: The New Zealand Experience' Journal of Small Business Management 32: 88-94.

Asian Development Bank (2002) Asian Development Outlook 2002, Asian Development Bank.

Bhagwati, Jagdish and Arvind Panagariya (2003) Bilateral trade treaties are a sham http://www.cfr.org/publication/6118/bilateral_trade_treaties_ are_a_sham.Html (Date accessed: 13 February 2010).

Bjorkman, Ingmar and Soren Kock (1995) 'Social Relationships and Business Networks: the Case of Western Companies in China' International Business Review 4: 519-535. 
Boisot, Max and John Child (1996) 'From Fiefs to Clans and network Capitalism: Explaining China's Emerging Economic Order' Administrative Science Quarterly 41: 600-628.

Burns, Diana (2009) China trade powers up http:/ / www.nzte.govt.nz/featurescommentary/Features/Going-global/Pages/China-trade-powersUp.aspx?pageId=1 (Date accessed: 10 June 2010).

Bruun, Ole (1995) Business and Bureaucracy in a Chinese City: An Ethnography of Private Business Households in Contemporary China, RoutledgeCurzon.

Cai, Hongbai and Daniel Treisman (2006) 'Did Government Decentralisation Cause China's Economic Miracle?' World Politics 58: 505-535.

Chow, Gregory C. (2005) 'Corruption and China's Economic Reform in the Early $21^{\text {st }}$ Century' CEPS Working Paper no. 116.

Chung, Henry F.L. (2003) 'International Standardization Strategies: The Experiences of Australian and New Zealand Firms Operating in the Greater China Markets' Journal of International Marketing 11 | 3: 48-82.

Clark, Donald, Peter Murrell and Susan Whiting (2008) 'The Role of Law in China's Economic Development' in China's great economic transformation, by Loren Brandt, Thomas G. Rawski (eds) Cambridge University Press.

Clark, Helen (2004) 'New Zealand and China to work towards FTA' http://www.beehive.govt.nz/release/new+zealand+and+china+work+ towards+fta. (Date accessed: 25 May 2010).

Clark, Helen (2008) 'NZ-China Free Trade Agreement' http://www.beehive.govt.nz/feature/nz-china+free+trade+agreement. (Date accessed: 25 May 2010). 
Corne, Peter Howard (1997) Foreign investment in China: the administrative legal system Hong Kong University Press.

Cox, Gary and Matthew McCubbins (2001) 'The Institutional Determinants of Economic Policy' in Presidents, Parliaments, and Policy: Political economy of institutions and decisions in Stephan Haggard and Mathew Daniel McCubbins (eds), Cambridge University Press.

Cremer, Rolf D. and Bala Ramasamy (2005) Effective Strategies for New Zealand Firms in China http://www.asianz.org.nz/our-work/knowledgeresearch/research-reports/business-research (Date accessed: 14 December 2009).

Cunningham, Vince (2005) To sign or not to sign http://www.cbbc.org/the_review/review_archive/business_guides/31 .html (Date accessed: 10 June 2010).

Desker, Barry (2004 ) 'In defence of FTAs: from purity to pragmatism in East Asia' The Pacific Review 1: 3-26.

Fernández, Raquel (1997) ‘Returns To Regionalism: An Evaluation Of Nontraditional Gains From Regional Trade Agreements' World Bank Policy Research Working Paper No. 1816.

Gao, Hongzhi (2009) Guanxi Dilemmas and Gatekeepers: A Qualitative Study of Chinese-Western Relationships in Marketing University of Otago.

Goff, Phil (2003) 'NZ signs consular agreement with China' http://www.beehive.govt.nz/release/nz+signs+consular+agreement+c hina (Date accessed: May 25 2010).

Goff, Phil (2008) ‘Strong support within Parliament for Free Trade Agreement' 
http://www.beehive.govt.nz/release/strong+support+within+parliam ent+free+trade+agreement (Date accessed: May 25 2010).

Gold, Thomas, Douglass Guthrie, and David Wank, David (2002) Social Connections in China, Cambridge University Press.

Gong, Ting (2004) ‘Dependent Judiciary and Unaccountable Judges: Judicial Corruption in Contemporary China' The China Review 4 (2): 33-54.

Goodman, David S. G. and Segal, Gerald (1994) China deconstructs: politics, trade, and regionalism, Routledge.

Goodman, David S. G. (2009) 'Sixty years of the People's Republic: local perspectives on the evolution of the state in China' The Pacific Review 22 (4): 429-450.

Groser, Tim (2010) 'Address to KEA China' http://www.beehive.govt.nz/speech/address+kea+china (Date accessed: May 18 2010).

Grossman, G. and E. Helpman (1991) Innovation and Growth in the World Economy, MIT Press, Cambridge, USA.

Guo, Sujian (2006) China's "peaceful rise" in the 21st century: domestic and international conditions, Ashgate Publishing Ltd.

Guthrie, Douglas (1998) 'The Declining Significance of Guanxi in China's Economic Transition' The China Quarterly 154: 254-282.

Guthrie, Douglas (2001) Dragon in a three-piece suit: the emergence of capitalism in China, Princeton University Press. 
The Heritage Foundation (2010) 'Index of Economic Freedom, 2010' http://www.heritage.org/index/Ranking.aspx (Date accessed: 14 July 2010).

$\mathrm{Hu}$, Jintao (2007) Hold High the Great Banner of Socialism with Chinese Characteristics and Strive for New Victories in Building a Moderately Prosperous Society in All, report at the 17th Party Congress.

Huang; Yasheng (1990) 'Web of Interests and Patterns of Behaviour of Chinese Local Economic Bureaucracies and Enterprises during Reforms' The China Quarterly 123: 431-458.

Huang, Yasheng (1996) 'Central-Local Relations in China During the Reform Era: The Economic and Institutional Dimensions' World Development 24 (4) 655-672.

Huang, Yasheng (2003) ‘One country, two systems: Foreign-invested enterprises and domestic firms in China' China Economic Review 14: 404416.

Huang, Yasheng (2008) Capitalism with Chinese Characteristics: Entrepreneurship and the State Cambridge University Press.

Hutchings, Kate and Georgina Murray (2002) 'Australian Expatriates' Experiences in Working Behind the Bamboo Curtain: An Examination of guanxi in Post-communist China' Asian Business \& Management 1: 373393.

Jacobs, Gabriele, Frank Belschak and Barbara Krug (2004) 'Social Capital in China: The meaning of guanxi in business' in Barbara Krug (ed) China's Rational Entrepreneurs: The Development Of The New Private Business Sector London, New York, RoutledgeCurzon. 
Jarrett, Kenneth and Huihan Lie (2009) 'Understanding China's Changing Civil Service' China Business Review 36: 36-39.

Jiang, Yang (2008) ‘China's Free Trade Agreements and Implications for the WTO' paper presented at the annual meeting of the ISA's 49th Annual Convention, Bridging Multiple Divides, San Francisco, CA.

Ju, Y. (1995) Communicating change in China, quoted in Tsang W.K. 'Can Guanxi be a source of sustained competitive advantage for doing business in China?' The Academy of management Executive (1998) 12 (2): 64-73.

Kawai, M., and G. Wignaraja (2009) 'The Asian "Noodle Bowl”: Is It Serious for Business?' ADBI Working Paper 136 Tokyo: Asian Development Bank Institute.

Key, John (2009) 'Speech to Federated Farmers National Council' http://www.beehive.govt.nz/speech/speech+federated+farmers+natio $\underline{\text { nal }+ \text { council+0 }}$ (Date accessed: June 29, 2010).

Kong, Qingjiang (2001) 'Enforcement of WTO Agreements in China: Illusion or Reality?' Journal of World Trade 35 (6): 1187-1214.

Kong, Tao (2005) 'Political Institutions and Economic Growth' in Ross Garnaut and Ligang Song (eds) The China Boom and its Discontents Canberra: Asia Pacific Press.

Krug, Barbara (2000) 'The Interdependence Between Political and Economic Entrepreneurship' Erasmus Research Institute of Management Report Series Research in Management No. ERS-2000-43-ORG. Available at SSRN: http://ssrn.com/abstract $=370852$. 
Krug, Barbara and Hans Hendrischke (2008) ‘Framing China: Transformation and Institutional Change through co-evolution' Management and Organization Review 4:1: 81-108.

Krug, Barbara (2009) 'Enterprise Ground Zero in China' in Barbara Krug and Hans Hendrischke The Chinese Economy in the 21st Century: Enterprise and Business Behaviour Edward Elgar Publishing.

Krugman, Paul (1994) 'The Myth of Asia's Miracle' Foreign Affairs (November/December): 62-78.

Langenburg, Eike A (2007) 'Guanxi and Business Strategy: Theories and Implications for Multinational Companies in China' from the series Contributions to Management Science Springer.

Lanteigne, Marc (2010) ' The Falcon and the Dragon' draft paper, soon to be published in The China Quarterly.

Li, Lianjiang (2004)`Political Trust in Rural China' Modern China 30 (2): 228258.

Liao, Lei and Yuming Che (2004) China makes breakthrough in market economy status Xinhua News Agency.

Lieberthal, Kenneth (2006) 'Completing WTO Reforms' China Business Review, (Sept.-Oct): 52-58.

Lipsky, Michael (1980) Street-level bureaucracy: dilemmas of the individual in public services; Russell Sage Foundation.

Luo, Yadong (2007) Guanxi and Business, Volume 5 of Asia-Pacific Business Series, World Scientific. 
Martin, Brett and Larsen, Gretchen (1999) 'Taming the tiger: key success factors for trade with China' Marketing Intelligence E Planning 17 (4): 202 $-208$.

Maharey Steve (2003) China - New Zealand education relationship further cemented http://www.beehive.govt.nz/release/china++new+zealand+education+relationship+further+cemented (Date accessed: 25 May 2010).

Mahon, David (2009) China and New Zealand http://www.mahonchina.com/chinaWatch.html (Date accessed: 9 June, 2010).

Mahon, David (2010) China Watch: 90, Available from http://www.mahonchina.com/chinaWatch.html.

Martin, Will (2003) 'China's Accession to the WTO: Impacts on China' in Kathie L. Krumm and Homi J. Kharas (eds) East Asia Integrates: A Trade Policy Agenda For Shared Growth The World Bank.

Matthews, Roger, Kevin Murphy, Peter Harris and Sarah Beaman (2006) Sister City Relationships and Opportunities, between Chinese and New Zealand Cities: A paper for the Metro Sector of Local Government New Zealand available online at http:/ / www.sistercities.org.nz.

MacKenzie, John (2005) Worth the paper it is written on? http://www.cbbc.org/the_review/review_archive/business_guides/31 .html (Date accessed: 10 June 2010).

Maynard-Moody, Steven (1990) 'Street-Wise Social Policy: Resolving the Dilemma of Street-Level Influence and Successful Implementation' The Western Political Quarterly 43 (4): 833-848. 
Millington, A., M. Eberhardt and B Wilkinson (2005) 'Gift Giving, Guanxi and Illicit Payments in Buyer-Seller Relations in China: Analysing the Experience of UK Companies' Journal of Business Ethics, 57:255-268.

Ministry of Commerce (People's Republic of China) and Ministry Of Foreign Affairs And Trade (New Zealand) (2005) Joint Study Report on the Free Trade Agreement between China and New Zealand available from http:// www.mfat.govt.nz/Trade-and-Economic-Relations/TradeAgreements/China/index.php.

Ministry of Commerce (People's Republic of China) and Ministry Of Foreign Affairs And Trade (New Zealand) (2008) New Zealand China Free Trade Agreement available from: http://www.chinafta.govt.nz/.

Ministry of Foreign Affairs and Trade (New Zealand) (2007) Our Future with Asia available from http://www.mfat.govt.nz/Media-andpublications/Publications/Asia-White-Paper/index.php.

Ministry Of Foreign Affairs And Trade (New Zealand) (2004) Free Trade Agreement with China: Release of Feasibility Study and Launch of Negotiations, Cabinet paper dated October 2004; obtained under the Official Information Act.

Ministry Of Foreign Affairs And Trade (New Zealand) (2004) China Free Trade Agreement (and Associated Instruments) National Interest Analysis available from http:/ / www.chinafta.govt.nz/1-The-agreement/index.php.

National Bureau of Statistics of China (2009) Statistical Communiqué of the People's Republic of China on the 2009 National Economic and Social Development 
http://www.stats.gov.cn/was40/gitij_en_detail.jsp?searchword=total+i mports\&channelid=9528\&record=1 (Date accessed: February 25 2010).

Nee, Victor (1992) ‘Organizational Dynamics of Market Transition: Hybrid Forms, Property Rights and Mixed Economy in China' Administrative Science Quarterly 37: 1-27.

New Zealand Statistics; Infoshare website. Available from:

http://www.stats.govt.nz/infoshare/.

Nordås, Hildegunn Kyvik (2006) 'Dynamic Gains from Trade' OECD Trade Policy Working Papers number 43, OECD.

North, Douglass C. (1994) 'Economic Performance Through Time' The American Economic Review 84 (3): 359-368.

North, Douglass C. and Barry R. Weingast (1989) 'Constitutions and Commitment: The Evolution of Institutions Governing Public Choice in Seventeenth-Century England' The Journal of Economic History 49:803832.

New Zealand Trade and Enterprise (2010) China Country Brief, March 2010. http://www.nzte.govt.nz/explore-export-markets/North-Asia/Doingbusiness-in-China/Pages/China-country-brief.aspx (Date accessed: 16 March 2010).

O'Sullivan, Fran (2010) China Ready to back NZ's UN bid http://www.nzherald.co.nz/opinion/news/article.cfm?c_id=466\&objec $\underline{\text { tid=10652855 }}$ (Date accessed: June 19 2010).

O'Sullivan, Fran (2009) So long, Sanlu http:/ / www.nzherald.co.nz/thefonterrafloat/news/article.cfm?c_id=1501678\&objectid=10569769\&pnu $\underline{m=0}$ (Date accessed: 18 February). 
Oi, Jean (1992) 'Fiscal reform and the economic foundations of Local State Corporatism in China' World Politics 45: 99-126.

Oi, Jean (1999) Rural China takes off: institutional foundations of economic reform, University of California Press.

The Otago Daily Times (2010) Otago to have presence at World Expo http:// www.odt.co.nz/news/dunedin/104242/otago-have-presenceworld-expo (Date accessed: May 16 2010).

Pearce, John and Richard Robinson (2000) 'Cultivating Guanxi as a Foreign Investor Strategy' Business Horizons 43 (1): 31-38.

Pistor, Katharina (2000) 'The Standardization Of Law And Its Effect On Developing Economies' G-24 Discussion Paper Series United Nations Conference on Trade and Development.

Radio New Zealand News (2010) NZ minister defends China's climate change image

http:/ / www.radionz.co.nz/news/stories/2010/05/09/124803b5571a (Date accessed: 10 May 2010).

Razeen, Sally (2006) 'Free Trade Agreements and the Prospects for Regional Integration in East Asia' Asian Economic Policy Review 1:306-321.

Ren, Xin (1997) Tradition of the Law and Law of the Tradition: Law, State and Social Control in China, Praeger Publishers.

Ribbonwood New Zealand (2010) Market Commentary, First Quarter http://www.ribbonwood.co.nz/market_commentary (Date accessed: 15 June 2010).

Rivera-Batiz, L. and P. Romer (1991) 'International Integration and 
Endogenous Growth' Quarterly Journal of Economics 106: 531-555.

Schiff, Maurice and Winters, L. Alan (1997) Regional Integration as Diplomacy World Bank.

Shi, Tianjian (2001) 'Cultural Values and Political Trust: A Comparison of the People's Republic of China and Taiwan' Comparative Politics 33 (4): 401419.

Shirk, Susan L. (1993) The Political Logic of Economic Reform in China University of California Press.

Smart Alan; Gifts (1993) 'Bribes, and Guanxi: A Reconsideration of Bourdieu's Social Capital' Cultural Anthropology 8 (3): 388-408.

State Council Information Office; China's Energy Conditions and Policies (2007 Energy White Paper), 2007.

The Australian (2010) Rio Tinto's Stern Hu jailed for 10 years http://www.theaustralian.com.au/business/mining-energy/rio-tintosstern-hu-jailed-10-years/story-e6frg9df-1225847088979 (Date accessed: April 1 2010).

The China Daily (2004a) Nation, New Zealand to launch FTA talks http://www.chinadaily.com.cn/english/doc/200411/22/content_393502.htm (Date accessed: June 8 2010).

The China Daily (2004b) Free trade talks with New Zealand start http://www.chinadaily.com.cn/english/doc/200412/07/content_398014.htm (Date accessed: June 8 2010). 
The National Business Review (2008) Distrust of local milkpowder offers gains for exporters http:/ / www.nbr.co.nz/article/distrust-local-milkpowderoffers-gains-exporters-35472 (Date accessed: 18 February 2010).

The New Zealand Herald (2009) Chinese company to buy 13pc stake in PGG Wrightson

http://www.nzherald.co.nz/business/news/article.cfm?c_id=3\&objecti $\underline{\mathrm{d}=10603576}$ (Date accessed: May 5 2010).

The New Zealand Herald (2010) Chinese want to buy $\$ 1.5 b$ NZ dairy empire http:/ / www.nzherald.co.nz/nz/news/article.cfm?c_id=1\&objectid=106 34177\&pnum $=0$ (Date accessed: May 5 2010).

The New Zealand Herald (2010) Key aims to double trade with China http://www.nzherald.co.nz/nz/news/article.cfm?c_id $=1$ Eobjectid $=10657156$ (Date accessed: August 6 2010).

The New York Times (2009) Chinese Trial Reveals Vast Web of Corruption http://www.nytimes.com/2009/11/04/world/asia/04crimewave.html (Date accessed: June 28 2010).

The New York Times (2010) Foreign Companies Chafe at China's Restrictions http://www.nytimes.com/2010/05/17/business/global/17lobby.html? pagewanted=1\&hp (Date accessed: May 16 2010).

The New Zealand Press Association (2008) Public divided over FTA, poll shows http://www.stuff.co.nz/national/339565 (Date accessed: 28 May 2010).

The South China Morning Post (2000) Criminal Empire Spread With Help From Friends in High Places 
http://www.scmp.com/portal/site/SCMP/menuitem.06f0b401397a029 733492d9253a0a0a0?vgnextoid=30c9f0ca823b1110VgnVCM100000360a0a 0aRCRD\&s=Archive (Date accessed: 13 July 2010).

Thun, Eric (2006) Changing lanes in China: foreign direct investment, local government, and auto sector development, Cambridge University Press.

Transparency International (2008) Corruption Perceptions Index, 2008 http://www.transparency.org/policy_research/surveys_indices/cpi/2 $\underline{008}$ (Date accessed: May 16 2010).

Unger, Jonathan and Chan, Anita (1995) 'China, Corporatism, and the East Asian model' The Australian Journal of Chinese Affairs 33: 29-53.

Walton, Julie (2008) ‘Managing Government Affairs' China Business Review 35 (5): 46-49.

Wang, Hongying (2000) 'Informal institutions and foreign investment in China' The Pacific Review 13 (4): 525-556.

Wank, David L. (1995) ‘Private Business, Bureaucracy, and Political Alliance in a Chinese City' The Australian Journal of Chinese Affairs 33: 55-71.

Wank, David L. (1996) 'The Institutional Process of Market Clientism: Guanxi and Private Business in a South China City' The China Quarterly 147: 820-838.

Wank, David L. (2002) 'Business-State Clientism in China: Decline or Evolution?' in Thomas Gold, Douglass Guthrie and David Wank (eds) Social Connections in China, Cambridge University Press.

Whalley, John (1998) 'Why do countries seek Regional Trade Agreements?' in Jeffrey A. Frankel (ed) The regionalization of the world economy University of Chicago Press. 
Xinhua News Agency (2004) China makes breakthrough in market economy status news.xinhuanet.com/english/2004-04/15/content_1422275.htm (Date accessed: 16 May 2010).

Xinhua News Agency (2006) China, New Zealand agree to accelerate FTA talks http://english.peopledaily.com.cn/200611/14/eng20061114_321168.ht ml (Date accessed: 16 May 2010).

Xinhua News Agency (2006) The Eleventh Five-Year Plan available online at http://www.gov.cn/english/special/115y_index.htm.

Ya Qin, Julia (2007) ‘Trade Investment and Beyond: The Impact of WTO Accession on China's Legal System' The China Quarterly 191: 720-741.

Yang, Dali (1994) 'Reform and the restructuring of central-local relations' in David Goodman and Gerald Segal (eds) China deconstructs: politics, trade and regionalism Routledge.

Yang, Mayfair (1994) Gifts, Favours and Banquets: The Art of Social Relationships in China, Cornell University Press.

Yang, Mayfair (2002) 'The Resilience of Guanxi and its New Deployments: A Critique of Some New Guanxi Scholarship' The China Quarterly 170: 459476.

Yeung, Irene Y. M. and Tung Rosalie L. (1996) 'Achieving business success in Confucian societies: The importance of guanxi (connections)' Organizational Dynamics 25 (2): 54-65.

Zhu, Yunxi (2009) 'Managing Business Relationships in New Zealand and China' Management International Review 49 (2): 225-248. 


\section{Appendixes}

Appendix 1:

HS Codes and products for all products exported to New Zealand in 2009 valued more than NZ\$ 10M.

\section{No Change in Tariff at Implementation of FTA:}

2601.11 Iron ores and concentrates; non-agglomerated

2709.00 Oils; petroleum oils and oils obtained from bituminous minerals, crude

4403.20 Wood; coniferous, in the rough, whether or not stripped of bark or sapwood, or roughly squared, untreated

4407.10 Wood, coniferous; sawn or chipped lengthwise, sliced or peeled, whether or not planed, sanded or end-jointed, of a thickness exceeding $6 \mathrm{~mm}$

4411.12 Medium density fibreboard (MDF), of a thickness not exceeding $5 \mathrm{~mm}$

4411.14 Medium density fibreboard (MDF), of a thickness exceeding $9 \mathrm{~mm}$

4703.21 Wood pulp; chemical wood pulp, soda or sulphate, (other than dissolving grades), semi-bleached or bleached, of coniferous wood

4705.00 Wood pulp; obtained by a combination of mechanical and chemical pulping processes

4804.11 Kraft paper and paperboard; kraftliner, uncoated, unbleached, in rolls or sheets, other than that of heading no. 4802 or 4803

4810.92 Paper and paperboard; multi-ply, coated with kaolin or other inorganic substances only, for non-graphic purposes, n.e.c. in heading no. 4810 , in rolls or sheets

5101.11 Wool; (not carded or combed), greasy (including fleece-washed wool), shorn 5101.21 Wool; (not carded or combed), degreased, (not carbonised), shorn

8541.60 Crystals; mounted piezo-electric

9809.00 Confidential items (excluded from table)

\section{Low Change in Tariff at Implementation of FTA:}

0202.30 Meat; of bovine animals, boneless cuts, frozen

0204.42 Meat; of sheep (including lamb), cuts with bone in (excluding carcasses and half-carcasses), frozen 
0402.10 Dairy produce; milk and cream, concentrated or containing added sugar or other sweetening matter, in powder, granules or other solid forms, of a fat content not exceeding $1.5 \%$ (by weight)

0402.21 Dairy produce; milk and cream, concentrated, not containing added sugar or other sweetening matter, in powder, granules or other solid forms, of a fat content exceeding $1.5 \%$ (by weight)

0402.29 Dairy produce; milk and cream, containing added sugar or other sweetening matter, in powder, granules or other solid forms, of a fat content exceeding $1.5 \%$ (by weight)

0404.10 Dairy produce; whey, whether or not concentrated or containing added sugar or other sweetening matter

0405.10 Dairy produce; derived from milk, butter

0405.90 Dairy produce; fats and oils derived from milk (other than butter or dairy spreads)

0406.10 Dairy produce; fresh cheese (including whey cheese), not fermented, and curd

0406.20 Dairy produce; cheese of all kinds, grated or powdered

4102.10 Skins; raw, of sheep or lambs, fresh, or salted, dried, limed, pickled or otherwise preserved, (but not tanned, parchment-dressed or further prepared), with wool on

\section{Medium Change in Tariff at Implementation of FTA:}

0303.79 Fish; frozen, n.e.c. in heading no. 0303 (excluding fillets, livers, roes and other fish meat of heading no. 0304)

0401.30 Dairy produce; milk and cream, not concentrated, not containing added sugar or other sweetening matter, of a fat content exceeding 6\% (by weight)

1901.90 Food preparations; of flour, meal, starch, malt extract or milk products, for uses n.e.c. in heading no. 1901

2301.20 Flours, meals and pellets; of fish or of crustaceans, molluscs or other aquatic invertebrates

3501.10 Casein

3501.90 Caseinates and other casein derivatives; casein glues 
3502.20 Albumins; milk albumin, including concentrates of two or more whey proteins

1502.00 Fats of bovine animals, sheep or goats; other than those of heading no. 1503

4102.21 Skins; raw, of sheep or lambs, pickled (but not tanned, parchment-dressed or further preserved), without wool on

7404.00 Copper; waste and scrap

7602.00 Aluminium; waste and scrap

0401.30 Dairy produce; milk and cream, not concentrated, not containing added sugar or other sweetening matter, of a fat content exceeding $6 \%$ (by weight)

\section{High Change in Tariff at Implementation of FTA:}

0307.49 Molluscs; cuttle fish and squid, frozen, dried, salted or in brine (whether in shell or not)

0404.90 Dairy produce; natural milk constituents (excluding whey), whether or not containing added sugar or other sweetening matter, n.e.c. in chapter 04

0504.00 Animal products; guts, bladders and stomachs of animals (other than fish), whole and pieces thereof, fresh, chilled, frozen, salted, in brine, dried or smoked

0507.90 Animal products; tortoise-shell, whalebone and whalebone hair, horns, antlers, hooves, nails, claws and beaks, unworked or simply prepared but not cut to shape, waste and powder of these products

0810.50 Fruit, edible; kiwifruit, fresh

1901.10 Food preparations; of flour, meal, starch, malt extract or milk products, for infant use, put up for retail sale

2204.21 Wine; still, in containers holding 2 litres or less

7208.39 Iron or non-alloy steel; in coils, without patterns in relief, flat-rolled, of a width $600 \mathrm{~mm}$ or more, hot-rolled, of a thickness of less than $3 \mathrm{~mm}$ 